Universidade de São Paulo

Escola de Artes, Ciências e Humanidades

Programa de Pós-Graduação em Têxtil e Moda

IBERÊ CRUZ FREITAS

A influência da etapa de fixação do processo de texturização por falsa torção no volume do fio de poliéster texturizado

São Paulo 


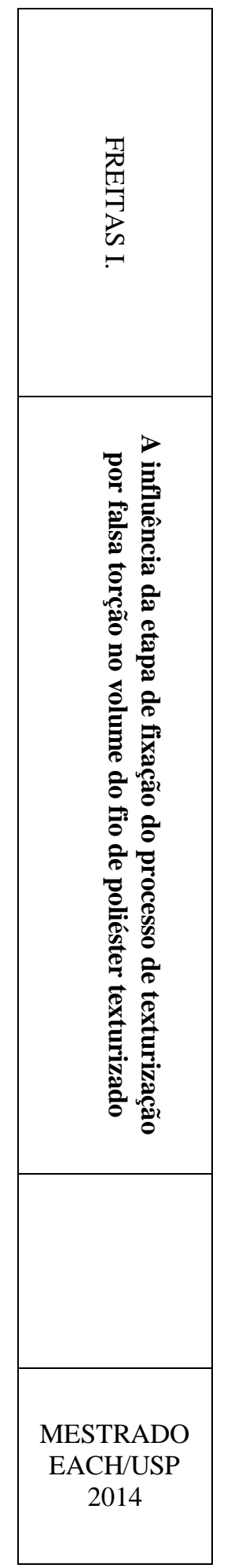


IBERÊ CRUZ FREITAS

\section{A influência da etapa de fixação do processo de texturização por falsa torção no volume do fio de poliéster texturizado}

Dissertação apresentada à Escola de Artes, Ciências e Humanidades da Universidade de São Paulo para obtenção de título de Mestre em Ciências.

Versão corrigida contendo as alterações solicitadas pela comissão julgadora em 30 de abril de 2014. A versão original encontra-se em acervo reservado na Biblioteca da EACH/USP e na Biblioteca Digital de Teses e Dissertações da USP (BDTD), de acordo com a Resolução CoPGr 6018, de 13 de outubro de 2011.

Área de concentração: Têxtil e Moda

Orientador: Prof. Dr. Fernando Auil

São Paulo 
Autorizo a reprodução e divulgação total ou parcial deste trabalho, por qualquer meio convencional ou eletrônico, para fins de estudo e pesquisa, desde que citada a fonte.

CATALOGAÇÃO-NA-PUBLICAÇÃO

Biblioteca

Escola de Artes, Ciências e Humanidades

Universidade de São Paulo

Freitas, Iberê Cruz

A influência da etapa de fixação do processo de texturização por falsa torção no volume do fio de poliéster texturizado / Iberê Cruz Freitas ; orientador, Fernando Auil. - São Paulo, 2014

100 f. : il.

Dissertação (Mestrado em Ciências) - Programa de PósGraduação em Têxtil e Moda, Escola de Artes, Ciências e Humanidades, Universidade de São Paulo

Versão corrigida

1. Fios (Indústria têxtil). 2. Poliéster - Análise físico-química. I. Auil, Fernando, orient. II. Título

CDD 22.ed. -677.028622 
Nome: FREITAS, Iberê Cruz

Título: A influência da etapa de fixação do processo de texturização por falsa torção no volume do fio de poliéster texturizado

Dissertação apresentada à Escola de Artes, Ciências e Humanidades da Universidade de São Paulo para obtenção de título de Mestre em Ciências.

Aprovado em: 30/04/2014

Banca Examinadora

Prof. Dr. Fernando Auil

Instituição Escola de Artes, Ciências e Humanidades da Universidade de São Paulo

Profa. Dra. Regina Sanches

Instituição Escola de Artes, Ciências e Humanidades da Universidade de São Paulo

Prof. Dra. Camila Borelli

Instituição: $\quad$ Fundação Educacional Inaciana Padre Medeiros de Sabóia 
Á minha família, especialmente minha esposa, com muito amor e carinho, pelo apoio incondicional em todos os momentos. 


\section{AGRADECIMENTOS}

Á Escola de Artes, Ciências e Humanidades da Universidade de São Paulo pela oportunidade de realização do curso para obtenção do título de Mestre.

À Prof. Regina Sanches pelo grande suporte dado durante o curso até a obtenção do título.

Ao Prof. Fernando Auil pela orientação prestada. 
Não pretendemos que as coisas mudem se sempre fazemos o mesmo. A crise é a melhor benção que pode ocorrer com as pessoas e países, porque a crise traz progressos. A criatividade nasce da angústia, como o dia nasce da noite escura. É na crise que nascem as invenções, os descobrimentos e as grandes estratégias. Quem supera a crise, supera a si mesmo sem ficar 'superado'. Quem atribui à crise seus fracassos e penúrias, violenta seu próprio talento e respeita mais os problemas do que as soluções. A verdadeira crise é a crise da incompetência... Sem crise não há desafios; sem desafios, a vida é uma rotina, uma lenta agonia. Sem crise não há mérito. É na crise que se aflora o melhor de cada um... 


\section{RESUMO}

FREITAS, Iberê C. A influência da etapa de fixação do processo de texturização por falsa torção no volume do fio de poliéster texturizado. 2014. $100 \mathrm{f}$. Dissertação (Mestrado em Ciências) - Escola de Artes, Ciências e Humanidades, Universidade de São Paulo, São Paulo, 2014.

A propriedade volume do fio texturizado é importante por questões estéticas e funcionais. O volume do fio pode garantir que um produto tenha bom desempenho mecânico tanto na produção dos artigos (como na tecelagem, malharia e acabamento) quanto para as aplicações finais dos produtos (produtos com alto fator de cobertura, com elasticidade, isolamento térmico etc.). A texturização por falsa torção fixada é um importante processo industrial que possui dentre os principais objetivos o aumento de volume. A etapa de fixação consiste em um tratamento térmico do fio ao final do processo, por meio da passagem do fio texturizado em um forno, conhecido como forno de fixação ou segundo forno. No presente estudo foi analisada a interação entre as variáveis temperatura do forno de fixação e sobrealimentação do fio dentro do forno de fixação. A propriedade volume dos fios texturizados é comumente tratada nas literaturas como encrespamento, termo que será utilizado no presente trabalho. Para a análise do volume do fio definiu-se três propriedades mecânicas: contração do encrespamento, módulo do encrespamento e estabilidade do encrespamento. Com a utilização da ferramenta estatística "planejamento do desenvolvimento" definiu-se que o estudo seria realizado com dois fatores (temperatura do forno e sobre alimentação do fio); dois diferentes níveis (mínimo e máximo para cada fator) e um ponto central. Para cada proposta de teste foram feitas 10 replicações e 50 ensaios foram realizados. Com as amostras dos fios texturizados foram realizados os ensaios para a determinação das propriedades: contração, módulo e estabilidade do encrespamento; com o equipamento Texturmat da Textechno. Com os dados, realizou-se a análise fatorial para a determinação da importância deles e a regressão linear, para a compreensão do comportamento desses dados em função dos ensaios realizados. As análises possibilitaram observar que a etapa de fixação é muito importante nas propriedades de volume do fio, sendo que a sobrealimentação do fio dentro do forno de fiação apresentou-se como a variável mais relevante para a definição desse parâmetro.

Palavras-chave: Texturização. Volume. Contração. Módulo. Estabilidade. Encrespamento. 


\begin{abstract}
FREITAS, Iberê $C$. The influence of heat setting stage from False Twist Texturing process on crimp of textured polyester yarn. 2014. $100 \mathrm{f}$. Dissertação (Mestrado em Ciências)- Escola de Artes, Ciências e Humanidades, Universidade de São Paulo, São Paulo, 2014.
\end{abstract}

Crimp properties are important by functional and aesthetics issues. The crimp of a yarn can provide a good mechanical performance in the production (weaving, knitting and finishing) and also a good result in the final application (products with high covering factor, elasticity, thermal insulation etc). The False Twist texturing is an important industrial process that has the objective of apply bulk on the yarn. The heat setting stage consists of a thermal treatment on the yarn at the end of the process, by the passage of yarn thru a heater that is known as heat setting heater or second heater only. At this paper was analyzed the interaction between second heater temperature and yarn overfeed inside second heater. For crimp analysis were considered three mechanical properties: crimp contraction, crimp module and crimp stability. Using the statistical tool, Design of Experiments, it was defined that would be used two factors (second heater temperature and yarn overfeed inside second heater); two different levels (minimum and maximum for each factor) and a center point. For each test proposal were realized 10 replications, resulting on 50 trials. With Texturmat, from Textechno, tests were realized on the samples (textured yarn) to verify the crimp properties (contraction, modulus and stability). A factor analysis was realized with data from Texturmat to verify the importance of each factor. A linear regression for each property was calculated to better understand the data in terms of the tests. In general it was possible to see the importance of heating set stage on crimp properties of textured yarns and the yarn overfeed inside second heater is the most important variable to define this parameter.

Key-words: Texturing. Crimp. Contraction. Modulus. Stability. Bulk. 


\section{LISTA DE ILUSTRAÇÕES}

Figura 1 - Estrutura química do PET .......................................................... 18

Figura 2 - $\quad$ Fluxo de produção do chip de PET................................................ 23

Figura 3 - Fluxo de fixação do fio multifilamento de PET................................. 23

Figura 4 - Fluxo de produção contínua do PET e do fio multifilamento de PET. 24

Figura 5 - Esquema de fiação do filamento de PET ............................................ 24

Figura 6 - Efeito do processo térmico na estrutura da fibra............................... 26

Figura 7 - Reorientação molecular........................................................... 28

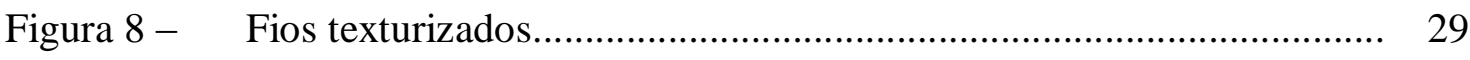

Figura 9 - $\quad$ Princípio da texturização por falsa torção.......................................... 30

Figura 10 - $\quad$ Princípio da aplicação de torção....................................................... 31

Figura $11-\quad$ Texturização por flyer.............................................................. 32

Figura 12 - Agregado de discos de fricção.......................................................... 32

Figura 13 - Esquema de meia máquina de texturização com perfil M.................. 34

Figura $14-\quad$ Forno de contato................................................................. 36

Figura 15 - Representação geométrica do planejamento fatorial $2^{2} \ldots \ldots \ldots \ldots \ldots \ldots \ldots \ldots . . . . . . . .48$

Figura 16 - Representação geométrica do planejamento fatorial $2^{2}$ da influência da etapa de fixação do processo de texturização por falsa torção na contração do encrespamento........................................................... 54

Figura 17 - Representação geométrica do planejamento fatorial $2^{2}$ da influência da etapa de fixação do processo de texturização por falsa torção no módulo do encrespamento................................................................

Figura 18 - Representação geométrica do planejamento fatorial $2^{2}$ da influência da etapa de fixação do processo de texturização por falsa torção na estabilidade do encrespamento 


\section{LISTA DE GRÁFICOS}

Gráfico $1-\quad$ Cosumo de fibras e filamentos têxteis no Brasil, no ano de 1970.......

Gráfico $2-\quad$ Cosumo de fibras e filamentos têxteis no Brasil, no ano de 2011.......

Gráfico 3 - Evolução do consumo das fibras têxteis no Brasil entre 1971 e 2011.

Gráfico 4 - Consumo mundial de fibras químicas no ano de 2012.

Gráfico 5 - Evolução da velocidade em função do tempo do processo de texturização por falsa torção

Gráfico 6- Efeito da variação da temperatura no forno de fixação no encolhimento do fio.

Gráfico 7 - Efeito da sobrealimentação em conjunto com a temperatura do forno de fixação no encolhimento do fio

Gráfico 8 - Boxplot da contração do encrespamento em função da temperatura e da sobrealimentação do forno de fixação.

Gráfico 9 - Apresentação do grau de influência das variáveis temperatura do forno de fixação e sobrealimentação do fio dentro do forno de fixação, e a interação dessas variáveis na contração do encrespamento.

Gráfico 10 - Efeito da temperatura do forno de fixação e da sobrealimentação do fio no forno de fixação, na contração do encrespamento.

Gráfico 11 - Efeito da interação das variáveis: temperatura do forno de fixação e sobrealimentação do fio dentro do forno de fixação, na contração do encrespamento.

Gráfico 12 - Comportamento da Contração do Encrespamento em função das regulagens de sobrealimentação do fio e da temperatura do forno de fixação.

Gráfico 13 - Boxplot do módulo do encrespamento em função da temperatura e da sobrealimentação do forno de fixação 
Gráfico 14 - Apresentação do grau de influência das variáveis temperatura do forno de fixação e sobrealimentação do fio dentro do forno de fixação e a interação das variáveis no módulo do encrespamento......

Gráfico 15 - Efeito da temperatura do forno de fixação e da sobrealimentação do fio no forno de fixação, no módulo do encrespamento.

Gráfico 16 - Efeito da interação das variáveis: temperatura do forno de fixação e sobrealimentação do fio dentro do forno de fixação, no módulo do encrespamento.

Gráfico 17 - Comportamento do Módulo do Encrespamento em função das regulagens de sobrealimentação do fio e da temperatura do forno de fixação

Gráfico 18- Boxplot da estabilidade do encrespamento em função da temperatura e da sobrealimentação do forno de fixação

Gráfico 19 - Apresentação do grau de influência das variáveis: temperatura do forno de fixação e sobrealimentação do fio dentro do forno de fixação, e a interação dessas variáveis na estabilidade do encrespamento.

Gráfico 20 - Efeito da temperatura do forno de fixação e da sobrealimentação do fio no forno de fixação na estabilidade do encrespamento.

Gráfico 21 - Efeito da interação das variáveis: temperatura do forno de fixação e sobrealimentação do fio dentro do forno de fixação, na estabilidade do encrespamento.

Gráfico 22 - Comportamento da Estabilidade do Encrespamento em função das regulagens de sobrealimentação do fio e da temperatura do forno de fixação 


\section{LISTA DE TABELAS}

Tabela 1 - Efeito da variação da temperatura no forno de fixação no encolhimento do fio........................................................................ 38

Tabela 2 - Efeito da sobrealimentação em conjunto com a temperatura do forno de fixação no encolhimento do fio....................................................... 39

Tabela 3 - $\quad$ Regulagens base para a texturização dos corpos de prova................. 46

Tabela $4-\quad$ Dados das propriedades de encrespamento..................................... 51

Tabela 5 - Média e desvio padrão dos resultados do ensaio para a determinação da contração do encrespamento......................................................... 53

Tabela 6- Análise de variância ANOVA (two way) da contração do

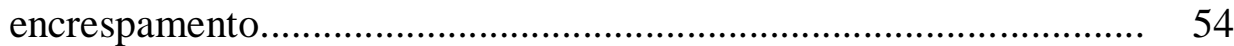

Tabela 7 - Média e desvio padrão dos dados resultantes do ensaio para a determinação do módulo do encrespamento....................................... 59

Tabela 8- Análise de variância ANOVA (two way) do módulo do encrespamento

Tabela 9 - Médias e desvios padrões dos dados coletados no ensaio para determinação da estabilidade do encrespamento................................. 65

Tabela 10 - Análise de variância ANOVA (two way) da estabilidade do encrespamento 


\section{LISTA DE EQUAÇÕES}

Equação 1 - Contração do encrespamento...................................................... 42

Equação 2 - Módulo do encrespamento......................................................... 42

Equação 3 - $\quad$ Estabilidade do encrespamento................................................... 42

Equação 4 - Estimativa do efeito principal do fator A no planejamento

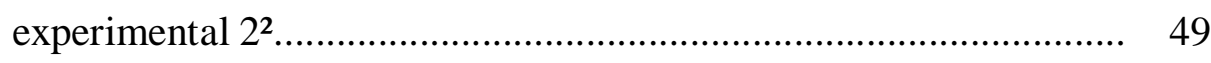

Equação 5 - Estimativa do efeito principal do fator $\mathrm{B}$ no planejamento

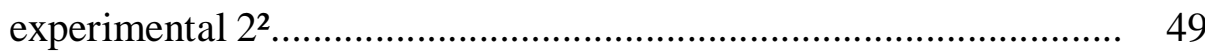

Equação 6- Estimativa do efeito principal do fator $\mathrm{C}$ no planejamento

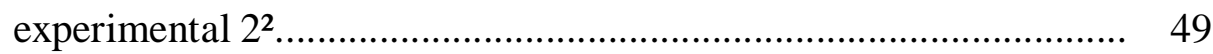

Equação 7 - Contração do encrespamento (Regressão Linear)............................ 58

Equação 8 - Módulo do encrespamento (Regressão Linear).............................. 64

Equação 9 - $\quad$ Estabilidade do encrespamento (Regressão Linear)......................... 71 


\section{SUMÁRIO}

1. INTRODUÇÃO

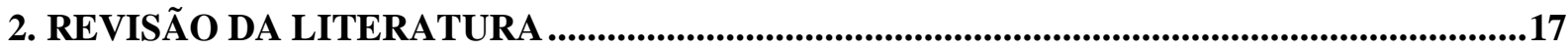

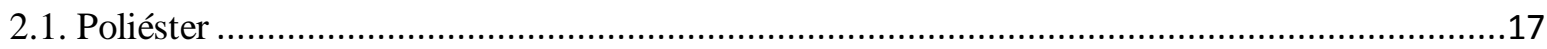

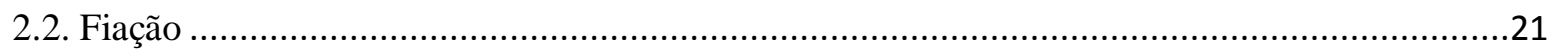

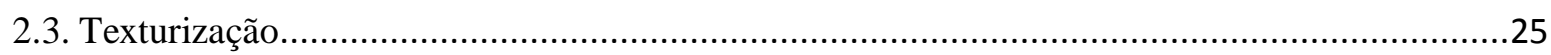

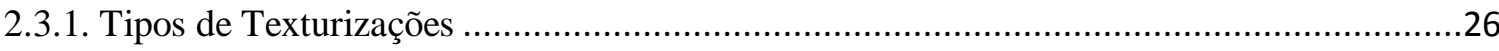

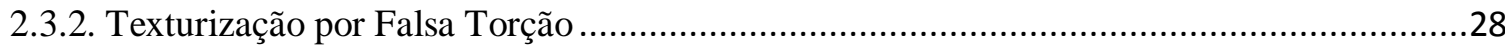

2.4. Etapa de fixação na texturização por Falsa Torção ………......................................................34

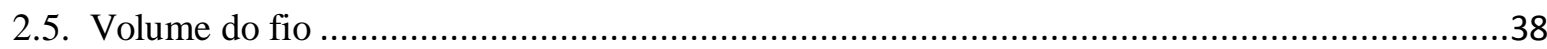

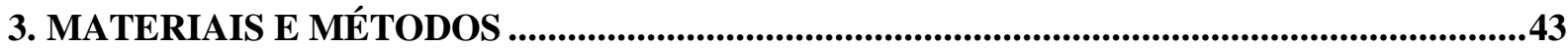

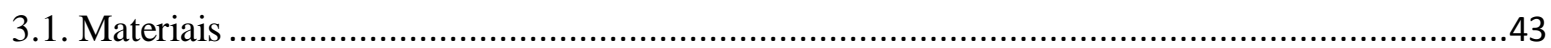

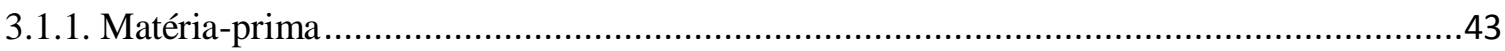

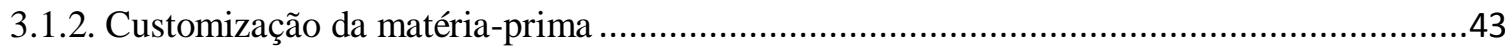

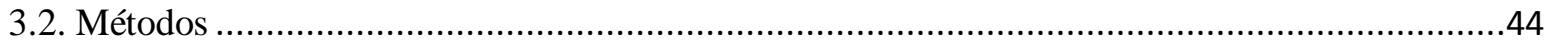

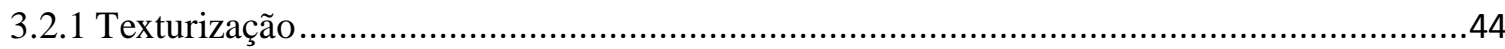

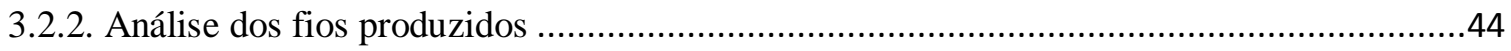

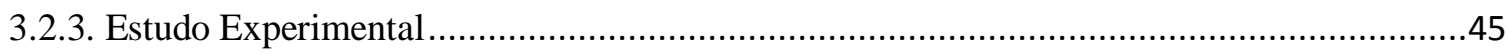

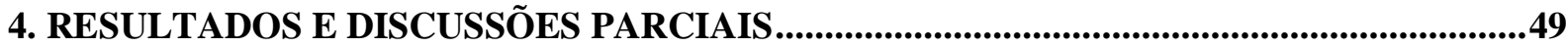

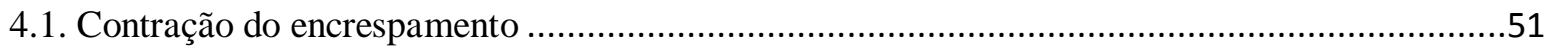

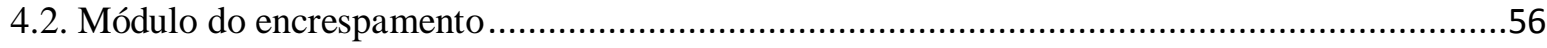

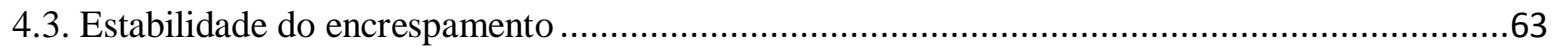

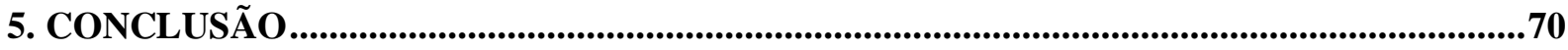

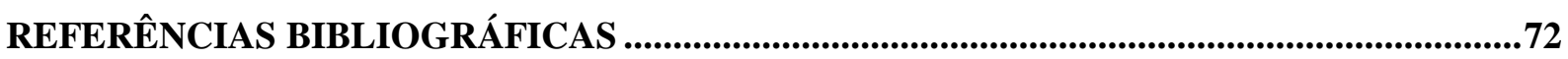

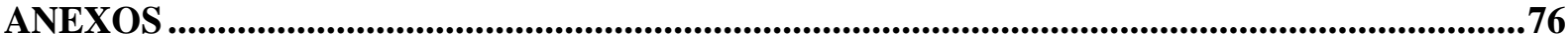

Anexo A: Relatório de análise da matéria-prima ....................................................................76 
Anexo B: Relatório de análise do fio texturizado

Anexo C: Resultados dos ensaios das propriedades de encrespamento .........................................79

Anexo D: Relatório do Minitab ${ }^{\circledR}$ da análise fatorial completa da contração do encrespamento ........89

Anexo E: Relatório do Minitab ${ }^{\circledR}$ da regressão linear da contração do encrespamento .....................91

Anexo F: Relatório do Minitab ${ }^{\circledR}$ da análise fatorial do módulo do encrespamento ..........................92

Anexo G: Relatório do Minitab ${ }^{\circledR}$ da regressão linear do módulo do encrespamento........................94

Anexo H: Relatório do Minitab ${ }^{\circledR}$ da análise fatorial da estabilidade do encrespamento ...................95

Anexo I: Relatório do Minitab ${ }^{\circledR}$ da regressão linear da estabilidade do encrespamento ....................97 


\section{INTRODUÇÃO}

Com a redução dos recursos naturais e com o aumento pela demanda de produtos têxteis a utilização das fibras sintéticas como fios têxteis estão se tornando mais populares (ESKIN, 2003).

A era das fibras sintéticas no mercado têxtil se concretizou com o surgimento das fibras de poliamida nos anos 30 e do poliéster nos anos 40 (ATKINSON, p. 3, 2012). Porém os fios sintéticos não possuem a aparência e o toque característico das fibras naturais certos processos se fazem necessários para combinar as propriedades positivas dos fios sintéticos, como, resistência, uniformidade e elasticidade com as características dos fios naturais (ESKIN, 2003).

Entre os anos 50 e 70 diversos processos de texturização foram desenvolvidos no intuito aplicar os efeitos desejados, entre os quais temos:

- Edge Crimping: Estiragem do fio termoplástico, em cima de um ponto aquecido, provocando diferentes pontos de esforços no fio texturizado;

- Knit-de-Knit: Tecimento de uma malha em máquina de pequeno diâmetro com fio termoplástico, com termofixação após o tecimento sendo finalizado com a desmalhagem e enrolamento do fio texturizado;

- Stuffer-box: o fio termoplástico é sobrealimentado dentro de uma câmara aquecida e pressurizada e após a saída do fio da câmara o mesmo é enrolado já texturizado;

- Falsa Torção: texturização por aplicação de alta torção no fio, com aplicação de calor e resfriamento antes da retirada da torção.

- Texturização a Ar: entrelaçamentos dos filamentos contínuos por jatos contínuos de ar, provocando laços devido as sobrealimentações dos cabos qu estão sendo texturizados.

Após aproximadamente 50 anos das tecnologias desenvolvidas, a texturização por falsa torção consolidou-se como o principal processo de texturização de fios de filamentos sintéticos (ATKINSON, p. 10, 2012).

O objetivo do trabalho é compreender melhor o processo de texturização por falsa torção, através de um estudo focado na etapa de fixação do fio no forno de fixação (segundo forno do processo). 
Boa parte da literatura trata a propriedade volume do fio texturizado com o termo encrespamento e por esse motivo o termo em questão será muito utilizado no presente trabalho.

Com a utilização da ferramenta Planejamento de Experimentos (DOE - Desing of Experiments), foram feitas as propostas de testes para estudar a influência da variável temperatura do forno de fixação e da variável sobrealimentação do fio dentro do forno de fixação nas propriedades do encrespamento no fio de poliéster texturizado.

$\mathrm{O}$ entendimento de todas as possibilidades do processo produtivo nos permite melhor desenvolver os produtos e de modo mais eficaz, criando diferenciais funcionais e melhorias nos custos dos produtos, permitindo a produção de fios mais competitivos no mercado. 


\section{REVISÃO DA LITERATURA}

\subsection{Poliéster}

Dentre os polímeros policondensados, o mais importante e o mais utilizado hoje é o poliéster. Os poliésteres são amplamente utilizados como recipientes, garrafas, filmes e também como fibras e filamentos têxteis.

O termo poliéster é utilizado para materiais poliméricos que possuem grupos ésteres na principal cadeia macromolecular polimérica e não para os grupos ésteres que se localizam nas cadeias secundárias (DEOPURA, 2008, p. 3).

Deopura (2008, p. 63) diz que a primeira produção de poliéster ocorreu em 1863. E ao longo do tempo uma diversidade de poliésteres foi desenvolvida.

O poliéster aromático mais importante, comercialmente falando, é o polietileno tereftalado (PET). Dentre os poliésteres aromáticos o PET pode ser considerado como o "carro chefe" dos poliésteres. O PET é um material branco ou creme claro, possui alta resistência térmica e estabilidade química, sendo resistente aos ácidos, bases, alguns solventes, óleos e gorduras. O peso molecular do PET é 192 e sua estrutura química é apresentada na Figura 1.

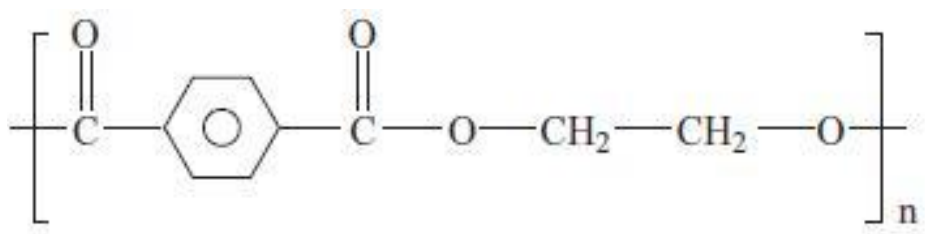

Figura. 1 - Estrutura química do PET

Dentre as fibras sintéticas, o PET é a fibra mais utilizada e compete fortemente com o algodão, sustentando um crescimento anual de 5\% (DEOPURA, 2008, p. 12).

Com base nas informações fornecidas pela a Associação Brasileira da Indústria Têxtil e de Confecção, o consumo de poliéster (fibra e filamento) no Brasil teve um crescimento de 1870\%, entre 1970 a 2011, (passando de 22500 toneladas para 443180 toneladas por ano), enquanto o aumento de consumo do algodão, no mesmo período, foi de 212,4\% (passando de 291300 toneladas para 910000 toneladas). 
O Gráfico 1 e o Gráfico 2 apresentam que o poliéster em 1970 representava apenas 4\% de todas as fibras têxteis consumidas no Brasil e que em 2011 já representava $26 \%$ desse total.

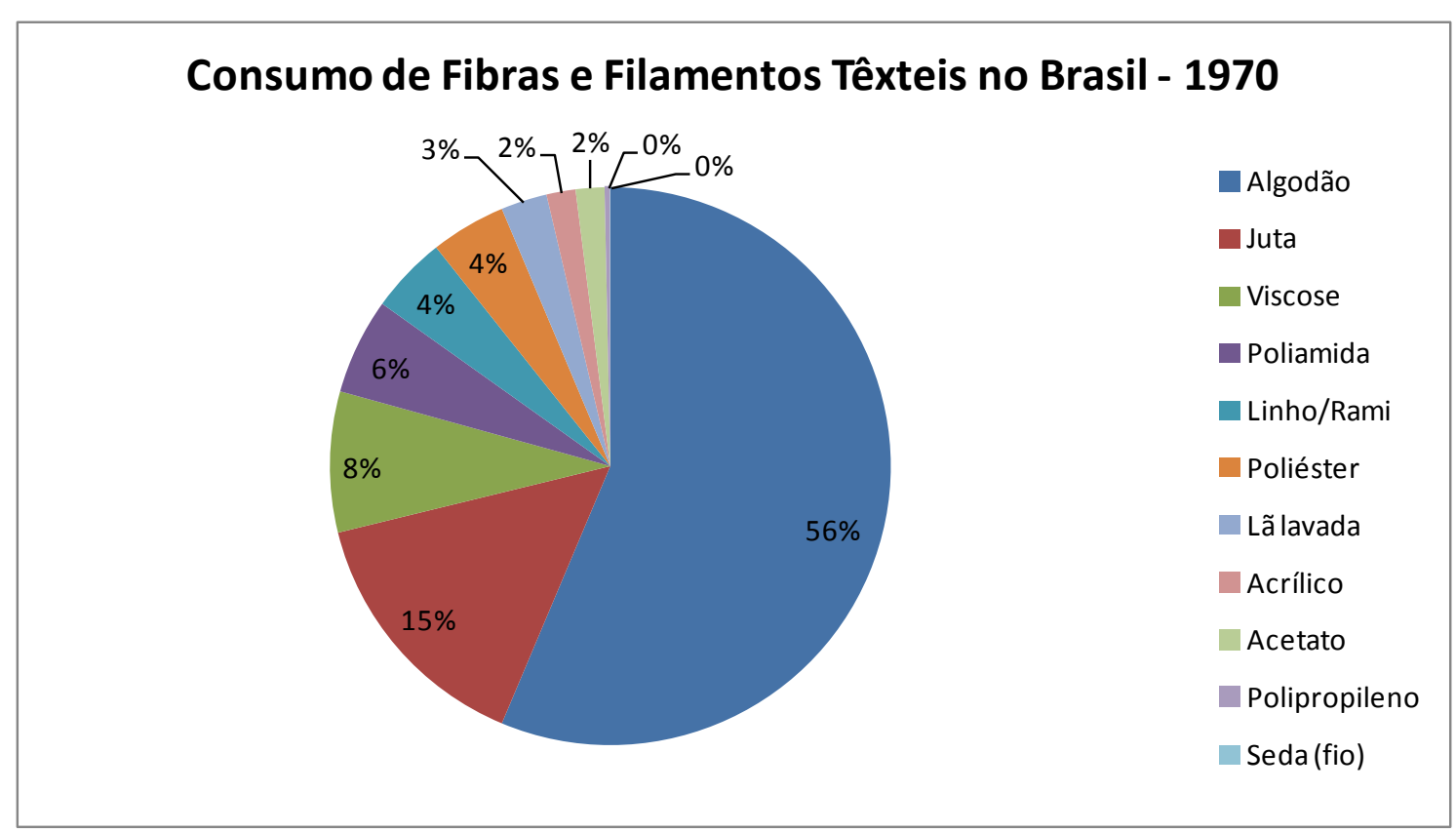

Gráfico 1 - Cosumo de fibras e filamentos têxteis no Brasil, no ano de 1970 (Autor, adaptados dos dados fornecidos pela Associação Brasileira da Indústria Têxtil e de Confecção).

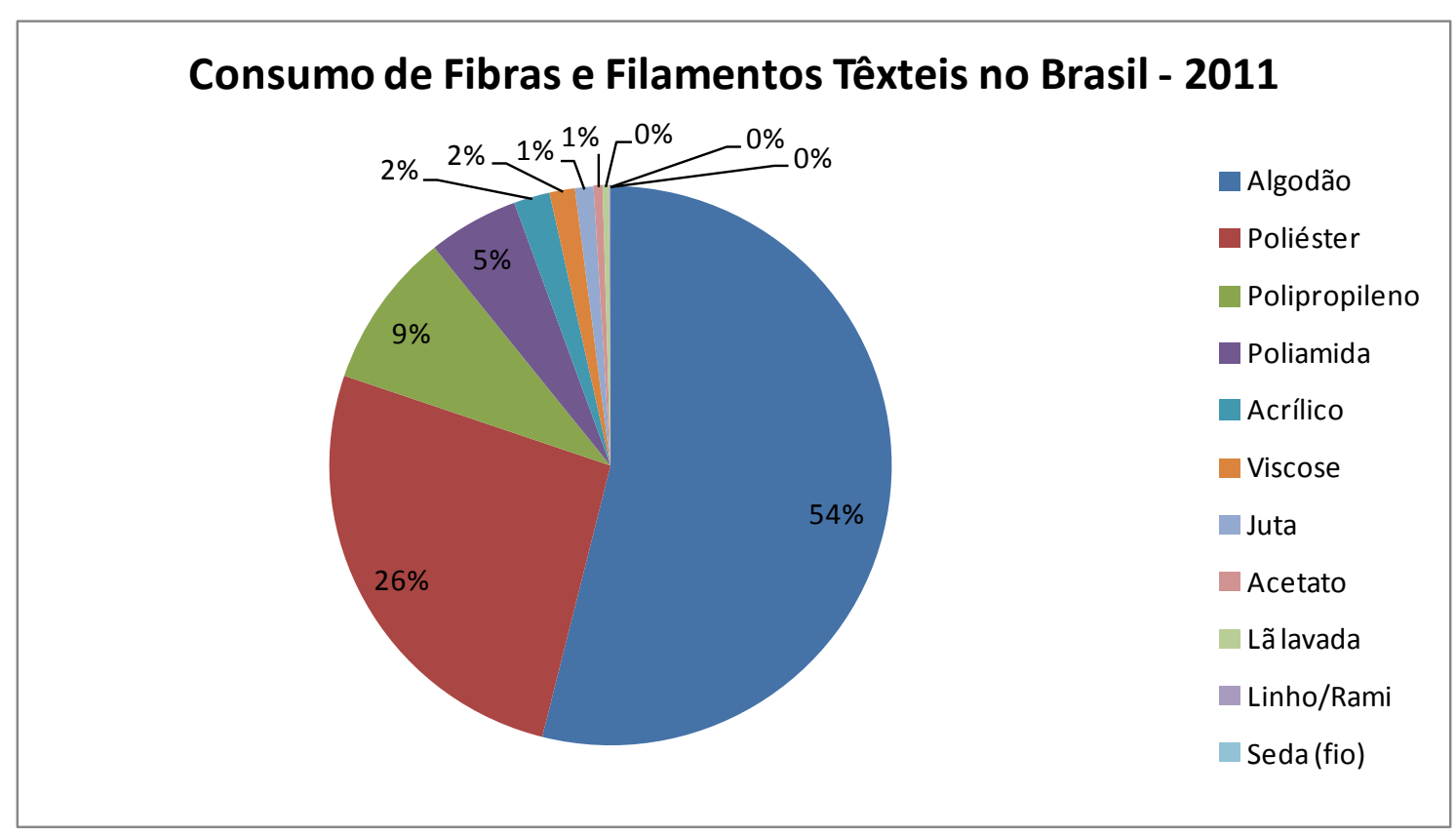

Gráfico 2 - Cosumo de fibras e filamentos têxteis no Brasil, no ano de 2011 (Autor, adaptados dos dados fornecidos pela Associação Brasileira da Indústria Têxtil e de Confecção). 
No Gráfico 3 é possível observar a evolução do consumo das fibras têxteis no Brasil entre os anos de 1971 e 2011. Fica evidente que o poliéster é, dentre todas as fibras, a que apresentou o maior crescimento nesse tempo

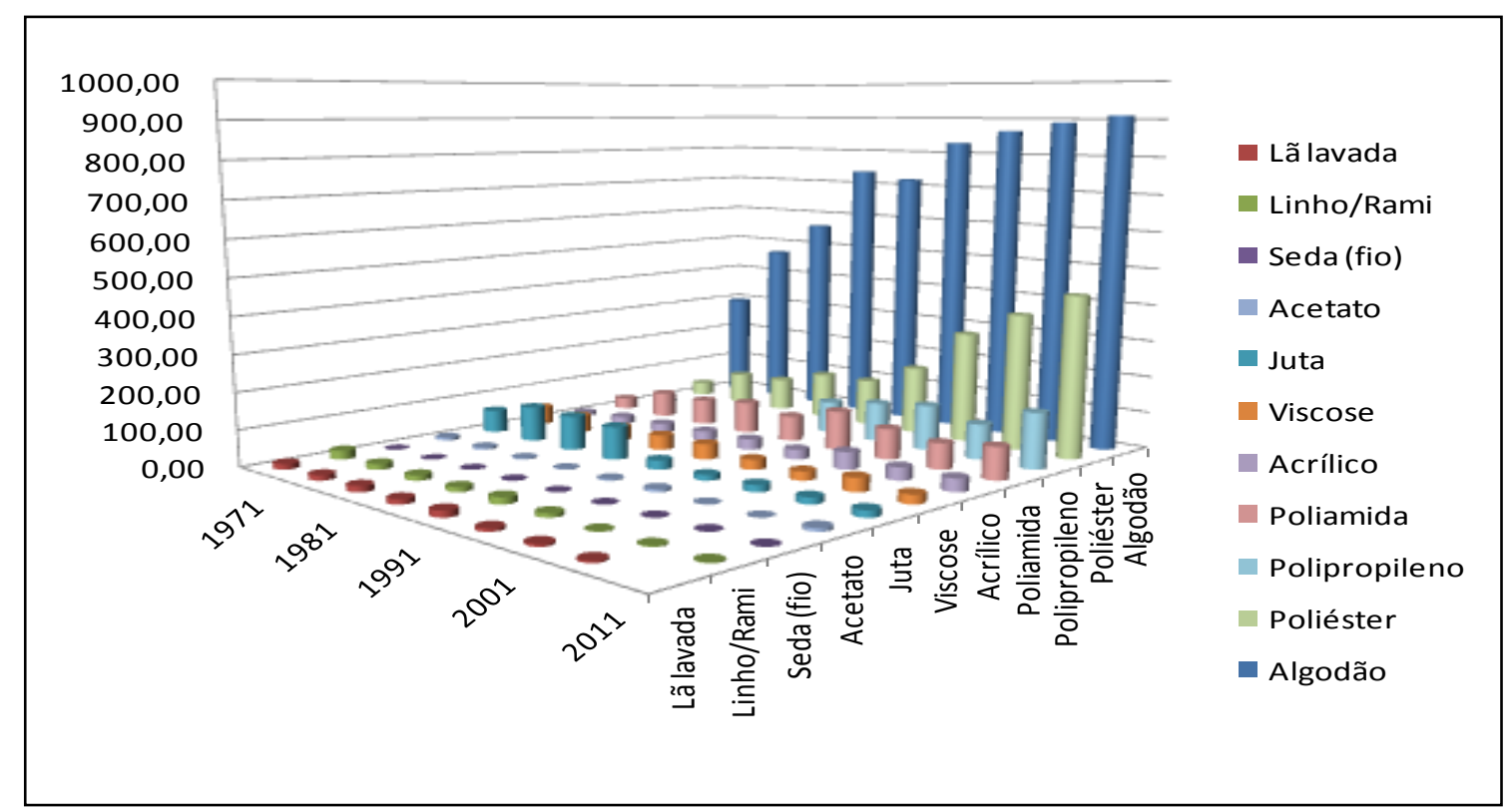

Gráfico 3 - Evolução do consumo das fibras têxteis no Brasil entre os anos de 1971 e 2011.

(Autor, adaptados dos dados fornecidos pela Associação Brasileira da Indústria Têxtil e de Confecção).

No Gráfico 4 observamos que no ano de 2012 as fibras de poliéster (fibras e fios filamentos) representavam $74 \%$ do consumo mundial de fibras químicas (sintéticas e artificiais). 


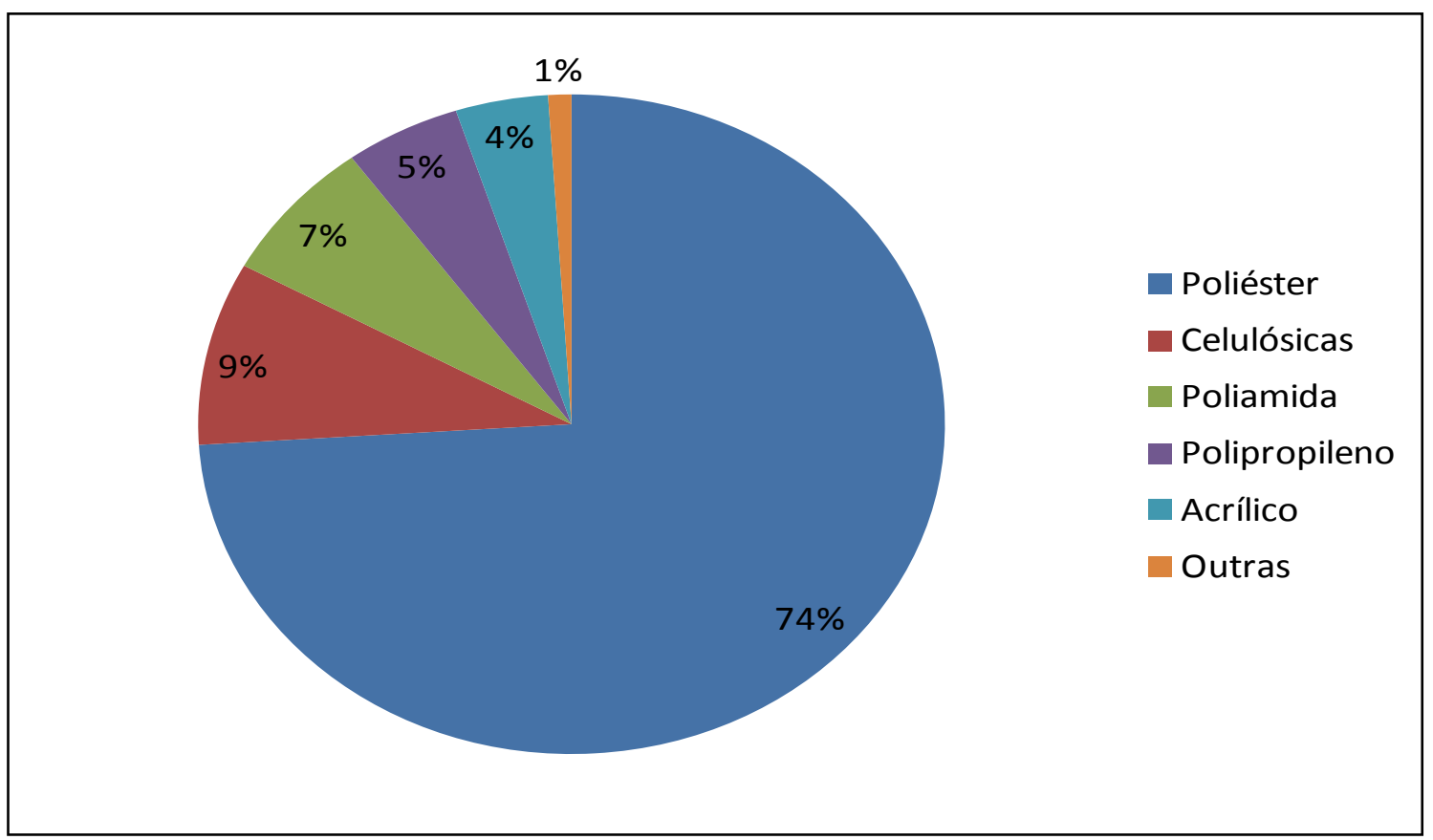

Gráfico 4 - Consumo mundial de fibras químicas no ano de 2012. (Autor, adaptados dos dados fornecidos pela Man-Made Fiber, 2013, p4).

Segundo Fourné (1998, p. 67), o PET foi desenvolvido por Whinfield e Dickson em 1939, e a patente foi vendida para ICI respectivamente licenciada pela DuPont, que depois sublicenciou para a Farbwerke Hoechst AG e para a Vereinigte Glanzstoff-Farbriken AG. A patente básica expirou em 1966.

A utilidade do poliéster como fibra têxtil foi descoberta quando o ácido tereftalico foi incorporado à molécula do polímero de poliéster. O PET tornou possível a grande abrangência de aplicações da fibra sintética, devido as suas excelentes características físicoquímicas em comparação com as fibras naturais, como por exemplo: excelente estabilidade dimensional e robustez, boa elasticidade devido seu volume e toque quente. Além disso, os cuidados com o poliéster são facilitados, pois seus artigos secam rápido, devido a baixa absorção de água, e boa resistência aos tratamentos de lavagens e a micróbios e bactérias (DEOPURA, 2008, p. 62).

Segundo Deopura (2008, p. 67), a indústria da confecção exige que o poliéster tenha algumas características como alta resistência, boa cristalização, boa resistência a luz etc. Assim, o poliéster aromático de alta temperatura de extrusão foi escolhido para produção.

O poliéster possui boa resistência à maioria dos ácidos minerais, porém o ácido sulfúrico concentrado dissolve o poliéster com decomposição parcial do material. O poliéster apresenta excelente resistência aos agentes alvejantes, solventes para limpeza e surfactantes e o grau de 
cristalinidade do poliéster e a orientação molecular determinam sua resistência. Substâncias básicas atacam a fibra de poliéster de duas maneiras: álcalis fortes causam a dissolução da superfície da fibra e bases fracas, como amônia ou outra base orgânica como metil amina, penetram nas regiões amorfas das estruturas (DEOPURA, 2008, p. 17). O Poliéster é uma fibra baixa de degradação química. No futuro possivelmente seja utilizado um poliéster degradável ou um poliéster de polímero "verde" (DEOPURA, 2008, p. 67).

Por falta de pontos de ligações químicas entre as fibras de poliéster e os corantes, normalmente são utilizados corantes dispersos. As fibras de poliéster devem ser tintas em meio aquoso com temperatura superior a $100^{\circ} \mathrm{C}$ ou com a utilização de carrier como bifenil e fenil salicilato. O tingimento do poliéster é mais lento do que o tingimento do triacetato de celulose ou do acetato de celulose (DEOPURA, 2008, p. 17).

Dentre as aplicações têxteis, podemos dizer que os fios de poliéster com maior peso molecular são usados para o desenvolvimento de filamentos industriais, que podem ser mais grossos, para aplicação em pneus, correias transportadoras, cintos de segurança, cordas, mangueiras e laminados pesados, ou podem ser do tipo mais fino para aplicação em linha de costura, tecidos laminados leve etc. As fibras são muito utilizadas para produção de tecidos com misturas. As fibras com título fino são utilizadas para misturas com algodão, por exemplo, e fibras com título grosso são utilizadas em misturas com fios como lã. Tecidos feitos com PET POY (Partially Oriented Yarn) microfilamentado geram artigos respiráveis, repelente a água, com leve caímento e toque agradável (DEOPURA, 2008, p. 19).

\subsection{Fiação}

O processo de fiação do poliéster consiste basicamente em três etapas. A primeira etapa consiste na produção do chip de poliéster, que é produzido por meio de polimerização. O chip de poliéster é então derretido por aquecimento ou por dissolução em algum solvente.

$\mathrm{Na}$ segunda etapa a massa derretida é extrudada por meio de fieiras e é convertida a filamentos visco-elásticos.

Então o material passa para um terceiro estágio que consiste na solidificação dos filamentos que podem ocorrer de três maneiras diferentes, dependendo do processo de derretimento da massa na primeira etapa. Caso o processo de derretimento tenha sido por meio de calor, a 
solidificação dos filamentos ocorrerá por resfriamento do material. Caso o derretimento seja por dissolução em um solvente, a solidificação pode ocorrer por imersão em um banho coagulador ou por meio da passagem do material por uma câmara quente onde o solvente é removido por evaporação. (DEOPURA, 2008, p. 77)

Deopura (2008, p. 67) diz que comercialmente as fibras de poliéster aromático PET são obtidas usando etileno glicol (EG) e dimetil tereftalado (DMT), ou etileno glicol e ácido tereftálico (TPA).

Existem dois procedimentos no processo de produção da fibra de PET. O primeiro é a produção do PET propriamente dito, enquanto o segundo é o processo de fiação do PET. Esses processos podem ocorrer por batelada, conforme Figuras 2 e 3, ou em um processo contínuo conforme Figura 4.

- Produção por batelada;

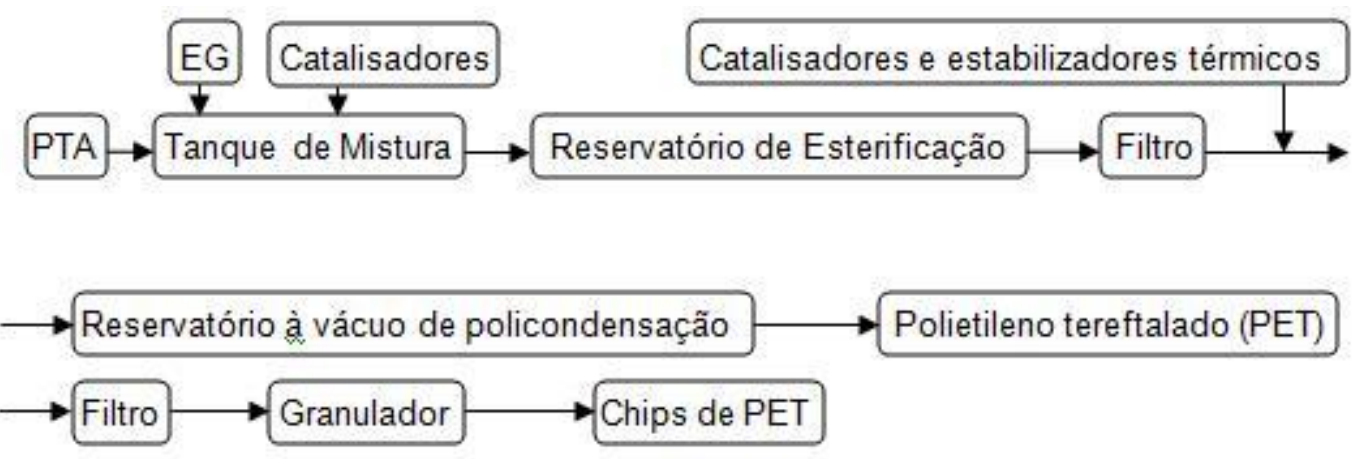

Figura 2 - Fluxo de produção do chip de PET.

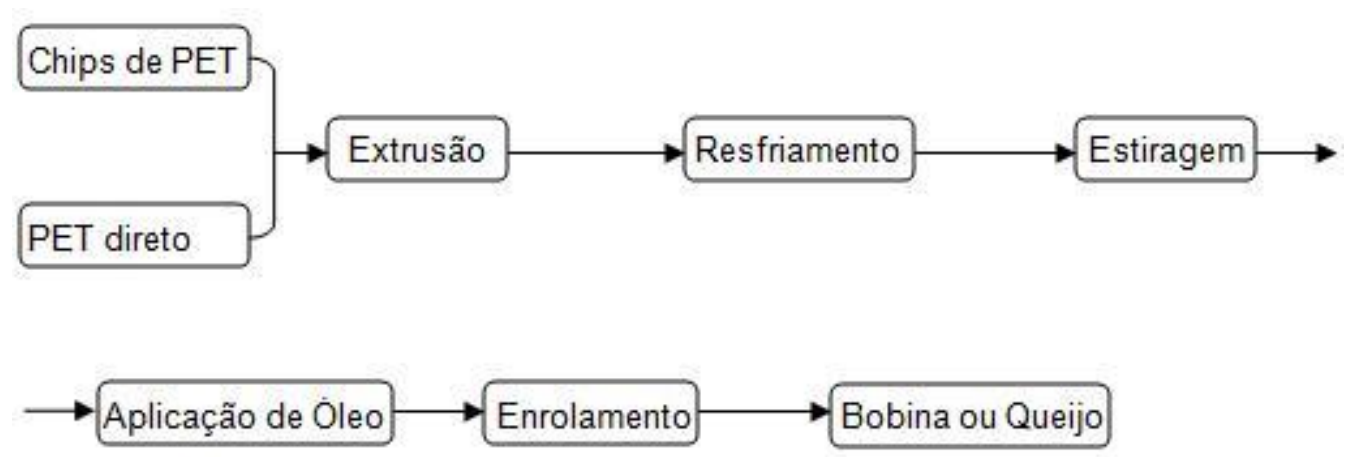

Figura 3 - Fluxo de fiação do fio multifilamento de PET. 
- Produção contínua

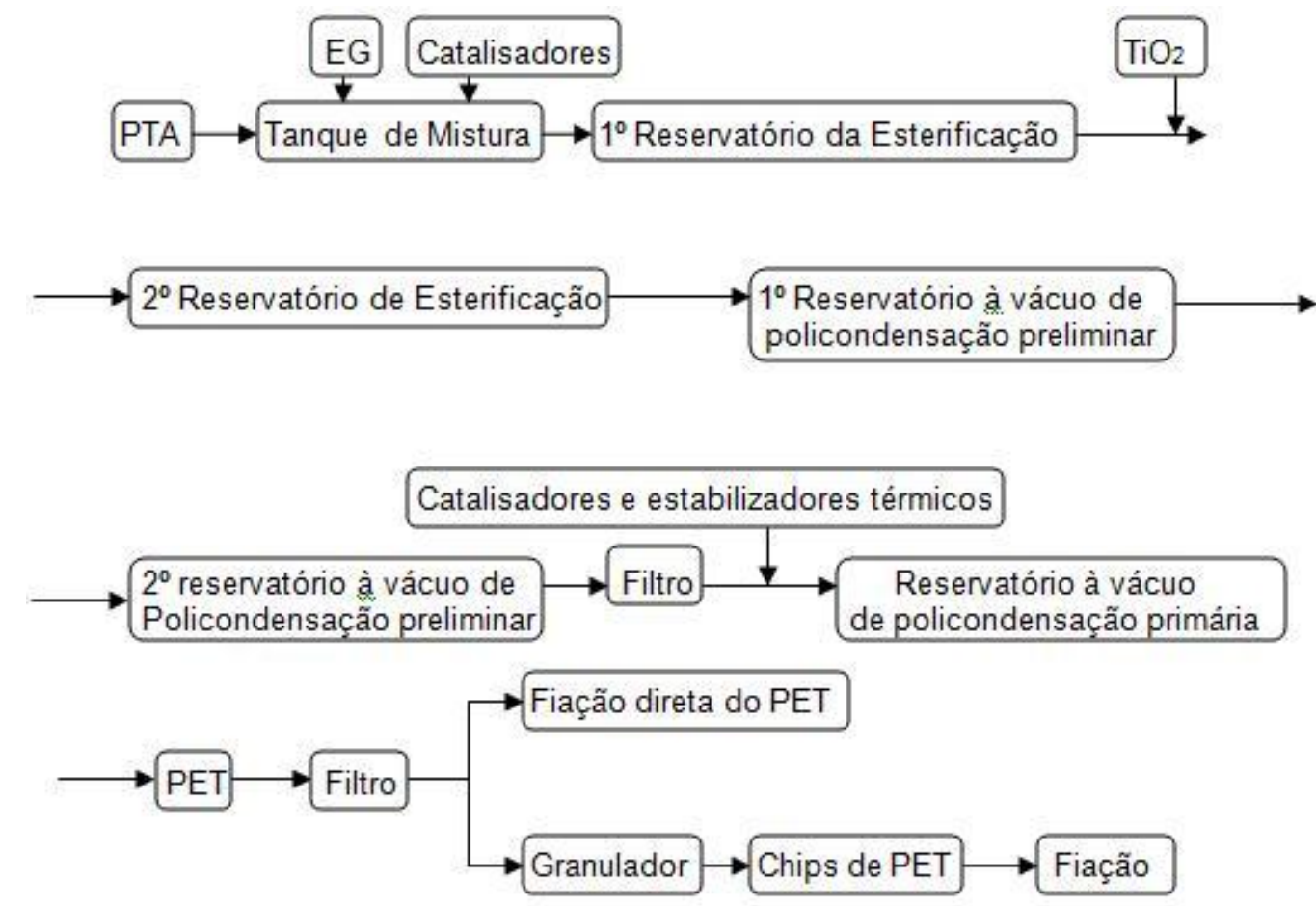

Figura 4 - Fluxo de produção contínua do PET e do fio multifilamento de PET.

Segundo Deopura (2008, p. 78), a fibra de PET é formada pela extrusão do polímero derretido. O polímero derretido (D) é conduzido com velocidade constante e sob alta pressão até os pequenos orifícios da fieira (E). Os filamentos visco-elásticos são extrudados e seguem verticalmente para o resfriamento $(\mathrm{F})$, solidificando e, então, sendo enrolado em bobinas. $\mathrm{O}$ esquema da extrusão a quente é apresentado na Figura 5.
A. Funil de carga com chips de PET
B. Recipiente da fiação
C. Grelha aquecida
D. PET derretido
E. Fieira
F. Ar Frio
G. Rolos de entrada
H. Defletor
I. Rolos de saída

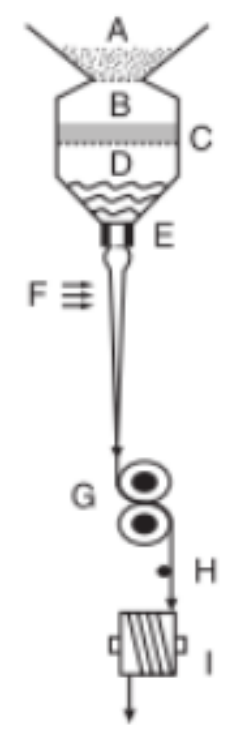

Figura 5 - Esquema de fiação de filamento PET. (DEOPURA, 2008, p. 79) 
A estiragem dos filamentos do PET pode acontecer, dependendo do tipo da fibra, sob condições frias ou quentes, gerando como conseqüência o afinamento do filamento e tornando-o mais comprido. O processo de estiragem normalmente é realizado com temperatura, que deve ser superior a temperatura de transição vítrea $\left(\mathrm{T}_{\mathrm{g}}\right)$ da fibra PET. O processo de estiragem ocorre com o alongamento da fibra entre 2 rolos, chamados godets, sendo que o rolo de saída gira com uma velocidade superior ao rolo de entrada. O processo de estiragem pode ocorrer continuamente ao processo de fiação ou em um processo posterior, como parte da texturização, por exemplo (DEOPURA, 2008, p. 82).

Regiões cristalinas e amorfas formam-se nos filamentos recém produzidos de PET. As cadeias moleculares do PET podem ser orientadas para que fiquem mais paralelas as paredes dos filamentos pela estiragem do material antes de sua completa solidificação. Isso resulta em um filamento mais cristalizado e resistente. Porém, nem todos os filamentos são estirados até o seu limite, pois quando os filamentos atingem o seu limite de comprimento a extensibilidade do filamento é reduzida (DEOPURA, 2008, p.83).

De acordo com Demir e Behery (1997, p. 23), as fiações podem ser classificadas de acordo com o grau de orientação molecular do fio gerado pelo processo de fiação. Ligado diretamente às velocidades de produção, as fiações podem gerar materiais conforme descrito abaixo:

- LOY: entre 500 e $1500 \mathrm{~m} / \mathrm{min}$ as fiações produzem fio com baixa orientação molecular (low-oriented yarn).

- MOY: entre 1500 e $2500 \mathrm{~m} / \mathrm{min}$ as fiações produzem fios com média orientação molecular (médium-oriented yarn).

- POY: entre 2500 e $4000 \mathrm{~m} / \mathrm{min}$ as fiações produzem o fio parcialmente estirado (partially oriented yarn).

- HOY: com velocidades entre 4000 e $6000 \mathrm{~m} / \mathrm{min}$ as fiações produzem os fios com alta orientação molecular (highly oriented molecular).

- FOY: com velocidades acima de $6000 \mathrm{~m} / \mathrm{min}$ as fiações produzem o fio completamente estirado (fully oriented yarn).

De acordo com Deopura (2008, p. 85), no processo de fiação, o tempo de formação da fibra normalmente é muito curto. Isso resulta em diferentes níveis do estado de relaxamento ao longo da cadeia polimérica da fibra de PET e pode causar estresses internos desuniformes, ou seja, muitos problemas de cristalização podem aparecer. Além disso, instabilidades na estrutura podem causar encolhimento na fibra, que podem ocasionar uma série de dificuldades 
nos processos posteriores de acabamento. Portanto, é necessário que os processos térmicos da fibra sejam muito bem controlados antes do uso do material.

Os parâmetros térmicos determinam a morfologia e a estabilidade dimensional das fibras termoplásticas. Esses parâmetros incluem três principais fatores: temperatura, tempo e velocidade. Na prática a temperatura deve ser ajustada para ser maior que a temperatura de transição vítrea $\left(\mathrm{T}_{\mathrm{g}}\right)$ e inferior que a temperatura de fusão $\left(\mathrm{T}_{\mathrm{m}}\right)$. As regulagens térmicas causam movimentos na cadeia polimérica da fibra, que ocasionam estresses internos, produzindo uma fibra completa e estável, conforme apresentado na Figura 6:

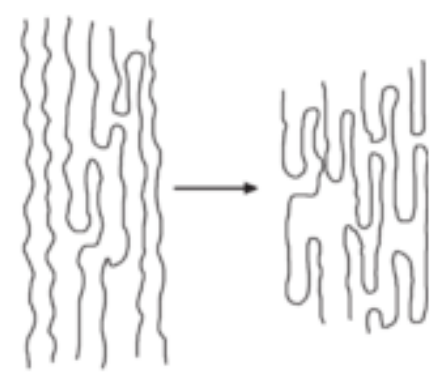
(a) antes do processo térmico
(b) depois do processo térmico

Figura 6 - Efeito do processo térmico na estrutura da fibra (DEOPURA, 2008, p.86)

Segundo MCINTYRE (2005, p. 133), filamentos estirados podem ser direcionados para uma série de aplicações. Eles podem ser simplesmente enrolados, podem ser torcidos ou podem ser direcionados para o processo de texturização. Muitos fios para vestuários precisam ser texturizados para adquirirem aparência e propriedades têxteis desejadas.

\subsection{Texturização}

Segundo Demir e Behery (1997, p. 35), aparência, toque, performance e custo são parâmetros importantes no desenvolvimento de fios e consequentemente nos tecidos. De acordo com a aplicação o grau de importância desses parâmetros pode mudar.

Fourné (1998, p. 431) afirma que a texturização busca converter a aparência "sintética" dos fios lisos em um artigo têxtil mais aceitável e conferir a esses fios propriedades associadas com fios naturais como o algodão e a lã, que possuem texturas intrínsecas ao material. 
McIntyre (2005, p. 43) apresenta que o objetivo da texturização é simular propriedades de fios fiados naturais, como aumento de volume, gerando benefícios como isolamento térmico, cobertura, maciez e transporte de umidade.

Segundo Denton (1987), “texturização é o meio pelo qual se aplicam pequenas distorções como encrespamento, loop, espiras nos filamentos sintéticos sem destruir a continuidade dos filamentos originais".

De acordo com Demir e Behery (1997, p. 42), fios texturizados é um termo genérico para fios de filamentos que possuem notável volume aparente do que um liso convencional de mesmo título e número de filamentos. Esse aumento de volume é obtido por meio de processos físicos, químicos, térmicos ou da combinação desses processos.

\subsubsection{Tipos de Texturizações}

Segundo Adreoli e Freti (2004, p.36), ao longo do tempo diversos princípios de texturização foram desenvolvidos, porém apenas alguns poucos se tornaram interessante segundo o ponto de vista industrial. Os processos mais importantes são a texturização por falsa torção e a texturização a ar.

Hawthorne (1964) afirma que fios texturizados podem ser divididos em dois grupos:

- Fios texturizados stretch:

- Fios texturizados com aparência de fiado.

Fios texturizados Stretch são caracterizados por alta extensibilidade e boa recuperação, porém possuem bulk moderado em comparação com os fios texturizados com aparência de fiado.

De acordo com Andreoli e Freti (2004, p.36), os fios texturizados stretch podem ainda ser divididos em duas categorias, conforme segue:

- Fios de alta elasticidade, caracterizados pelo alto alongamento e a alta contração dos encrespamentos. No caso da texturização por falsa torção é o fio convencionalmente chamado de FT (Falsa Torção), onde é utilizado apenas um forno ao longo do processo (forno de texturização);

- Fios fixados, caracterizados por uma elasticidade e uma contração menor do encrespamento, onde no processo de texturização por falsa torção é convencionalmente 
chamado de FTF (Falsa Torção Fixado), onde são utilizados dois fornos ao longo do processo (forno de texturização e forno de fixação).

O método de texturização termomecânico faz uso das propriedades termoplásticas dos fios sintéticos. O processo consiste na deformação mecânica, por meio da aplicação de uma torção deformadora enquanto aplica-se calor até que o material chegue a condição semi-plástica e fixe a deformação durante o resfriamento. $\mathrm{O}$ encrespamento permanente é aplicado ao fio por meio da reorientação molecular. A Figura 7 apresenta como a reorientação molecular ocorre no processo de texturização. (DEMIR, BEHERY, 1997, p.43).

A grande maioria dos processos de texturização de fios sintéticos dependem das propriedades termoplásticas do material. A fixação do encrespamento é resultado de mudanças na estrutura a nível molecular, por meio da cristalização e reorganização cristalina (MILER, 1999).

Os filamentos, em um fio stretch, podem ficar na forma de duas dimensões em zig-zag ou em três dimensões na forma helicoidal. Com essa configuração a textura pode ser facilmente deformada por uma pequena carga. Devido essa textura ser resultado de um rearranjo molecular, assim que essa carga é removida os filamentos recuperam a textura original (DEMIR, BEHERY, 1997, P.43).
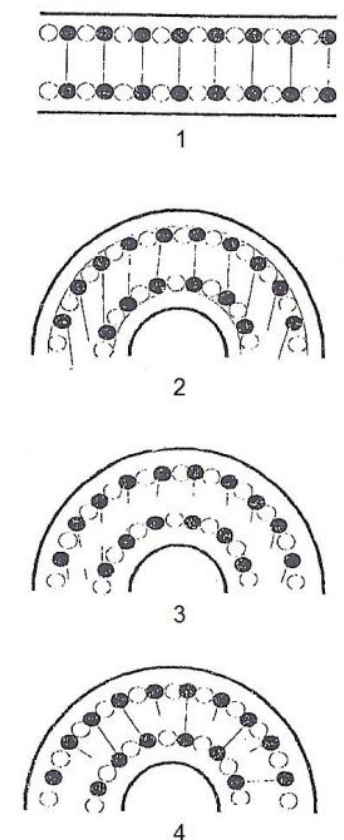

1 - Ligações intermoleculares mantêm os filamentos lisos;

2 - flexão dos filamentos estressando as ligações;

3 - O calor rompendo as ligações;

4 - Novas ligações são formadas após o resfriamento e a fibra mantém-se flexionada.

Figura 7 - Reorientação Molecular (DEMIR, BEHERY, 1997, p.64)

A texturização a ar é o principal método de texturização para a geração de fios texturizados com a aparência de fio fiado. A texturização a ar é um processo mecânico que consiste na 
aplicação de ar pressurizado por meio de um jet, com um certo ângulo, causando turbulência contra o fio que passa no jet. Além da pressão do ar, é necessário que o fio que passa através do jet seja sobre-alimentado para possibilitar a formação dos loops e amarração dos fios.

A Figura 8 apresenta um comparativo entre os fios produzidos pela tecnologia de texturização a ar e pela tecnologia de texturização por falsa torção.

1.

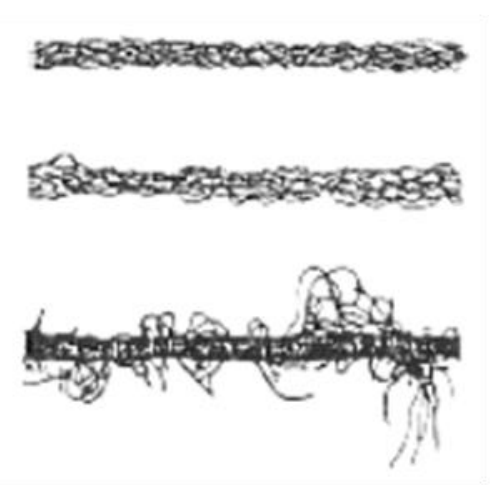

1 - Fio texturizado FTF - Falsa Torção

Fixado;

2 - Fio Texturizado FT - Falsa Torção;

3 - Fio Texturizado a Ar.

Figura 8 - Fios texturizados (ANDREOLI E FRETI, 2004, p. 49)

\subsubsection{Texturização por Falsa Torção}

Segundo Fourné (1998, p. 439), a texturização por falsa torção é predominante dentre os fios texturizados utilizado no mercado.

De acordo com Lord (2003, p. 89) e Özçelik (2007, p. 55), a principal proposta da texturização dos fios de filamentos é criar uma estrutura volumosa para atender aos seguintes requisitos:

1. O vazio da estrutura confere ao material um bom isolamento térmico;

2. O vazio da estrutura faz com que o material fique com uma densidade menor com bom poder de cobertura;

3. A superfície desorganizada do fio dispersa os raios de luz conferindo ao produto uma aparência mais fosca;

4. O volume do fio faz com que os artigos confeccionados fiquem mais macios do que os artigos confeccionados com fios lisos que são mais magros; 
5. A estrutura do fio texturizado confere maior elasticidade ao produto em comparação com um fio liso.

De acordo com Demir e Behery (1997, p.49), os requisitos básicos para a texturização termomecânica são descritos abaixo e ilustrados na Figura 9:

1. Aquecer os filamentos acima da temperatura de transição vítrea $(\mathrm{Tg})$, porém abaixo da temperatura de fusão (Tm);

2. Deformar o filamento da maneira desejada, como, por exemplo, com torção;

3. Resfriar os filamentos abaixo da $\mathrm{Tg}$, enquanto ainda mantêm a aplicação da deformação;

4. Rearranjar os filamentos já resfriados, para que possam apresentar o seu volume (textura).

OBS: As etapas 1 e 2 podem ser simultâneas ou intercaladas;

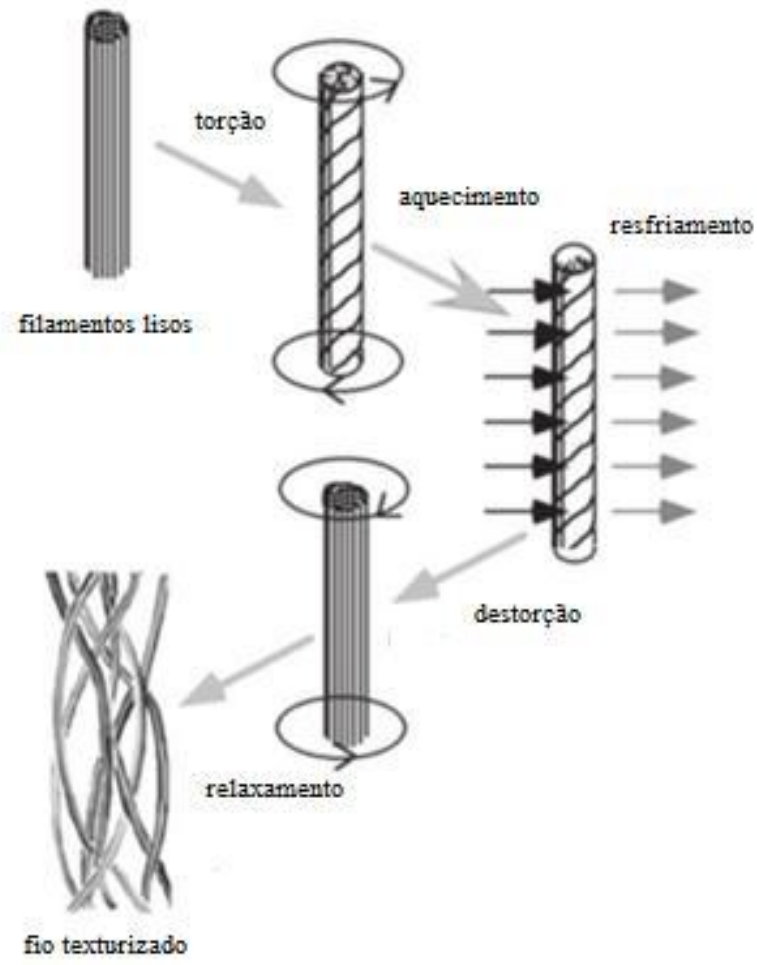

Figura 9 - Princípio da texturização por falsa torção (LORD, 2003, p.91)

Andreoli e Freti (2004, p. 37) dizem que o conceito de texturização por falsa torção teve o inicio do seu desenvolvimento por volta de 1930, com o desenvolvimento do processo descontínuo de torção - fixação - destorção. Em um primeiro processo, o fio recebia um alto número de torções (entre 2500 e $4500 \mathrm{t} / \mathrm{m}$ em função do título), era acondicionado em um 
suporte específico para receber um tratamento térmico, normalmente realizado em autoclave. Então, o fio seguia para a distorção, onde toda a torção era removida e até aplicava-se um pouco de torção no sentido oposto ao inicial para dar certa estabilidade ao fio.

Logo esse processo caiu em desuso devido o grande número de processos necessários para viabilizar esse produto. Por volta do ano de 1950 surgiu a primeira máquina de texturização por falsa torção contínua, onde já existia um forno de texturização para a formação da textura ,e caso desejado, um segundo forno para a fixação da textura.

Imagine um fio preso em suas extremidades. Ao aplicarmos uma torção no meio do fio a parte superior e a parte inferior terão a mesma quantidade de torções, porém em sentidos opostos. Imaginando o fio em um fluxo contínuo a parte anterior ao ponto de aplicação de torção fica todo torcido enquanto a parte posterior fica sem torção (por receber torção no sentido oposto). A Figura 10 apresenta primeiramente um fio estático com as extremidades fixas sendo torcidas e em seguida a imagem apresenta um fio em fluxo sendo torcido e em seguida sendo destorcido.

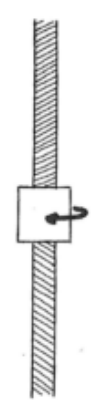

1

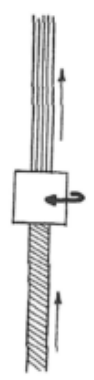

2

Figura 10 - Princípio de aplicação de torção. (ANDREOLI E FRETI, 2004, p. 38)

Bhattacharya (2010, p. 68) apresenta que o dispositivo aplicador de torção deve estar posicionado logo após as zonas de aquecimento e resfriamento do processo de texturização. O processo de texturização por falsa torção conhecida como primeira geração é a texturização por flyer. O mecanismo de aplicação da torção consiste em um tubo oco, com um pino em seu meio, por onde o fio passa e dá uma volta em torno do pino. A torção vai sendo aplicada ao fio de acordo com a rotação do pino, conforme Figura 11. 

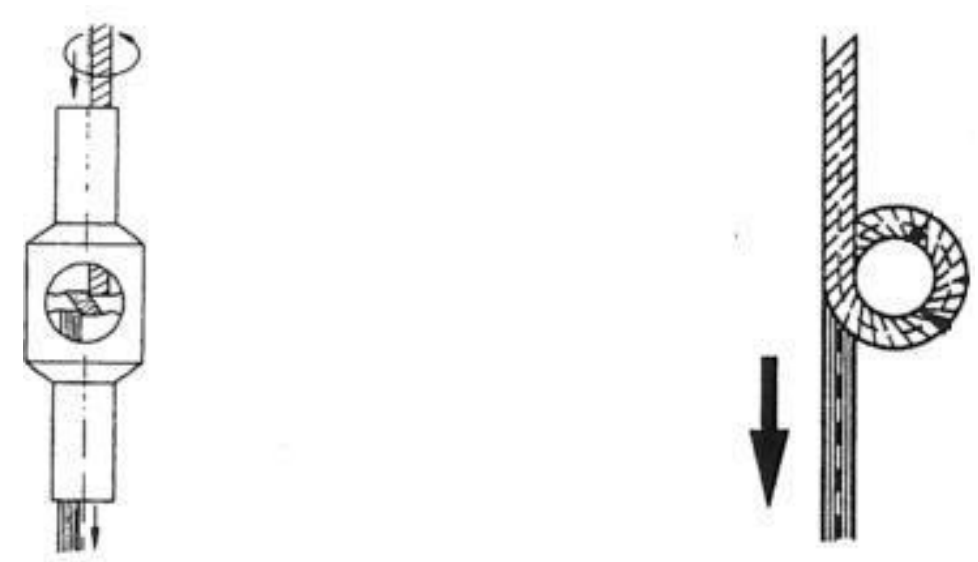

Figura 11 - Texturização por Flyer: (ANDREOLI E FRETI, 2004, p.39)

Porém, devido à baixa velocidade de produção, mesmo com toda evolução do processo (200 $\mathrm{m} / \mathrm{min}$ ), essa tecnologia tornou-se obsoleta.

No ano de 1972, foi patenteado o sistema de texturização por fricção de discos, conforme Figura 12. O sistema consiste no fio passando centralizadamente em um agregado composto por três fusos com discos de friccção, gerando torção no fio por contato com os discos.. A quantidade de torção aplicada na texturização é uma relação da velocidade periférica do disco e a velocidade linear do fio que está sendo texturizado (D/Y).

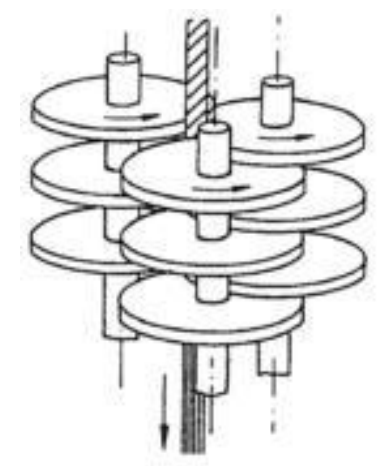

Figura 12 - Agregado de discos de fricção (ANDREOLI E FRETI, 2004, p. 40)

A eficiência do processo depende de uma série de parâmetros, como por exemplo: configuração do agregado, geometria, composição dos discos e número de torções aplicadas. Ainda de acordo com Andreoli e Freti (2004, p.40), um dos parâmetros mais importantes para o bom andamento do processo de texturização por falsa torção é a composição dos discos de texturização. Dentre as composições mais utilizadas existem a de Poliuretano, a de revestimento de cerâmica e a de cerâmica pura. Para a poliamida, as composições de discos mais indicadas são a de cobertura de cerâmica e a de cerâmica pura. 
A tecnologia de texturização por falsa torção, que é a mais importante dentre os atuais processos de texturização, apresentou uma extraordinária evolução desde o seu desenvolvimento. O Gráfico 5 apresenta a evolução das velocidades do processo de texturização por falsa torção desde a sua criação $(10 \mathrm{~m} / \mathrm{min})$ até as velocidades atuais que podem chegar até $1500 \mathrm{~m} / \mathrm{min}(1000-1200 \mathrm{~m} / \mathrm{min}$ são as mais usuais). (ANDREOLI, FRETI, 2004, p. 37-41)

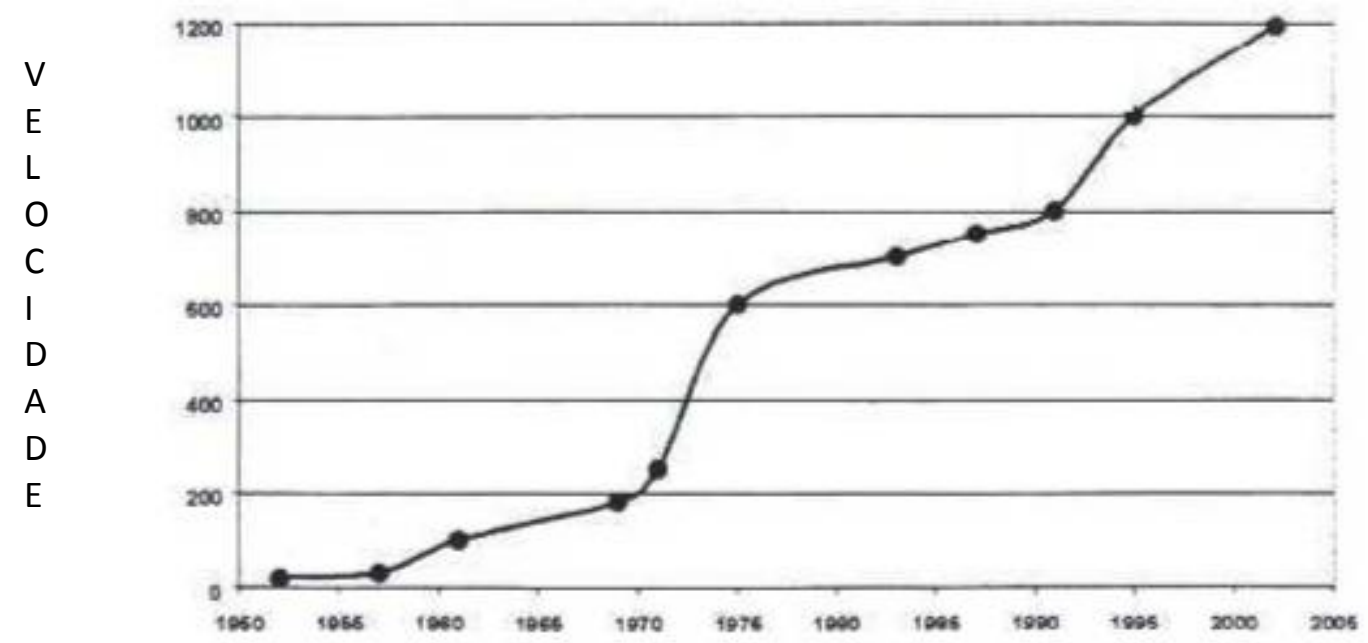

Gráfico 5 - Evolução da velocidade em função do tempo do processo de texturização por falsa torção. (ANDREOLI E FRETI, 2004, p. 39)

As máquinas possuem as zonas de aquecimento e resfriamento do fio para conferir as propriedades termoplásticas ao fio necessárias para a texturização. Os fornos podem transmitir o calor por contato (nos fornos convencionais) por meio de tubos ou ranhuras em fornos que podem variar $160^{\circ} \mathrm{C}$ até $250^{\circ} \mathrm{C}$ para fornos mais longos $-2 \mathrm{~m}$ de comprimento e de $200^{\circ} \mathrm{C}$ até $320^{\circ} \mathrm{C}$ para fornos mais curtos $-1,4 \mathrm{~m}$ de comprimento. Outra possibilidade de transmissão de calor é pormeio de convecção, onde fornos HT (high temperature - alta temperatura) possuem resistores que podem chegar até $600^{\circ} \mathrm{C}$, o que favorece na redução do comprimento dos fornos, além do aumento de velocidade de produção.

McIntyre (2005, p.43) apresenta que na texturização por falsa torção os fios são aquecidos próximos da temperatura de fusão e, então, são torcidos enquanto ainda estão aquecidos, então o fio é resfriado e em seguida destorcido.

Um dos fatores mais importantes da texturização são as temperaturas atingidas pelos fios dentro dos fornos, principalmente no forno de texturização. Para cada material existe uma configuração adequada dos fornos, afim de adquirir as propriedades desejadas de cada fio. 
Altas temperaturas somadas aos stresses mecânicos sofridos pelo fio durante o processo de torção conferem aos materiais mudanças em suas estruturas (DAYIOGLU, KARAKAS, 2004).

Ao sair do forno, o fio passa por uma placa de resfriamento que pode variar de $1-1,5 \mathrm{~m}$ de comprimento, para que seja entregue ao agregado de texturização a uma temperatura entre $70^{\circ} \mathrm{C}-100^{\circ} \mathrm{C}$.

Dependendo da aplicação, as máquinas podem possuir um segundo forno, que possui um comprimento menor e opera com temperaturas mais baixas que o primeiro forno. Máquinas com apenas 1 forno são utilizadas para produzir fios FT (falsa torção). As máquinas com 2 fornos são utilizadas para a produção de fios FTF (falsa torção fixado), porém podem ser reguladas para produzirem fios FT (é possível desabilitar o segundo forno), por esse motivo as máquinas com 2 fornos são mais utilizadas que as máquinas com apenas 1 forno.

A Figura 13 apresenta o esquema de meia máquina de texturização com perfil de forno de texturização 'M', assim como a passagem do fio por todos os órgãos da máquina.

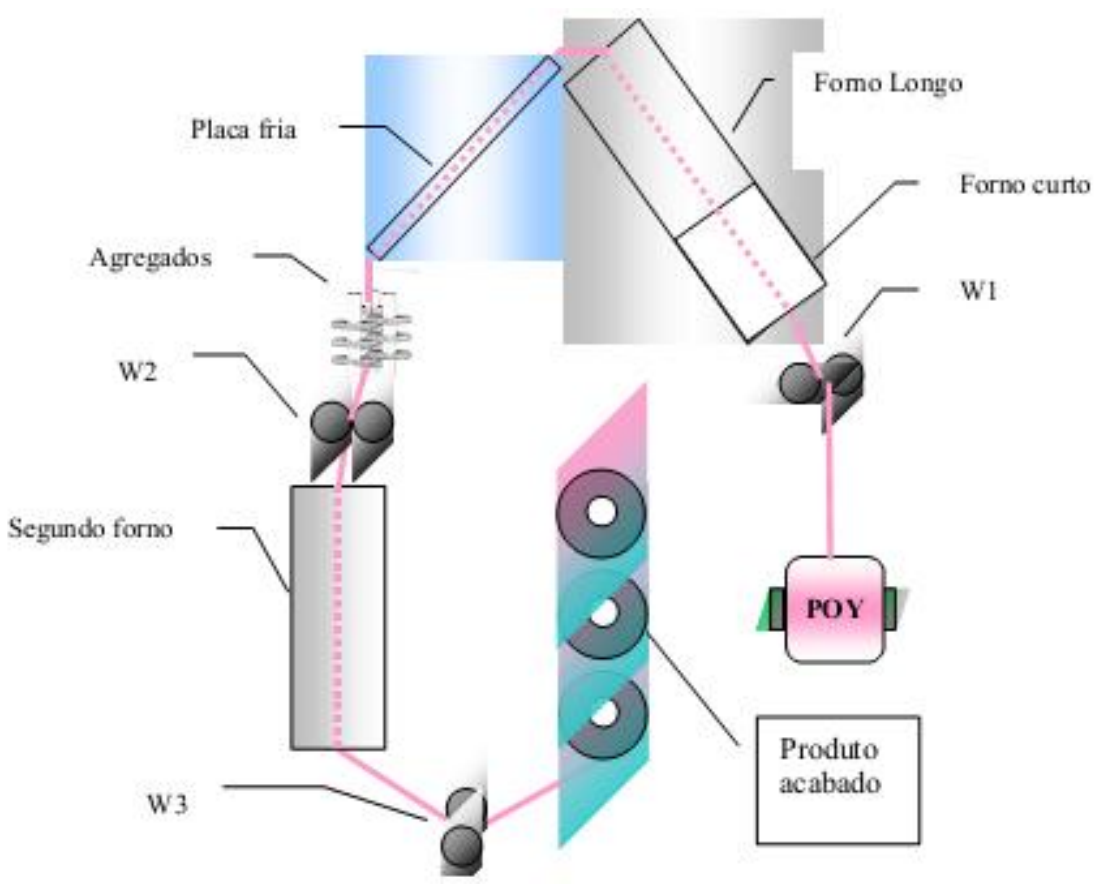

Figura 13 - Esquema de meia máquina de texturização com perfil M (SILVA, 2009, p. 34). 


\subsection{Etapa de fixação na texturização por Falsa Torção}

As macromoléculas nas estruturas semicristalinas orientadas raramente estão no seu estado de equilíbrio, seja nas regiões cristalinas ou nas regiões amorfas das fibras (GUPTA, 2002, p. 587).

A termofixação de um material proporciona a estabilização em um certo padrão, com a aplicação de calor. O fornecimento de energia térmica permite que o material relaxe em uma configuração mais estável (GREER, 1969).

Segundo Hearle (2001, p. 114), o forno de fixação, assim como o forno de texturização, pode ser classificado como forno de contato ou forno HT (high temperature - alta temperatura).

O forno de contato tem sido utilizado há muitos anos em máquinas de texturização de diversos fornecedores. É um forno confiável e de baixo custo operacional, porém possui certas desvantagens que o torna pouco aplicável em máquinas de alta velocidade. $\mathrm{O}$ seu funcionamento consiste no aquecimento elétrico de líquidos que se vaporizam. Com as estufas completamente seladas, e com a presença de exaustores é criado condições de vácuo. Uma vez que a temperatura dos aquecedores permita, o vapor condensa-se fazendo com que o calor que o líquido perde seja transmitido ao tubo por onde passa o fio com uma temperatura constante (com variação de mais ou menos $1^{\circ} \mathrm{C}$ ), independente da carga de fio que passa pelo forno.

Porém, uma vez que a restrição desse forno vai de $110^{\circ}$ à $235^{\circ} \mathrm{C}$ faz com que o forno tenha uma restrição na transmissão de calor. Para um fio que roda a $900 \mathrm{~m} / \mathrm{min}$ precisaria ter um forno de texturização ( $1^{\circ}$ forno) de pelo menos 2,5 metros, enquanto que para velocidades mais baixas 2 metros de forno é mais que o suficiente para a operação. Logo, para o desenvolvimento de maquinários com maior velocidade de produção precisariam possuir fornos cada vez maiores para garantir a transmissão de calor necessária para o bom desempenho do processo, que conseqüentemente geraria a necessidade de espaços cada vez maiores para a alocação das máquinas. A Figura 14 ilustra um forno de contato.

O forno HT foi apresentado em 1991 na feira ITMA (Internationale Textilmaschinen Ausstellung - Exposição Internacional de Maquinas Têxteis) em Hannover, na Alemanha. A principal vantagem do forno HT é a capacidade de trabalhar com altíssimas temperaturas, fazendo com que o fio consiga atingir a temperatura ideal de trabalho em um espaço muito menor de tempo. Os fornos HT possuem normalmente 1 metro de comprimento e a 
velocidade de trabalho do fio pode ser bem superior ao de trabalho com forno de contato, mesmo com um forno menor. Além da transmissão de temperatura, outra vantagem do forno é que o fio tem muito menos contato com as superfícies dos guias do que nos fornos de contato, logo, o fio sofre muito menos atrito e tensões, fazendo com que possibilite maiores velocidades de trabalho (HEARLE, 2001, p. 103).
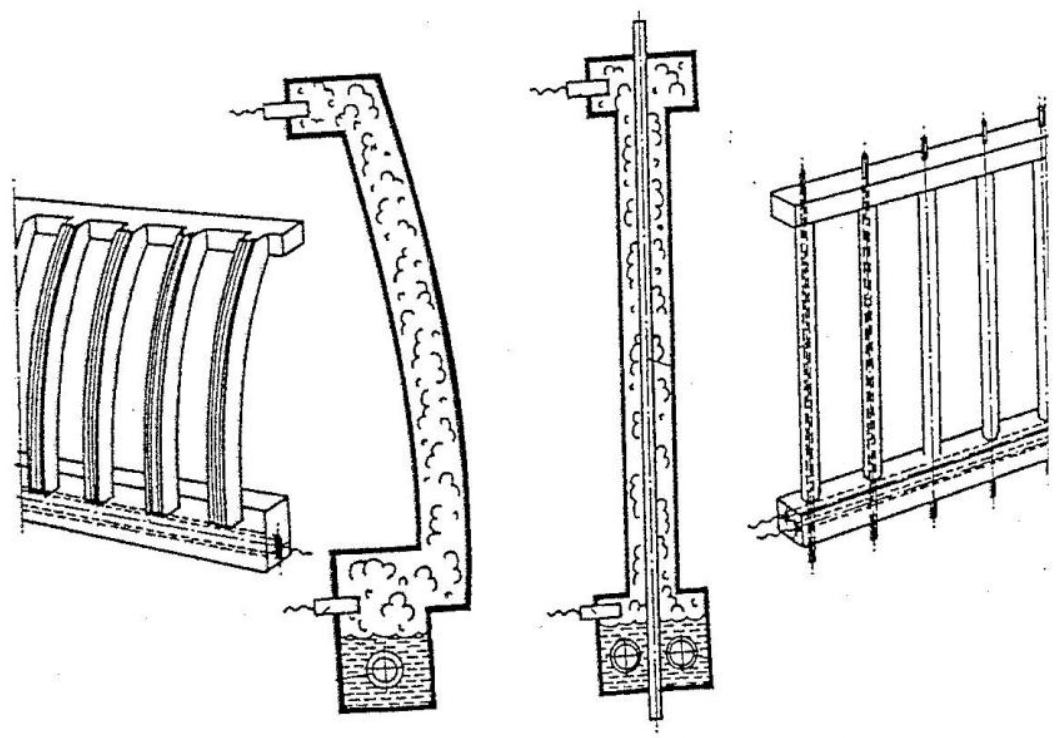

Figura 14 - Forno de contato (Fourne, 1998).

Segundo Fourné (1998, p. 223), a passagem do fio, estirado e texturizado, pelo forno de fixação com alta temperatura faz com que ele perca parcialmente o volume obtido com a texturização.

Karakas (2004, P. 19) apresentou que as condições de termofixação devem ser adaptadas com a natureza do material. A temperatura da termofixação deve ser definida em função do tempo de permanência de exposição.

Lord (2003, p.96) afirma que a passagem do fio texturizado pelo forno de fixação deve ocorrer com sobrealimentação para que o fio possa estruturar o seu volume. Essa sobrealimentação normalmente é na ordem de 4 à $5 \%$.

De acordo com Hearle (2001, p.114), a etapa de fixação consiste na passagem do fio por meio de um tubo com comprimento entre 1,0 à $1,3 \mathrm{~m}$ para fornos de contato e $0,6 \mathrm{~m}$ para fornos HT, onde o fio é aquecido sob relaxamento controlado. O fio é submetido a essas condições para reduzir o encolhimento e/ou o volume do fio. Para reduzir e/ou modificar o volume do fio texturizado, o fio normalmente é aquecido a temperaturas entre $150^{\circ}$ e $235^{\circ} \mathrm{C} \mathrm{em}$ fornos de 
contato. Como o forno de fixação, o forno HT também pode ser utilizado com temperaturas maiores, porém ele possui uma grande desvantagem em comparação ao forno de contato que é a tendência de ter problemas com a estática elétrica do fio, fazendo com que esse vibre muito dentro do forno podendo até fazer com que o fio fique em contato com as suas paredes, o que pode causar a ruptura do fio.

A temperatura do forno de fixação e a sobrealimentação do fio nele deve ser considerada como uma relação, desde que suas combinações tenham efeito nítido no encolhimento do fio. Antes de passar pelo forno de fixação, o fio possui um encolhimento muito alto, a ponto de não ser aceitável em algumas aplicações. Para reduzir esse encolhimento o forno de fixação é utilizado. Para fornos de contato são utilizadas temperaturas entre $150^{\circ}$ à $240^{\circ} \mathrm{C}$ e para fornos HT são utilizadas temperaturas de até $350^{\circ} \mathrm{C}$.

A sobrealimentação no forno de fixação pode aumentar ou reduzir o efeito da temperatura alterando a tensão do fio dentro do forno. A sobrealimentação normalmente varia entre 3 à $12 \%$, dependendo da configuração da máquina e da aplicação a qual se destina o fio produzido.

Se a sobrealimentação do fio no forno de fixação é alta, a tensão do fio no forno fica baixa, permitindo que a temperatura tenha máxima influência no efeito do fio. Caso a sobrealimentação seja baixa, a tensão do fio dentro do forno de fixação é alta, restringindo o efeito da temperatura no efeito do fio e podendo até mesmo gerar quebras dentro do forno (HEARLE, 2001, p. 119).

Com base em Hearle (2001, p. 170), a quantidade de calor que aplica-se no fio ao longo do processo de texturização é o principal fator que regula o encolhimento de um fio texturizado. Como o forno de texturização é configurado em função de gerar boas características de tingimento e boa eficiência de produção, o forno de fixação fica responsável por regular essa característica do fio.

Na Tabela 1 e no Gráfico 6, podemos verificar a influência da temperatura de fixação no encolhimento do fio. O teste foi realizado em um fio de poliéster Dtex 167/34, seção transversal redonda, à $700 \mathrm{~m} / \mathrm{min}$ de velocidade de produção e com temperatura de texturização de $210^{\circ} \mathrm{C}$. 
Tabela 1 - Efeito da variação da temperatura no forno de fixação no encolhimento do fio (HEARLE, 2001, p. 170).

\begin{tabular}{cc}
\hline Temperatura do forno de fixação $\left({ }^{\mathbf{0}} \mathbf{C}\right)$ & Encolhimento (\%) \\
\hline Temp. ambiente (forno desligado) & 34,7 \\
\hline 150 & 20,3 \\
\hline 160 & 16,3 \\
\hline 170 & 11,9 \\
\hline 180 & 10,4 \\
\hline 190 & 7,9 \\
\hline 200 & 7,5 \\
\hline 210 & 6,2 \\
\hline 220 & 4,8 \\
\hline 230 & 4,0 \\
\hline
\end{tabular}

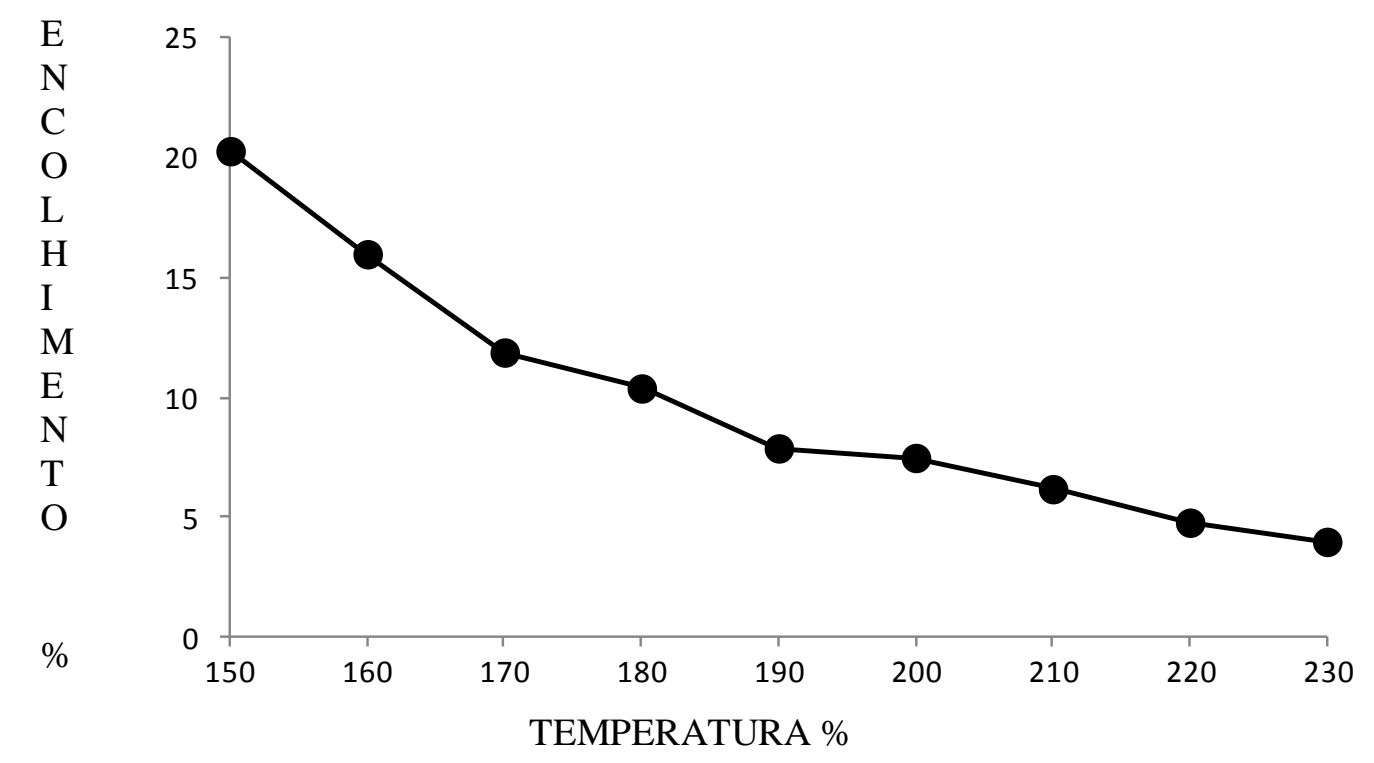

Gráfico 6 - Efeito da variação da temperatura no forno de fixação no encolhimento do fio (HEARLE, 2001, p. 171).

Além da temperatura, a sobrealimentação do fio no forno de fixação também tem uma influência muito importante no grau de encolhimento do fio texturizado. A sobrealimentação é responsável pela tensão exercida sobre o fio dentro do forno de fixação. O seu efeito é 
apresentado na Tabela 2 e no Gráfico 7, abaixo. Para a análise foi utilizado um fio de poliéster Dtex 167/34, com velocidade de $800 \mathrm{~m} / \mathrm{min}$.

Tabela 2 - Efeito da sobrealimentação em conjunto com a temperatura do forno de fixação no encolhimento do fio (HEARLE, 2001, p. 171).

Temperatura do forno de Fixação $\left({ }^{\circ} \mathrm{C}\right)$

\begin{tabular}{|c|c|c|c|c|c|c|c|c|c|c|}
\hline \multirow{6}{*}{ 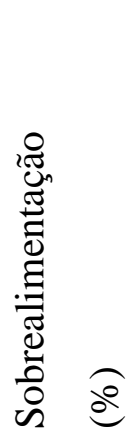 } & & 140 & 150 & 160 & 170 & 180 & 190 & 200 & 210 & 220 \\
\hline & 4 & 37,4 & 32,8 & 28,6 & 22,9 & 18,9 & 15,9 & 14,3 & 12,3 & 10,0 \\
\hline & 6 & 37,2 & 33,4 & 28,7 & 24,6 & 21,8 & 18,5 & 15,0 & 12,7 & 10,6 \\
\hline & 8 & 39,3 & 34,1 & 30,4 & 26,7 & 22,6 & 20,0 & 17,3 & 15,0 & 12,4 \\
\hline & $\mathbf{1 0}$ & 38,4 & 35,9 & 32,0 & 28,3 & 25,3 & 21,7 & 20,4 & 17,9 & 15,6 \\
\hline & 12 & 40,3 & 37,1 & 34,4 & 31,1 & 28,4 & 25,3 & 22,8 & 20,7 & 17,2 \\
\hline
\end{tabular}

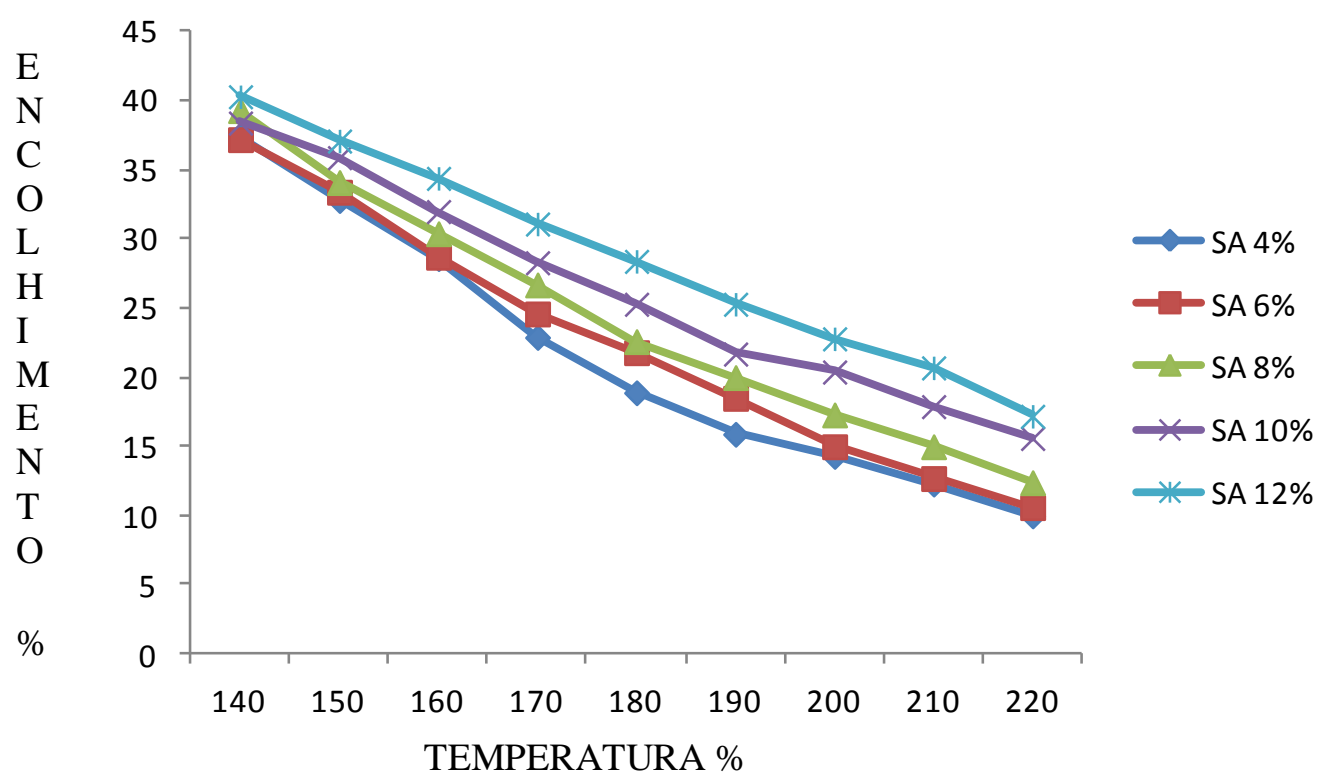

Gráfico 7 - Efeito da sobrealimentação em conjunto com a temperatura do forno de fixação no encolhimento do fio (HEARLE, 2001, p. 172).

Em um trabalho similar ao apresentado por Hearle, Freitas e Auil (2013, p. 46), confirmaram que tanto a temperatura do forno de fixação quanto a sobrealimentação do fio dentro forno são influentes no encolhimento residual do fio de poliéster, porém observaram que a interação entre as duas regulagens possui baixa influência na propriedade em questão. 


\subsection{Volume do fio}

De acordo com Silva (2009, p.29), o volume de um fio pode ser definido como a capacidade que o mesmo tem de ocupar um espaço livre. Propriedade essa diretamente ligada com a propriedade de cobertura gerada pelo tecido produzido com o fio.

O encrespamento, de acordo com os padrões têxteis, pode ser definido como ondulações ou sucessivos loops produzidos naturalmente (no caso das fibras naturais), mecanicamente ou quimicamente. $\mathrm{O}$ encrespamento pode ser avaliado conforme o grau de desvio da linearidade padrão (BAUER-KURZ ,2000, p.5).

A partir do momento que um fio liso é texturizado, ganhando volume e permitindo que ocorra a presença de ar entre os filamentos, diversas propriedades são incrementadas. Por exemplo, o ar estático que permanece entre as fibras funciona como bom isolante térmico, fazendo com que o fio texturizado proporcione maior sensação de calor do que um fio liso, uma vez que retém a temperatura do corpo.

De acordo com a Canoglu (2009), as propriedades de encrespamento que podem ser analisadas são: encrespamento, módulo e estabilidade.

Com base na norma DIN 53840, a contração do encrespamento pode ser definida como a redução do comprimento linear do fio em função do encrespamento formado (volume) pela texturização do fio.

O módulo do encrespamento é o comportamento do alongamento do encrespamento. Essa propriedade indica a elasticidade que o encrespamento confere ao fio texturizado.

A estabilidade do encrespamento é a retenção do encrespamento mediante a grande tensão mecânica. Essa propriedade também pode ser conhecida como a retenção mecânica do encrespamento. A estabilidade do encrespamento é uma das propriedades mais importantes uma vez que ela vai indicar a capacidade de o fio manter a textura mediante os esforços que ele vai sofrer tanto, no processo de produção dos artigos têxteis, quanto na aplicação do produto final. (BAUER-KURZ, 2000, p.41).

Dayioglu e Karakas (2004) estudaram a influência da temperatura do forno de texturização e da velocidade de produção sobre as propriedades contração, módulo e estabilidade de encrespamento no fio de poliamida texturizada por falsa torção não fixada.

A temperatura de texturização foi variada de $160^{\circ} \mathrm{C}$ à $220^{\circ} \mathrm{C}$ e puderam observar que o módulo do encrespamento aumentava coforme aumentava a temperatura de texturização. As 
propriedades contração e estabilidade do encrespamento aumentaram até $200^{\circ} \mathrm{C}$ e a partir daí começaram a diminuir. Possivelmente essa redução nas propriedades é provocada pela diminuição da orientação molecular provocada pelo início da fusão da fibra que começa pelas ligações moleculares mais fracas a partir dessa temperatura aproximadamente, sob tensão.

Com relação a velocidade de produção, observou-se que quanto menor a velocidade do fio maiores eram as propriedades de encrespamento. Com aumento da energia recebida dentro dos fornos de texturização e mais tempo para o resfriamento do fio nas placas frias, o fio texturizado em velocidades mais baixas tem condições melhores de formar novas ligações e, então, incrementar as propriedades de encrespamento.

Canoglu (2009) fez um estudo semelhante, porém estudando a influência do forno de texturização no fio de poliéster texturizado por falsa torção. Variando a temperatura do forno de texturização entre $175^{\circ} \mathrm{C}$ a $205^{\circ} \mathrm{C}$ observou que existe incremento nas propriedades do encrespamento do fio texturizado, conforme a temperatura do forno de texturização é elevada dentro do intervalo proposto.

Stein (Textechno) afirma que pequenas variações nos fios texturizados podem provocar grandes mudanças nas características do tecido final. Quando as mudanças ocorrem de modo provocado, efeitos diferentes são obtidos, permitindo ao produtor de fio texturizado comercializar uma maior gama de produtos. Por outro lado, quando essas pequenas variações ocorrem de maneira inesperada o que surge é uma série de problemas que geram transtornos ao longo da cadeia têxtil.

Consequentemente, os métodos de análise dos fios texturizados devem ser sensíveis o suficiente para detectar essas pequenas variações. Por outro lado, ele também afirma que é difícil definir padrões dos ensaios de volume de fio que permitam conferir ao teste a característica de controle de qualidade.

Segundo Fourné (1998, p.741), existem duas maneiras de analisar o volume de um fio texturizado.

1. Geometricamente baseado nas propriedades do encrespamento: quantidade de encrespamentos por unidade de comprimento;

2. Propriedades do encrespamento desenvolvidas na fibra: contração do encrespamento; estabilidade do encrespamento, módulo do encrespamento, força de desencrespamento. 
Canoglu (2009) e Stein (Texechno) apresentam um modelo para análise da contração do encrespamento, módulo do encrespamento e estabilidade do encrespamento, utilizando o instrumento Textechno Texturmat ME, que usa como base a norma DIN 53840.

O ensaio citado pela norma DIN também é mundialmente conhecida como ensaio de EKB, devido o nome das propriedades em alemão, que seguem abaixo:

- Einkräuselung: Contração do encrespamento;

- Kennkräuselug: Módulo do encrespamento;

- Krauselbeständigkeit: Estabilidade do encrespamento.

Com base na norma DIN 53840 apresenta-se os procedimentos abaixo:

- Produzir meadas do fio a ser analisado, com um título próximo de 2500 dtex. As meadas serão submetidas a várias cargas ao longo do teste e o seu comprimento será medido em cada etapa do teste;

- Aplicar carga de $2 \mathrm{cN} /$ tex por 10 segundos e medir o comprimento Lg;

- Aplicar carga de $0,01 \mathrm{cN} /$ tex, submeter ao ar seco e quente $\left(120^{\circ} \mathrm{C}\right)$ por 10 minutos e medir o comprimento Lz;

- Aplicar carga de 0,1 cN/tex por 10 segundo e medir o comprimento Lf;

- Aplicar carga de $10 \mathrm{cN} /$ tex por 10 segundo, em seguida aplicar carga de 0,01 cN/Tex por 10 minutos e medir o comprimento Lb;

- Calcular as propriedades de encrespamento conforme Equação 1, Equação 2 e Equação 3, apresentadas abaixo:

$$
\begin{aligned}
& \text { - contração do encrespamento }=\frac{L g-L z}{L g} \times 100(\%) \\
& \text { - módulo do encrespamento }=\frac{L g-L f}{L g} \times 100(\%) \\
& \text { - estabilidade do encrespamento }=\frac{L g-L b}{L g} \times 100(\%)
\end{aligned}
$$

Outros métodos para a análise de volume do fio são propostos. O teste Heberlein se difere da norma DIN apresentada acima, na forma de revelar o encrespamento. No teste Heberlein o encrespamento se forma em água quente $\left(95^{\circ} \mathrm{C}\right)$. Então, é retirado o comprimento com a meada úmida e outra medida é retirada com a meada seca e acondicionada. 
Outro teste utilizado no mercado para a cotnração do encrespamento é o Hatra, onde o encrespamento se forma também em água quente $\left(80^{\circ} \mathrm{C}\right)$ e as medidas são retiradas com a meada submersa em água a $20^{\circ} \mathrm{C}$.

Existe também o teste do Tubo, onde um comprimento determinado de meada, sob uma tensão determinada, é colocada dentro de um tubo onde a ação da água fervente faz com que o fio se retraia, revelando o grau de encrespamento do fio.

Todos os testes citados acima são estáticos, feitos com de meada, ou parte dela. Outra opção a ser utilizada para a avaliação do volume do fio é a aplicação de ensaios dinâmicos.

A proposta do teste dinâmico não indica o volume do fio propriamente dito, mas sim a força do encrespamento e também a força do encolhimento do fio. Segundo Rodgers e Ghosh, essas propriedades estão relacionadas às propriedades de encrespamento obtidas pelos fios durante o processo de texturização. A contração é explicada pelo fato de a energia do calor fornecido (energia) superar as forças moleculares a ponto de permitir que ligações estressadas retornem a um estado mais relaxado. Caso a contração seja bloqueada, impedindo o encolhimento do material, formam-se mais ligações estressadas pelas condições térmicas.

Para esse teste, recomenda-se a utilização de um equipamento chamado Dynafil ${ }^{\circledR}$ da Textechno ${ }^{\circledR}$. O teste consiste na passagem do fio através de um tubo aquecido (como os do forno da máquina de texturização), com uma pequena sobrealimentação para que o fio possa contrair na zona de medição da força da contração. A força do encolhimento segue o mesmo princípio, porém a temperatura utilizada no tubo aquecido é superior ao da força do encrespamento. No teste realizado por Stein (Textechno, p. 3 - 4) a temperatura do ensaio da força do encrespamento era de $120^{\circ}$ enquanto a temperatura do ensaio da força do encolhimento era de $245^{\circ} \mathrm{C}$.

De acordo com os testes comparativos realizado por Stein (Textechno), a maioria dos testes apresentaram coerência com relação a tendência dos resultados, porém ficou confirmado que não existe um fator universal capaz de cobrir todos os resultados ou parte deles.

Outra importante análise feita pelo autor é que os ensaios estáticos são passíveis de erros externos, como por exemplo, a produção da meada, leitura das medidas, o controle do tempo em que as meadas devem ser expostas a temperaturas para a formação do encrespamento. A utilização de equipamentos como Texturmat $\mathrm{ME}^{\circledR}$ reduz as possibilidades da influência do erro humano na análise do material.

O teste dinâmico também está sujeito a erros humanos, uma vez que uma série de regulagens são necessárias para a realização dos testes de acordo com o que se deseja obter. 
Deve-se definir muito bem o que se deseja analisar para definir que tipo de teste realizar. $\mathrm{O}$ ensaio dinâmico, apesar de não apresentar as propriedades do encrespamento propriamente ditas, faz uma análise linear no fio, podendo apresentar pequenas variações ao longo do comprimento do corpo de prova, enquanto a análise estática pode não apresentá-las, uma vez que o ponto irregular pode estar sendo compensado ao longo do corpo de prova. Ao mesmo tempo, ter bem definida as propriedades do encrespamento pode garantir a boa reprodutibilidade do fio texturizado. 


\section{MATERIAIS E MÉTODOS}

\subsection{Materiais}

\subsubsection{Matéria-prima}

Fio parcialmente orientado (POY) de poliéster, de ampla utilização no mercado têxtil para os mais diversos segmentos. Título comercial 250 denier (250 gramas para $9000 \mathrm{~m}$ linear do material) com 48 filamentos (POY PES 250den f48), semi-opaco, seção transversal redonda.

\subsubsection{Customização da matéria-prima}

Pensando em futura reprodutibilidade do experimento, foi feita a caracterização da matériaprima.

Com a utilização do equipamento Statimat, realizou-se os ensaios de título, alongamento e tenacidade do fio parcialmente orientado (POY).

Com a utilização do equipamento Dynafil, realizou-se os ensaios para verificação de força de estiro e filamentos quebrados.

Os resultados da caracterização da matéria-prima são apresentados no Anexo A. 


\subsection{Métodos}

\subsubsection{Texturização}

A texturização do fio de poliéster foi realizada em Máquina Barmag ${ }^{\circledR} \mathrm{AFK}-1000$, com forno de texturização de alta temperatura (HT) com perfil V e o forno de fixação de contato. A alimentação é feita em POY.

As regulagens que foram mantidas fixas para a texturização da matéria-prima descrita no item acima são apresentadas na Tabela 3.

Tabela 3 - Regulagens base para a texturização dos corpos de prova.

\begin{tabular}{lc}
\hline \multicolumn{1}{c}{ Regulagem } & Valor \\
\hline Velocidade & $650 \mathrm{~m} / \mathrm{min}$ \\
\hline Taxa de estiragem & 1,79 \\
\hline Temperatura do forno de & Estufa Curta: $400^{\circ} \mathrm{C}$ \\
\cline { 2 - 2 } texturização ( $1^{\circ}$ forno) & Estufa Longa: $310^{\circ} \mathrm{C}$ \\
\hline Formação dos discos de texturização & 1.5 .1 \\
\hline Tipo dos discos de texturização & Poliuretano \\
\hline D/Y & 1,68 \\
\hline
\end{tabular}

\subsubsection{Análise dos fios produzidos}

Após a texturização dos fios de poliéster a serem utilizados no estudo, o material seguiu para análises físicas em laboratório para determinação de suas características.

Os fios texturizados foram caracterizados, buscando a reprodutibilidade de futuros testes. Utilizando o equipamento Statimat ${ }^{\circledR}$ da Textechno $^{\circledR}$, foram realizados ensaios de título, alongamento e tenacidade. Para o encolhimento foi utilizado processo de submersão de meada em água quente $\left(82^{\circ} \mathrm{C}\right)$ por 10 minutos, com comparação do comprimento da meada antes e após a submersão, sempre pré tensionada com 20 gramas. Os dados da caracterização estão apresentados no Anexo B. 
Os ensaios que geram os dados de encrespamento foram realizados utilizando o equipamento Texturmat $^{\circledR}$ da fabricante Textechno ${ }^{\circledR}$. Com o equipamento foram obtidos os dados da contração do encrespamento, do módulo de encrespamento e da estabilidade de encrespamento. O ensaio foi realizado conforme norma alemã DIN 53840, que segue descrita abaixo:

- Produzir meadas do fio a ser analisado, com um título próximo de 2500 dtex. As meadas serão submetidas a várias cargas ao longo do teste e o seu comprimento será medido em cada etapa do teste;

- Aplicar carga de $2 \mathrm{cN} /$ tex por 10 segundos e medir o comprimento da meada (Lg);

- Aplicar carga de $0,01 \mathrm{cN} /$ tex submeter ao ar seco e quente $\left(120^{\circ} \mathrm{C}\right)$ por 10 minutos e medir o comprimento da meada (Lz);

- Aplicar carga de $0,1 \mathrm{cN} /$ tex por 10 segundos e medir o comprimento da meada (Lf);

- Aplicar carga de $10 \mathrm{cN} /$ tex por 10 segundos, em seguida aplicar carga de 0,01 cN/Tex por 10 minutos e medir o comprimento da meada (Lb);

- Calcular as propriedades de encrespamento que seguem abaixo:

○ Contração do encrespamento $(\mathrm{CE})=$ Equação 1

○ Módulo do encrespamento (ME) = Equação 2

- Estabilidade do encrespamento $(\mathrm{EE})=$ Equação 3

Os dados referentes ao encrespamento do fio texturizado de poliéster obtidos na análise estão apresentados no Anexo C.

\subsubsection{Estudo Experimental}

Os métodos de planejamento de experimentos são muito úteis nos projetos que visam desenvolver novos produtos ou aperfeiçoar produtos e processos já existentes. Com o uso do planejamento de experimentos é possível desenvolver produtos que sejam mais fáceis de fabricar, com melhores desempenhos e maior confiabilidade.

A utilização de planejamentos fatoriais é normalmente utilizado para experimentos que envolvem diversos fatores a serem analisados, em que, além da compreensão da influência dos fatores individualmente no resultado é necessário também compreender a interação dos fatores. 
O planejamento fatorial realiza todas as combinações possíveis dos níveis dos fatores na sequência de testes propostas pelo planejamento.

O planejamento fatorial mais utilizado é aquele em que $k$ fatores são analisados com apenas dois níveis (mínimo e máximo). Os níveis a serem analisados podem ser quantitativos ou qualitativos. Esse planejamento é conhecido como fatorial $2^{\mathrm{k}}$.

O tipo mais simples de planejamento $2^{\mathrm{k}}$ é o planejamento com apenas dois fatores a serem analisados, gerando um planejamento fatorial $2^{2}$.

O planejamento fatorial $2^{2}$ é representado na Figura 15 . O planejamento pode ser representado geometricamente através de um quadrado, onde cada uma das combinações do experimento representa um dos vértices do quadrado. No planejamento $2^{2}$ é comum denotar os níveis baixo e alto dos fatores A e B com os sinais - e +. Além disso, também é comum marcar as combinações dos tratamentos com uma série de letras minúsculas. Se uma letra estiver presente, então o fator correspondente é corrido no nível alto naquela combinação de tratamentos. Se a letra estiver ausente representa que o fator é corrido em seu nível mínimo. A combinação de tratamentos onde todos os fatores correm em seu nível mínimo será representada pelo algarismo 1.

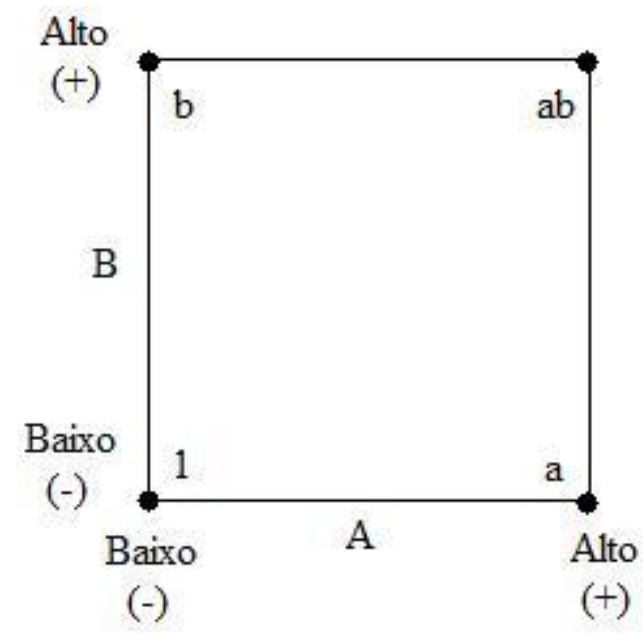

Figura 15 - Representação geométrica do planejamento fatorial 2². (MONTGOMERRY, 2011, p. 219).

Os efeitos de interesse no planejamento $2^{2}$ são os efeitos principais A e B e o fator de interação de segunda ordem $\mathrm{AB}$. 
Para estimar o efeito principal do fator A, é calculada a diferença da média das análises com o fator A em seu nível máximo com a média das análises com o fator A em seu nível mínimo, conforme Equação 4.

$A=\frac{a+a b}{2 n}-\frac{b+(1)}{2 n}=\frac{1}{2 n}[a+a b-b-(1)]$

O efeito principal do fator B é calculado de maneira análoga ao do fator A. O efeito principal de $\mathrm{B}$ é a diferença entre a média dos valores encontrados com o fator B em seu nível máximo com a média dos valores encontrados com o fator B em seu nível mínimo, conforme apresentado na Equação 5.

$B=\frac{b+a b}{2 n}-\frac{a+(1)}{2 n}=\frac{1}{2 n}[b+a b-a-(1)]$

A interação dos fatores A e B é estimada pela diferença das médias das diagonais da Figura 15, conforme apresentado pela Equação 6.

$A B=\frac{a b+(1)}{2 n}-\frac{a+b}{2 n}=\frac{1}{2 n}[a b+(1)-a-b]$

A preocupação do uso do planejamento fatorial com dois níveis na análise de experimentos é a suposição de linearidade nos efeitos dos fatores entre os dois níveis analisados.

Não é necessária a linearidade perfeita para a validade do planejamento fatorial no sistema $2^{\mathrm{k}}$. Porém, existe um método para replicar pontos centrais que dará proteção contra curvatura, assim como permitirá uma estimativa equivalente, independentemente do erro a ser obtido (MONTGOERY, 2011).

No estudo a seguir foi realizado o planejamento $2^{2}$ com o auxílio do software de análise estatístico Minitab ${ }^{\circledR} 16$ para a programação dos testes do estudo da influência da sobrealimentação do fio dentro do forno de fixação e da influência da temperatura do forno de fixação nas propriedades do encrespamento do fio texturizado por falsa torção. Para a programação foi utilizando a técnica de planejamento do desenvolvimento ou design of experiments (DOE). Foi utilizado o ponto central para verificação da linearidade dos dados. 
Os fatores e os níveis do estudo são dados abaixo:

- Sobrealimentação: $5 \%$ e $29 \%$.

- Temperatura do forno de fixação: $140^{\circ} \mathrm{C}$ e $220^{\circ} \mathrm{C}$.

- Ponto Central: $180^{\circ} \mathrm{C}$ e $17 \%$ de sobrealimentação do fio dentro do forno.

O nível máximo de sobrealimentação foi definido além dos valores convencionais da indústria. $\mathrm{O}$ objetivo foi verificar se os resultados a serem apresentados pelo estudo indicariam alguma tendência diferente do comumente encontrado pela indústria. Para os valores de temperatura do forno de fixação os níveis foram definidos com base nos limites do equipamento.

Para cada combinação foram realizadas dez replicações, assim como para o ponto central que foram coletados dez valores, no intuito de gerar maior confiança nos dados coletados.

Após a realização dos testes e a coleta das informações, com a utilização do Minitab ${ }^{\circledR}$, foi realizada a análise fatorial para cada uma das propriedades do encrespamento (contração, módulo e estabilidade), para que fossem mensuradas a importância de cada uma das variáveis em estudo sobre as propriedades, assim como as suas interações.

Prosseguindo com o estudo, foi feito a regressão linear simples, com o Minitab ${ }^{\circledR}$, para avaliar a existência de uma relação funcional entre as variáveis dependentes (contração, módulo e estabilidade) e as variáveis independentes (temperatura e sobrealimentação), determinando assim a equação das propriedades em estudo em função das variáveis. 


\section{RESULTADOS E DISCUSSÕES PARCIAIS}

Conforme mencionado no Capítulo 3, os resultados dos ensaios realizados no equipamento Textechno Texturmat $\mathrm{ME}^{\circledR}$ para a determinação das propriedades do encrespamento estão apresentados na Tabela 4, localizada no Anexo C.

Tabela 4 - Dados das propriedades de encrespamento.

\begin{tabular}{|c|c|c|c|c|}
\hline $\begin{array}{c}\text { TEMPERATURA } \\
\left({ }^{\circ} \mathrm{C}\right)\end{array}$ & $\begin{array}{c}\text { SOBREALIMENTAÇÃO } \\
(\%)\end{array}$ & $\begin{array}{l}\mathrm{CC} \\
(\%)\end{array}$ & $\begin{array}{l}\mathrm{MC} \\
(\%)\end{array}$ & $\begin{array}{l}\mathrm{EC} \\
(\%)\end{array}$ \\
\hline 140 & 5 & 12,36 & 8,69 & 71,46 \\
\hline 220 & 5 & 10,9 & 7,22 & 76,35 \\
\hline 140 & 29 & 30,64 & 20,12 & 82,02 \\
\hline 220 & 29 & 23,31 & 15,31 & 79,65 \\
\hline 140 & 5 & 12,73 & 8,96 & 71,25 \\
\hline 220 & 5 & 10,97 & 7,38 & 76,59 \\
\hline 140 & 29 & 30,13 & 19,83 & 81,34 \\
\hline 220 & 29 & 21,04 & 13,75 & 76,84 \\
\hline 140 & 5 & 11,93 & 8,41 & 70,34 \\
\hline 220 & 5 & 10,25 & 6,8 & 76,66 \\
\hline 140 & 29 & 29,64 & 19,55 & 80,88 \\
\hline 220 & 29 & 23,59 & 15,54 & 78,92 \\
\hline 140 & 5 & 12,19 & 8,57 & 70,6 \\
\hline 220 & 5 & 9,43 & 6,27 & 75,26 \\
\hline 140 & 29 & 30,5 & 20,46 & 81,23 \\
\hline 220 & 29 & 20,69 & 13,55 & 76,37 \\
\hline 140 & 5 & 12,36 & 8,77 & 71,44 \\
\hline 220 & 5 & 10,25 & 6,76 & 76,95 \\
\hline 140 & 29 & 29,64 & 19,63 & 80,49 \\
\hline 220 & 29 & 23,4 & 15,33 & 78,25 \\
\hline 140 & 5 & 12,34 & 8,64 & 70,96 \\
\hline 220 & 5 & 8,54 & 5,55 & 75,8 \\
\hline
\end{tabular}




\begin{tabular}{|c|c|c|c|c|}
\hline 140 & 29 & 28,57 & 19,07 & 80,15 \\
\hline 220 & 29 & 23,37 & 15,47 & 78,29 \\
\hline 140 & 5 & 12,56 & 8,85 & 71,77 \\
\hline 220 & 5 & 9,68 & 6,38 & 75,89 \\
\hline 140 & 29 & 29,62 & 20,46 & 80,14 \\
\hline 220 & 29 & 23,05 & 15,19 & 80,15 \\
\hline 140 & 5 & 12,39 & 8,68 & 70,88 \\
\hline 220 & 5 & 10,37 & 6,91 & 75,96 \\
\hline 140 & 29 & 27,89 & 18,42 & 80,12 \\
\hline 220 & 29 & 21,45 & 14,14 & 77,37 \\
\hline 140 & 5 & 11,76 & 8,33 & 70,77 \\
\hline 220 & 5 & 10,72 & 7,11 & 76,84 \\
\hline 140 & 29 & 27,52 & 18,05 & 79,59 \\
\hline 220 & 29 & 22,65 & 14,88 & 77,43 \\
\hline 140 & 5 & 12,47 & 8,92 & 71,13 \\
\hline 220 & 5 & 10,5 & 6,98 & 76,4 \\
\hline 140 & 29 & 28,24 & 18,65 & 79,58 \\
\hline 220 & 29 & 23,27 & 15,36 & 77,46 \\
\hline 180 & 17 & 24,69 & 16,72 & 81,01 \\
\hline 180 & 17 & 25,00 & 16,91 & 80,38 \\
\hline 180 & 17 & 22,52 & 15,27 & 79,13 \\
\hline 180 & 17 & 23,81 & 16,14 & 79,33 \\
\hline 180 & 17 & 22,74 & 15,57 & 79,09 \\
\hline 180 & 17 & 22,74 & 15,66 & 78,26 \\
\hline 180 & 17 & 24,03 & 16,73 & 79,31 \\
\hline 180 & 17 & 24,06 & 16,00 & 79,43 \\
\hline 180 & 17 & 25,07 & 16,98 & 81,37 \\
\hline 180 & 17 & 23,29 & 15,74 & 79,59 \\
\hline
\end{tabular}

Abaixo apresentaremos os as análises de cada uma das propriedades individualmente. 


\subsection{Contração do encrespamento}

A Tabela 5 apresenta as médias e o desvio padrão dos resultados encontrados referente a contração do encrespamento.

Tabela 5 - Média e desvio padrão dos resultados do ensaio parra a determinação da contração do encrespamento.

\begin{tabular}{cccc}
\hline $\begin{array}{c}\text { Temperatura do } \\
\text { forno de fixação } \\
\left({ }^{\mathbf{C}} \mathbf{C}\right)\end{array}$ & $\begin{array}{c}\text { Sobrealimentação } \\
(\boldsymbol{\%})\end{array}$ & Média $(\%)$ & Desvio Padrão \\
\hline 140 & 5 & 12,31 & 0,2864 \\
\hline 220 & 5 & 10,16 & 0,7514 \\
\hline 140 & 29 & 29,24 & 1,1072 \\
\hline 220 & 29 & 22,58 & 1,0940 \\
\hline 180 & 17 & 23,80 & 0,9493 \\
\hline
\end{tabular}

A Figura 16 apresenta o planejamento fatorial $2^{2}$ do estudo da influência da etapa de fixação do processo de texturização por falsa torção na propriedade contração do encrespamento, por representação geométrica.

Fazendo a análise de variância ANOVA (two-way), com nível de significância de 0,05, para os dados encontrados de contração do encrespamento, podemos observar que a diferença entre as médias dos testes são significativas $(\mathrm{P} \leq 0,05)$, o que já nos mostra que o teste apresentou relevância nos resultados. O relatório gerado pelo Minitab ${ }^{\circledR}$ está apresentado no Anexo D e os dados da análise seguem demonstrados na Tabela 6. 


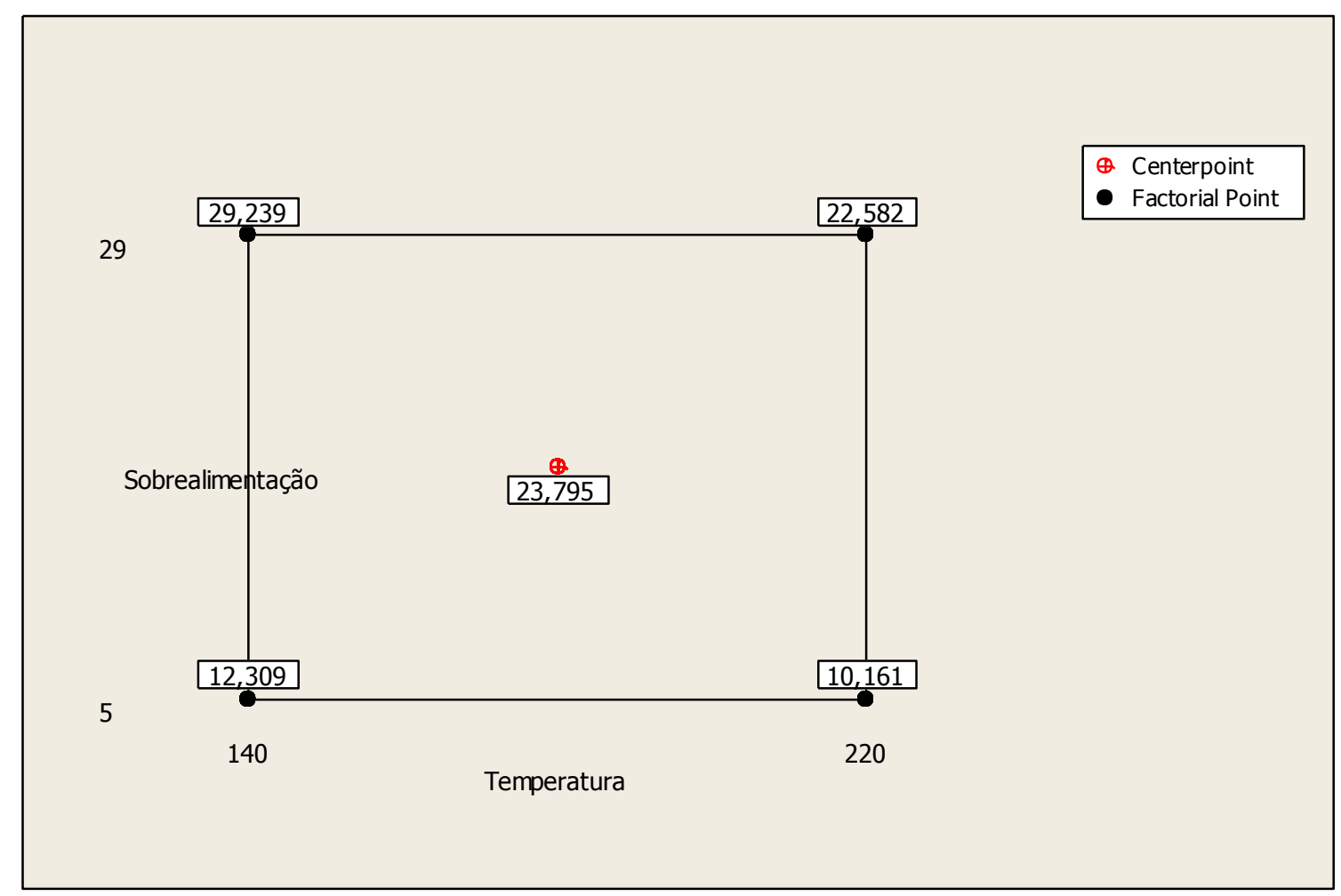

Figura 16 - Representação geométrica do planejamento fatorial $2^{2}$ da influência da etapa de fixação do processo de texturização por falsa torção na contração do encrespamento.

Tabela 6 - Análise de variância ANOVA (two way) da contração do encrespamento.

\begin{tabular}{lccccc}
\hline $\begin{array}{c}\text { Fonte de } \\
\text { Variação }\end{array}$ & $\begin{array}{c}\text { Soma de } \\
\text { Quadrados }\end{array}$ & $\begin{array}{c}\text { Quadrado } \\
\text { Médio }\end{array}$ & $\begin{array}{c}\text { Grau de } \\
\text { Liberdade }\end{array}$ & F & P \\
\hline Temperatura & 193,82 & 193,82 & 1 & 252,58 & 0,000 \\
\hline Sobrealimentação & 2153,70 & 2153,70 & 1 & 2806,65 & 0,000 \\
\hline Interação & 50,83 & 50,83 & 1 & 66,24 & 0,000 \\
\hline Curvatura & 218,18 & 218,18 & 1 & 274,73 & 0,000 \\
\hline Resíduo & 27,62 & 0,77 & 45 & & \\
\hline Total & 2425,98 & & 49 & & \\
\hline
\end{tabular}

Para ilustrar como a diferença entre as médias são relevantes o Gráfico 8 apresenta o boxplot da contração do encrespamento em função da temperatura do forno de fixação e da sobrealimentação do fio dentro do forno de fixação. 
Uma vez definida que a diferença entre as médias são relevantes, fizemos a análise fatorial dos dados encontrados para começar a compreensão entre a variável dependente contração do encrespamento e as variáveis independentes temperatura do forno de fixação e sobrealimentação do fio dentro do forno de fixação.

Com base no relatório gerado pelo Minitab ${ }^{\circledR}$, que está localizado no Anexo D, é possível observarmos o grau de influência de cada uma das variáveis assim como o grau de influência da interação das variáveis, conforme Gráfico 9. Da análise fatorial observamos que a sobrealimentação do fio dentro do forno de fixação é a variável que possui maior influência na contração do encrespamento, seguido da temperatura do forno de fixação e por fim a interação das duas variáveis. $\mathrm{O}$ alto valor do coeficiente de determinação ajustado $\left(\mathrm{R}^{2}\right.$ adj. = 98,53\%) nos indica que a análise feita explica com boa margem de confiança as variações encontradas no experimento.

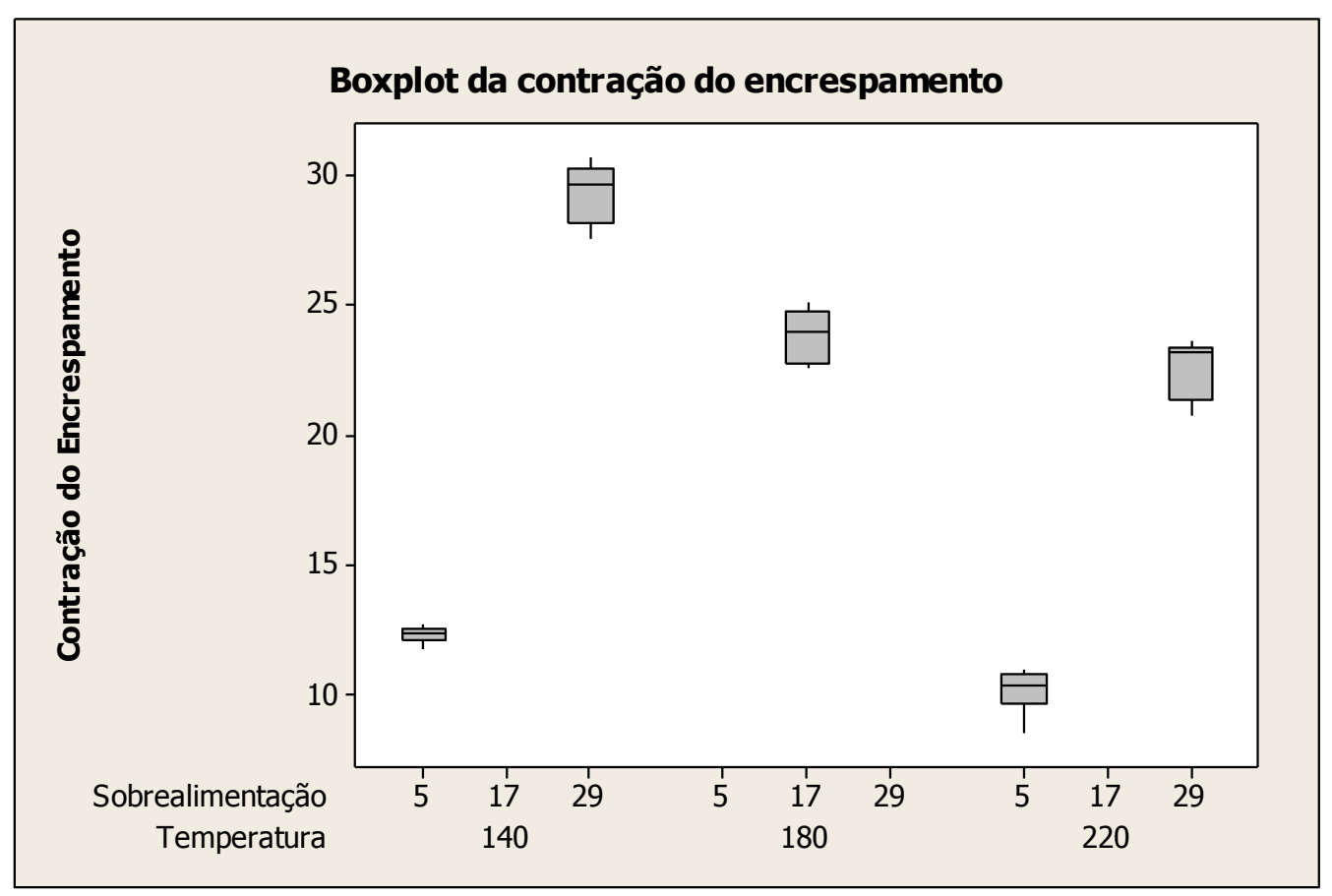

Gráfico 8 - Boxplot da contração do encrespamento em função da temperatura e da sobrealimentação do forno de fixação 


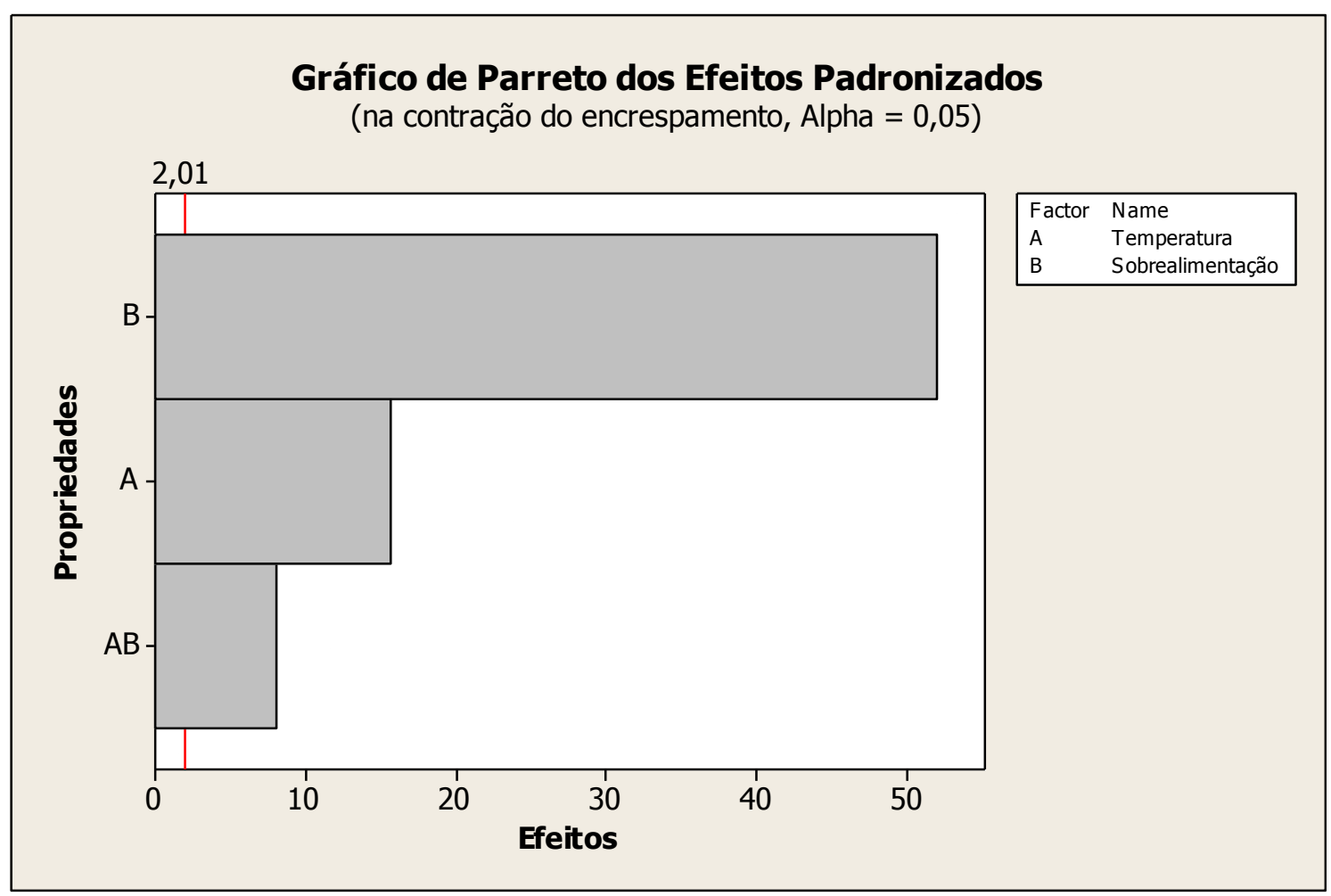

Gráfico 9 - Apresentação do grau de influência das variáveis temperatura do forno de fixação e sobrealimentação do fio dentro do forno de fixação e a interação das variáveis na contração do encrespamento.

O Gráfico 10 apresenta individualmente o efeito de cada uma das variáveis independentes na contração do encrespamento. Apresenta que o alcance dos valores de mínimo e máximo da contração do encrespamento estão fortemente relacionados com a sobrealimentação do fio dentro do forno de fixação.

O Gráfico 11 apresenta a interação das variáveis temperatura do forno de fixação e sobrealimentação do fio no forno de fixação na contração do encrespamento. Analisando o gráfico, observamos que, para atingir o valor máximo da contração de encrespamento, devemos trabalhar com a temperatura mais baixa possível no forno de fixação (no caso do experimento $140^{\circ} \mathrm{C}$ ) e com o máximo de sobrealimentação do fio dentro do forno de fixação (5\% no caso do experimento). 


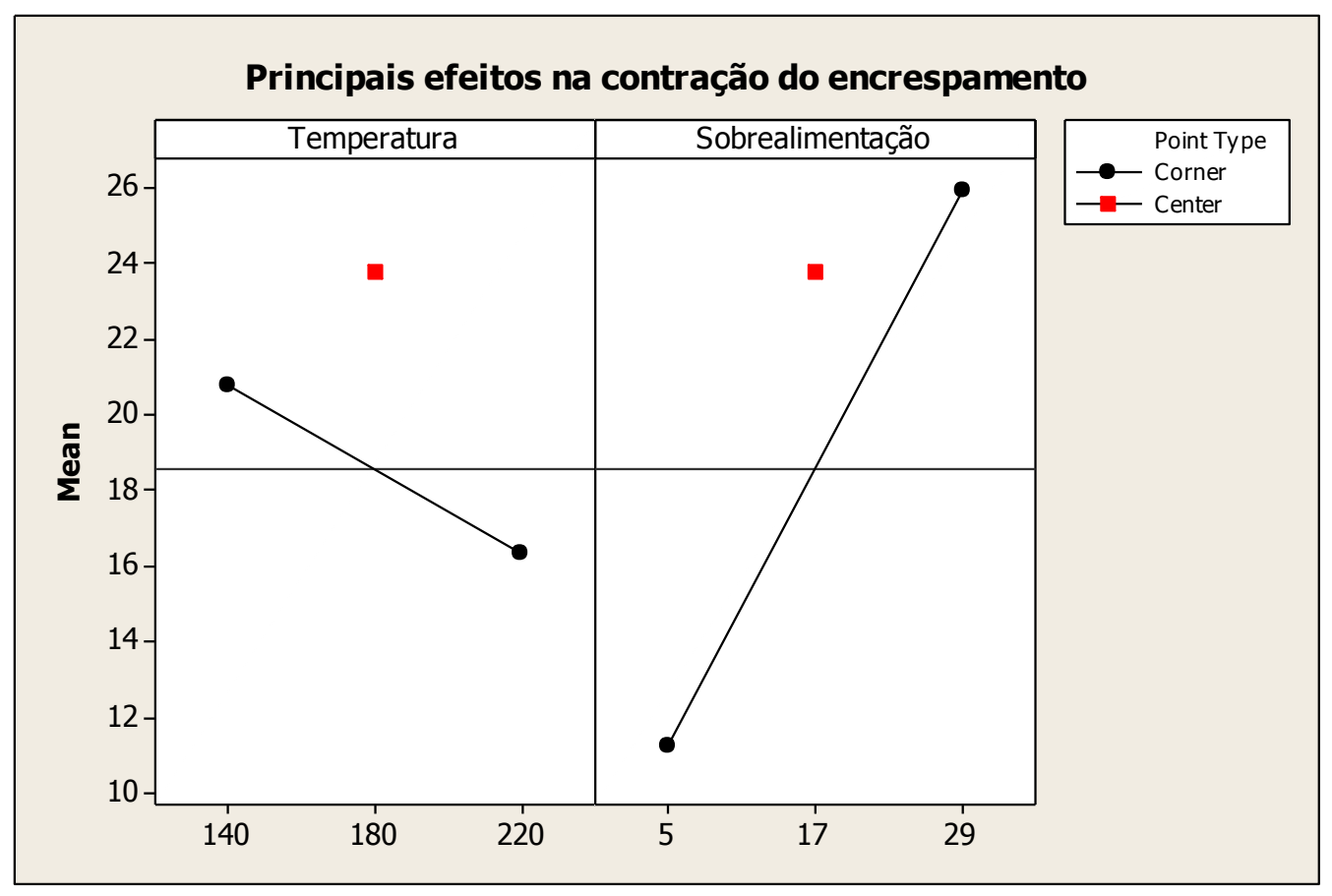

Gráfico 10 - Efeito da temperatura do forno de fixação e da sobrealimentação do fio no forno de fixação na contração do encrespamento.

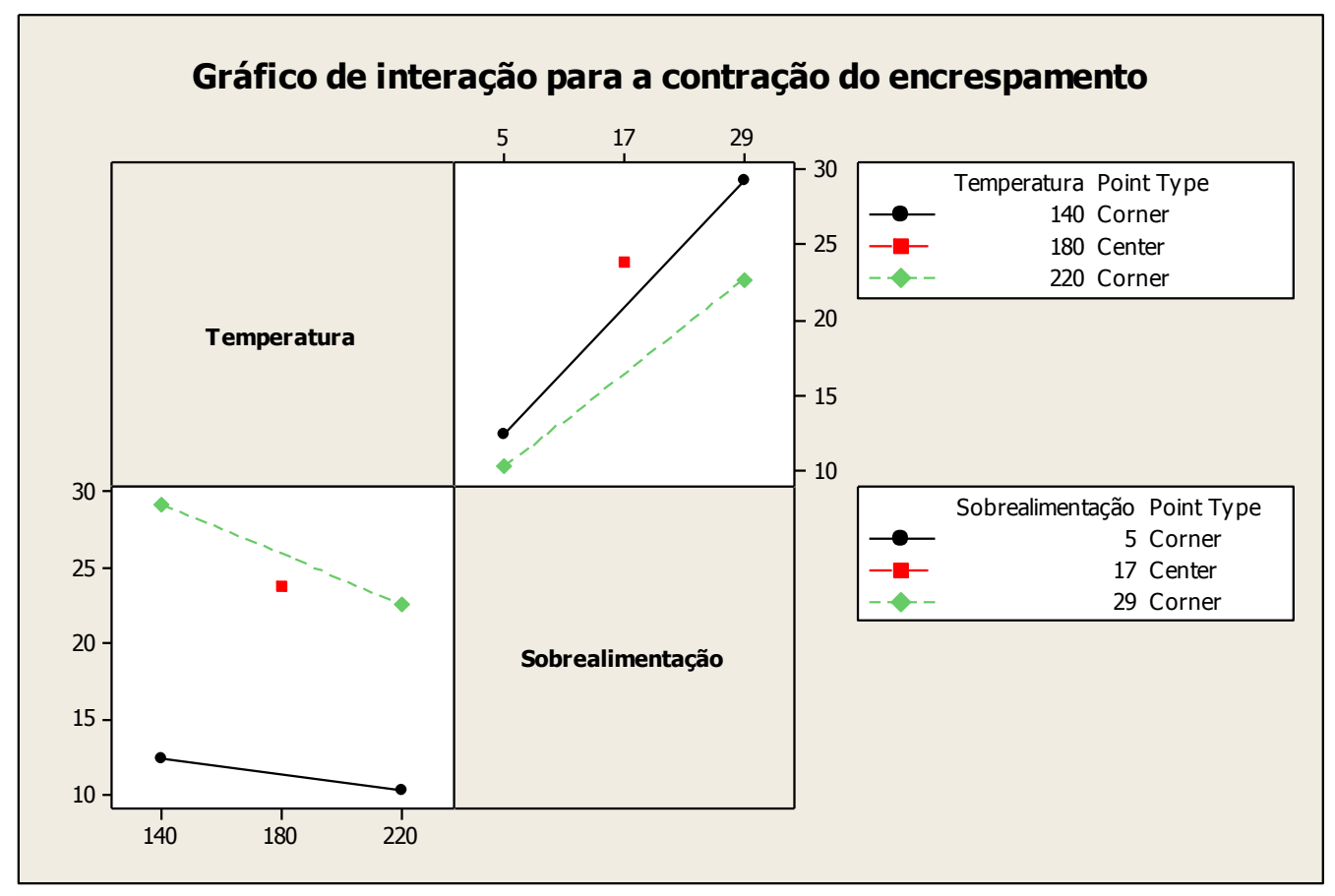

Gráfico 11 - Efeito da interação das variáveis temperatura do forno de fixação e sobrealimentação do fio dentro do forno de fixação na contração do encrespamento. 
Buscando identificar um modelo matemático que melhor represente a dependência da contração do encrespamento do fio texturizado em função das variáveis temperatura do forno de fixação e sobrealimentação do fio dentro do forno de fixação, foi feita a regressão linear, cujo relatório está localizado no Anexo E. A fórmula gerada pela regressão linear é expressa a seguir (Equação 7):

$$
\mathrm{CE}=19,1+0,611 \mathrm{SA}-0,0550 \mathrm{TF}
$$

Onde:

CE - Contração do encrespamento;

SA - Sobrealimentação do fio dentro do forno de fixação;

TF - Temperatura do forno de fixação.

Para visualização do comportamento da contração do encrespamento em função da sobrealimentação do fio dentro do forno de fixação e em função da temperatura do forno de fixação apresenta-se o Gráfico 12.

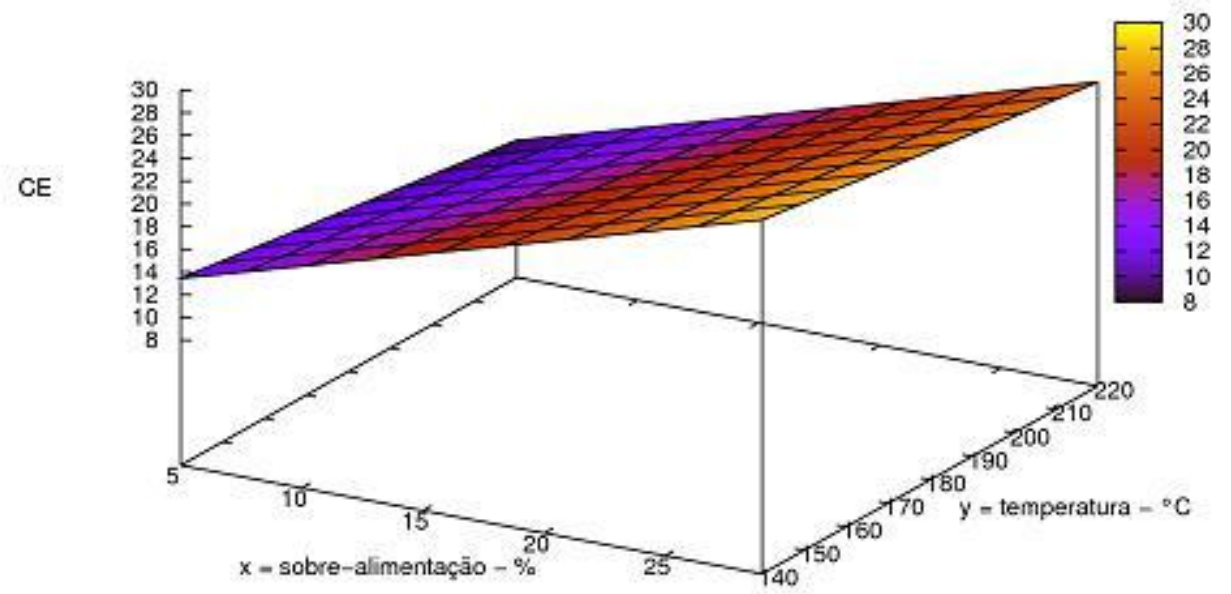

Gráfico 12 - Comportamento da Contração do Encrespamento em função das regulagens de sobrealimentação do fio e da temperatura do forno de fixação. 


\subsection{Módulo do encrespamento}

Analogamente à contração do encrespamento foram feitas as mesmas análises para o módulo do encrespamento.

A Tabela 7 apresenta a média e o desvio padrão dos dados obtidos no ensaio de encrespamento realizado com o equipamento Texturmat $\mathrm{ME}^{\circledR}$.

Tabela 7 - Média e desvio padrão dos dados resultantes do ensaio para a determinação do módulo do encrespamento.

\begin{tabular}{cccc}
\hline $\begin{array}{c}\text { Temperatura do } \\
\text { forno de fixação } \\
\left({ }^{\mathbf{C}} \mathbf{C}\right)\end{array}$ & $\begin{array}{c}\text { Sobrealimentação } \\
(\boldsymbol{\%})\end{array}$ & Média $(\boldsymbol{\%})$ & Desvio Padrão \\
\hline 140 & 5 & 8,68 & 0,2061 \\
\hline 220 & 5 & 6,74 & 0,5410 \\
\hline 140 & 29 & 19,42 & 0,8482 \\
\hline 220 & 29 & 14,85 & 0,7515 \\
\hline 180 & 17 & 16,17 & 0,6204 \\
\hline
\end{tabular}

A Figura 17 apresenta o planejamento fatorial $2^{2}$ do estudo da influência da etapa de fixação do processo de texturização por falsa torção, na propriedade módulo do encrespamento, geometricamente. 


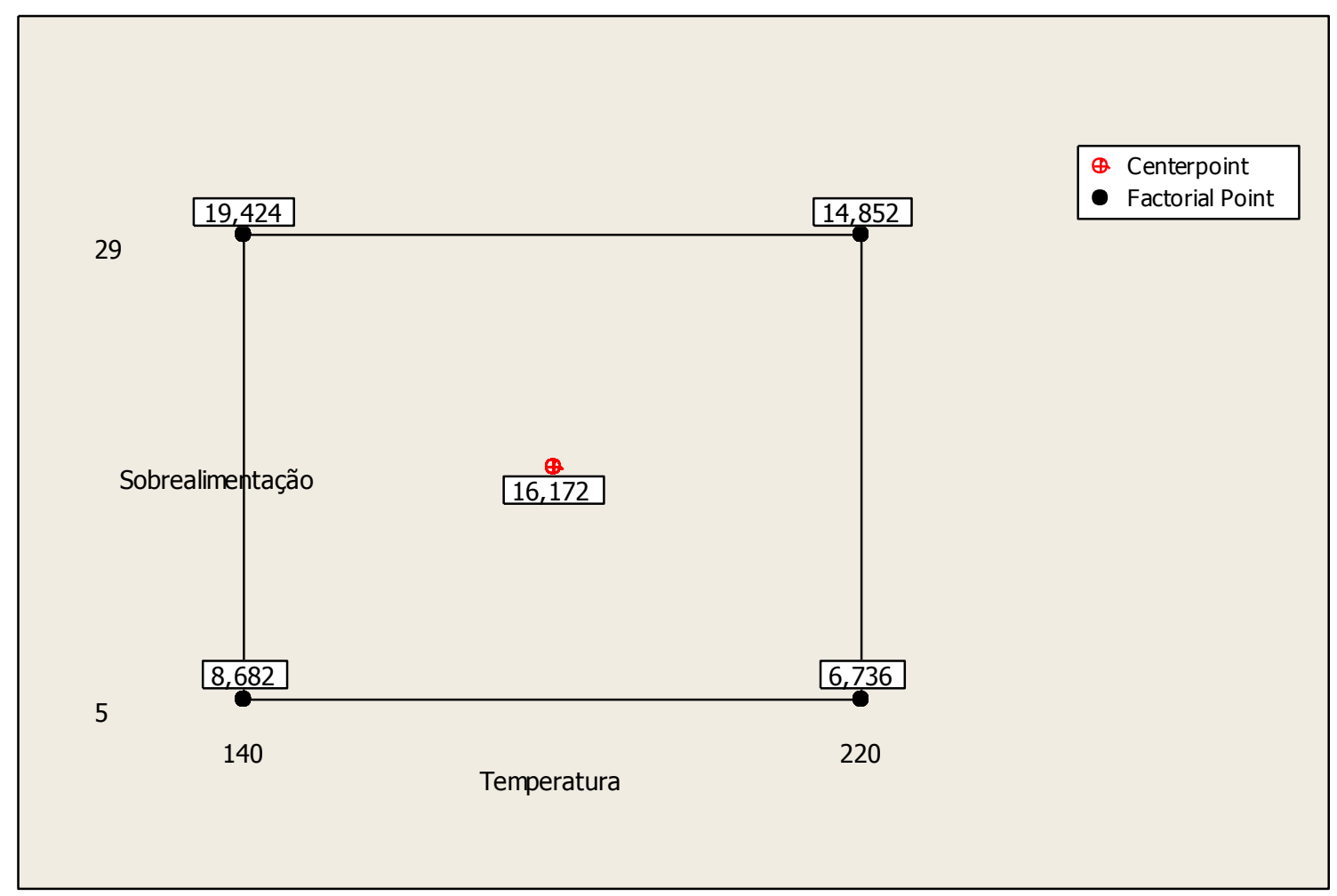

Figura 17 - Representação geométrica do planejamento fatorial $2^{2}$ da influência da etapa de fixação do processo de texturização por falsa torção no módulo do encrespamento.

Para verificar se as médias encontradas no ensaio de determinação do módulo de encrespamento são diferentes de acordo com as regulagens aplicadas, foi realizado a análise de variância ANOVA(two way), com nível de significância de 0,05, cujos dados estão apresentados na Tabela 8. O relatório gerado pelo programa Minitab ${ }^{\circledR}$ está apresentado no Anexo G.

Como os valores de P são inferiores a 0,05, podemos afirmar que as médias são diferentes e, portanto, as variações nos testes apresentaram resultados significativos. Para ilustrar essa diferença das médias, apresentamos o Gráfico 13, com boxplot com as médias e variações dos dados obtidos. 
Tabela 8 - Análise de variância ANOVA (two way) do módulo do encrespamento.

\begin{tabular}{lccccc}
\hline $\begin{array}{c}\text { Fonte de } \\
\text { Variação }\end{array}$ & $\begin{array}{c}\text { Soma de } \\
\text { Quadrados }\end{array}$ & $\begin{array}{c}\text { Quadrado } \\
\text { Médio }\end{array}$ & $\begin{array}{c}\text { Grau de } \\
\text { Liberdade }\end{array}$ & F & P \\
\hline Temperatura & 106,21 & 106,211 & 1 & 262,36 & 0,000 \\
\hline Sobrealimentação & 889,06 & 889,060 & 1 & 2196,17 & 0,000 \\
\hline Interação & 17,24 & 17,240 & 1 & 42,59 & 0,000 \\
\hline Curvatura & 112,41 & 112,41 & 1 & 280,43 & 0,000 \\
\hline Resíduo & 14,57 & 0,405 & 45 & & \\
\hline Total & 1027,08 & & 49 & & \\
\hline
\end{tabular}

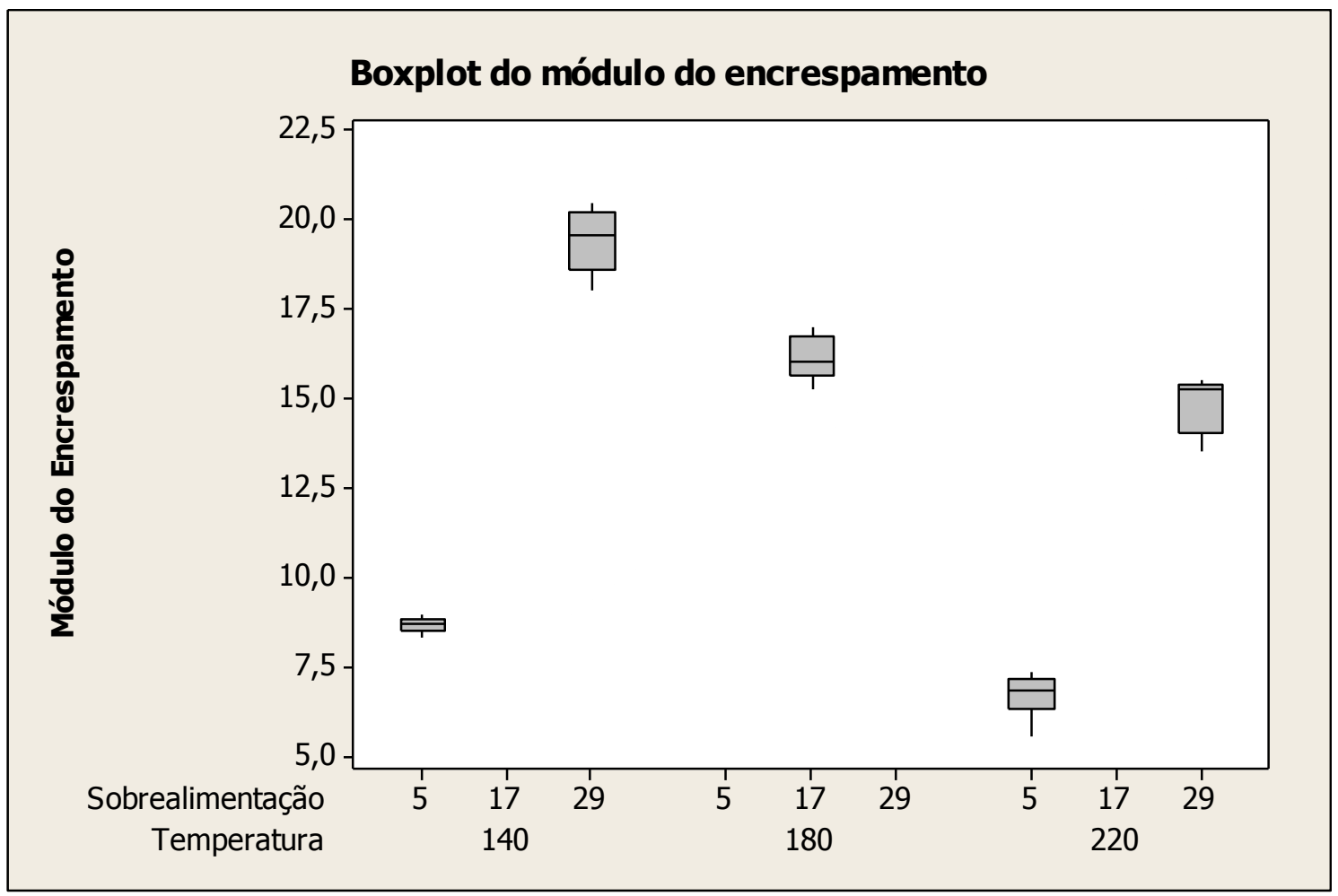

Gráfico 13 - Boxplot do módulo do encrespamento em função da temperatura e da sobrealimentação do forno de fixação

Uma vez confirmado que as regulagens testadas geraram resultados significativos, realizamos a análise fatorial dos dados para começar a identificar a relação entre a variável dependente 
módulo do encrespamento com as variáveis independentes temperatura do forno de fixação e a sobrealimentação do fio dentro do forno de fixação.

Com a realização da análise fatorial, é possível observar o grau de importância de cada uma das variáveis independentes e também o grau de importância de sua interação. Com base no relatório gerado pelo Minitab®, que se encontra no Anexo F, é possível observar que a sobrealimentação do fio dentro do forno de fixação é a variável mais influente, seguido da temperatura do forno de fixação, e por fim, da interação das duas variáveis. O alto valor do fator do coeficiente de determinação ajustado $\left(\mathrm{R}^{2}\right.$ adj. $\left.=98,28 \%\right)$ indica que a análise representa bem o fenômeno aqui estudado.

O Gráfico 14 apresenta o grau de influência de cada uma das variáveis de modo independente e o grau de influência de sua interação. Com os dados apresentados no Gráfico 14 é possível observar que todos os três itens apresentam influência significativos no módulo de encrespamento.

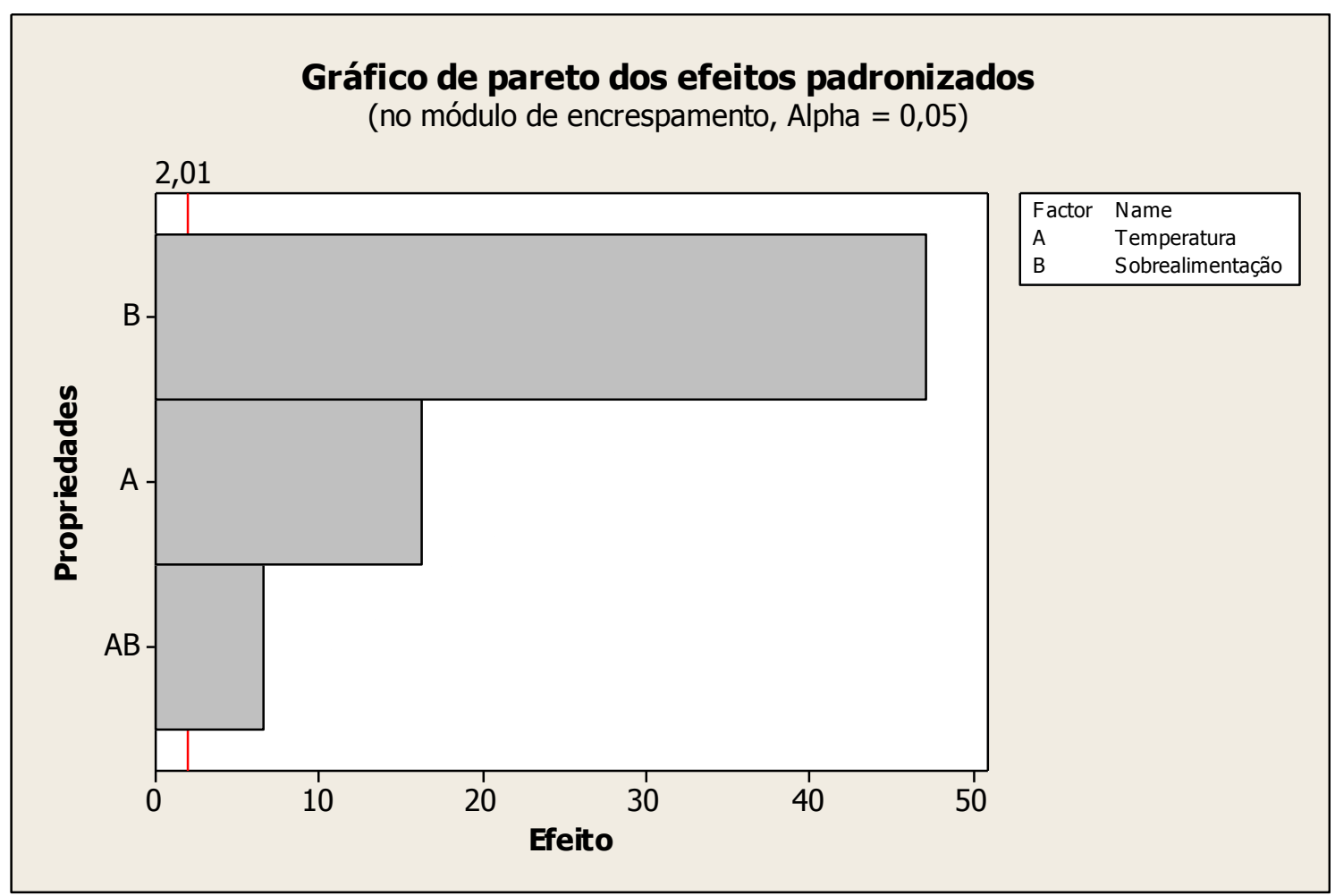

Gráfico 14 - Apresentação do grau de influência das variáveis temperatura do forno de fixação e sobrealimentação do fio dentro do forno de fixação e a interação das variáveis no módulo do encrespamento. 
Para melhor compreendermos a influência de cada uma das variáveis no comportamento do módulo do encrespamento, apresentamos o Gráfico 15. Com esse gráfico, podemos observar que a sobrealimentação do fio dentro do forno de fixação é extremamente importante para atingirmos os valores máximo e mínimo do módulo do encrespamento.

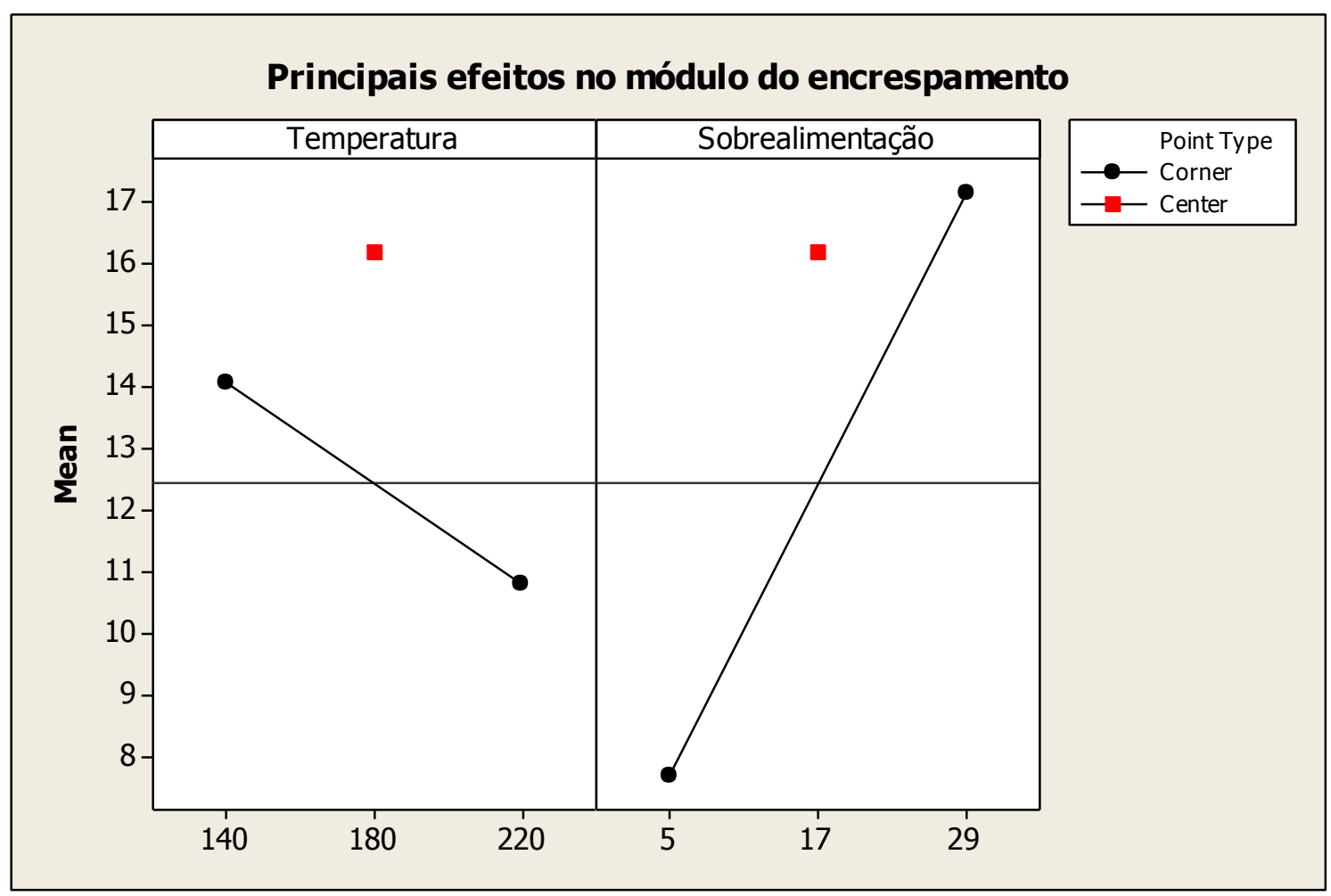

Gráfico 15 - Efeito da temperatura do forno de fixação e da sobrealimentação do fio no forno de fixação no módulo do encrespamento.

O Gráfico 16 apresenta o efeito da interação da variável temperatura do forno de fixação com a variável sobrealimentação do fio dentro do forno de fixação no módulo do encrespamento do fio texturizado. Com o Gráfico 13, é possível observar que o menor valor do módulo de encrespamento é atingido com a temperatura do forno de fixação mais elevada e sobrealimentação do fio dentro do forno mais reduzida. Para obtenção do máximo valor do módulo de encrespamento do fio texturizado, é necessário reduzir a temperatura do forno de fixação e aumentar a sobrealimentação do fio dentro do forno de fixação. 


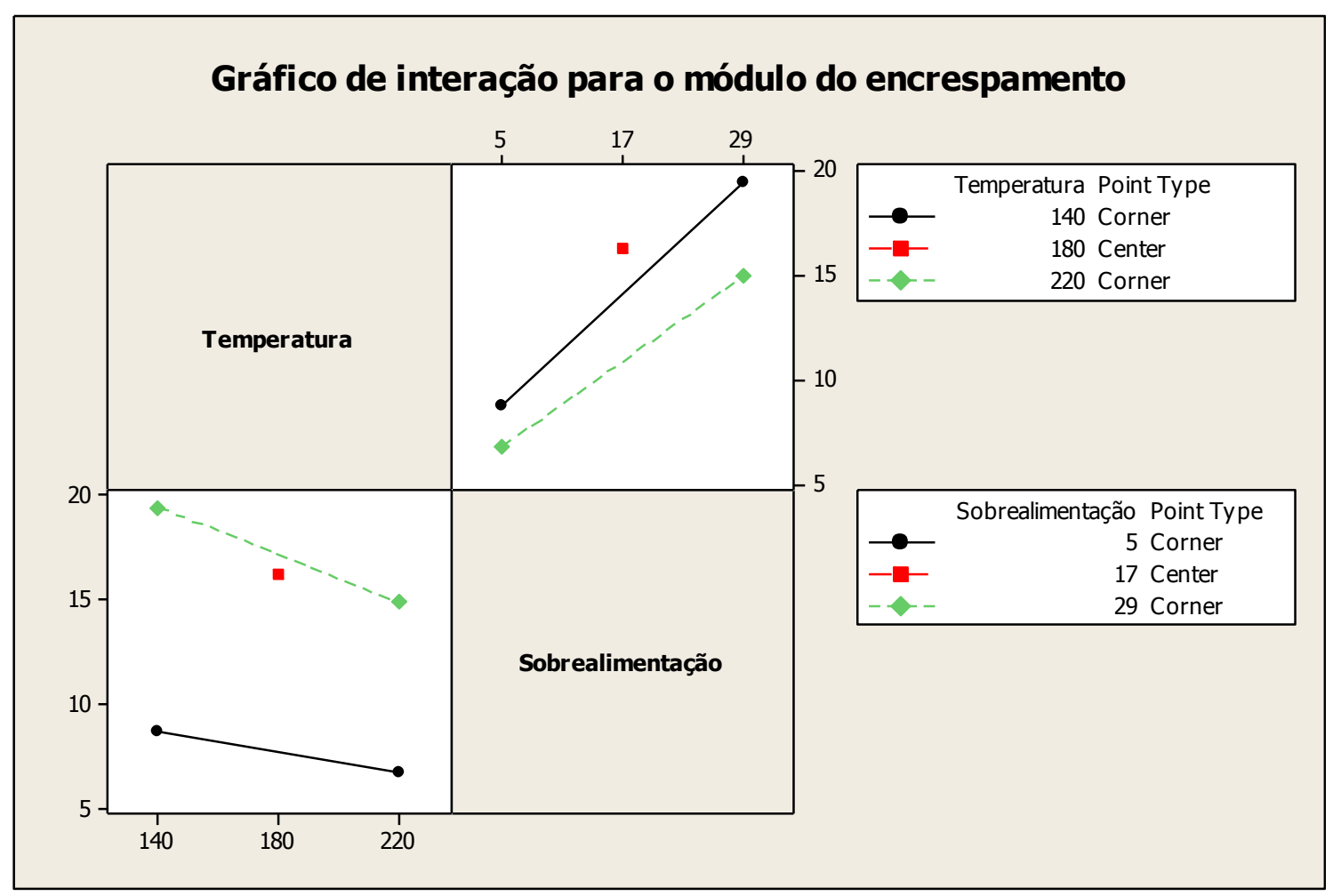

Gráfico 16 - Efeito da interação das variáveis temperatura do forno de fixação e sobrealimentação do fio dentro do forno de fixação no módulo do encrespamento.

Para a determinação de um modelo matemático que represente a dependência do módulo de encrespamento com a temperatura do forno de fixação e a sobrealimentação do fio dentro do forno de fixação, foi feito a regressão linear, cujo relatório está apresentado no Anexo G. A fórmula gerada encontra-se abaixo na Equação 8:

$$
\mathrm{ME}=13,8+0,393 \mathrm{SA}-0,0407 \mathrm{TF}
$$

Onde:

ME - Módulo do encrespamento do fio texturizado;

SA - Sobrealimentação do fio dentro do forno de fixação;

$\mathrm{TF}$ - Temperatura do forno de fixação.

Para visualização do comportamento do módulo do encrespamento em função da sobrealimentação do fio dentro do forno de fixação e em função da temperatura do forno de fixação apresenta-se o Gráfico 17. 


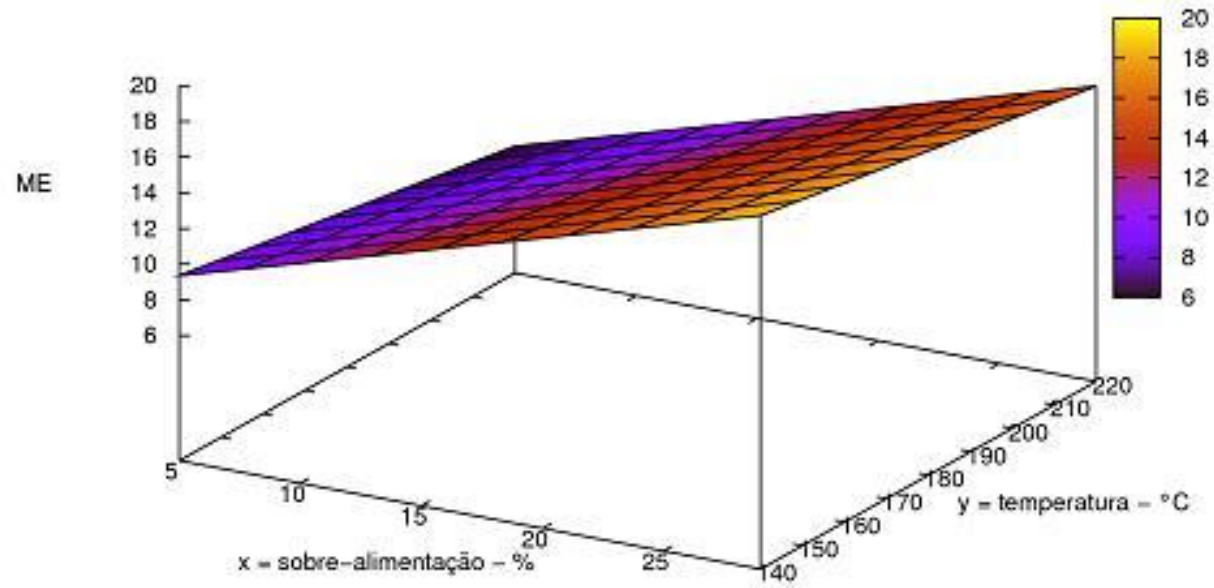

Gráfico 17 - Comportamento do Módulo do Encrespamento em função das regulagens de sobrealimentação do fio e da temperatura do forno de fixação.

\subsection{Estabilidade do encrespamento}

Os dados a serem apresentados para a estabilidade do encrespamento seguem as mesmas linhas dos dados que foram apresentados na contração do encrespamento e no módulo do encrespamento.

A Tabela 9 apresenta a média e o desvio padrão dos dados obtidos no ensaio para a determinação da estabilidade do encrespamento, com o equipamento Texturmat $\mathrm{ME}^{\circledR}$.

Tabela 9 - Médias e desvios padrões dos dados coletados no ensaio para determinação da estabilidade do encrespamento.

\begin{tabular}{cccc}
\hline $\begin{array}{c}\text { Temperatura do } \\
\text { forno de fixação } \\
\left({ }^{\mathbf{0}} \mathbf{C}\right)\end{array}$ & $\begin{array}{c}\text { Sobrealimentação } \\
(\boldsymbol{\%})\end{array}$ & Média $(\boldsymbol{\%})$ & Desvio Padrão \\
\hline 140 & 5 & 71,06 & 0,4354 \\
\hline 220 & 5 & 76,27 & 0,5319 \\
\hline 140 & 29 & 80,55 & 0,7983 \\
\hline 220 & 29 & 78,07 & 1,2157 \\
\hline 180 & 17 & 79,69 & 0,9493 \\
\hline
\end{tabular}


A Figura 18 apresenta geometricamente, por meio do quadrado, o planejamento fatorial $2^{2}$ do estudo da influência da etapa de fixação do processo de texturização por falsa torção na estabilidade do encrespamento.

Ainda com os dados obtidos no ensaio para determinação da estabilidade do encrespamento do fio texturizado foi feita a análise de variância, com nível de significância de 0,05, para verificar se as alterações de regulagens feitas nos testes provocou alteração nas médias. A Tabela 10 apresenta os dados da análise de variância ANOVA (two way), cujo relatório gerado pelo Minitab ${ }^{\circledR}$ está apresentado no Anexo $\mathrm{H}$.

Com os dados apresentados, podemos observar que devido ao fato de todos os valores $\mathrm{P}$ serem inferiores a 0,05 indica que as médias apresentadas para cada regulagem se diferem significativamente, o que valida o teste realizado.

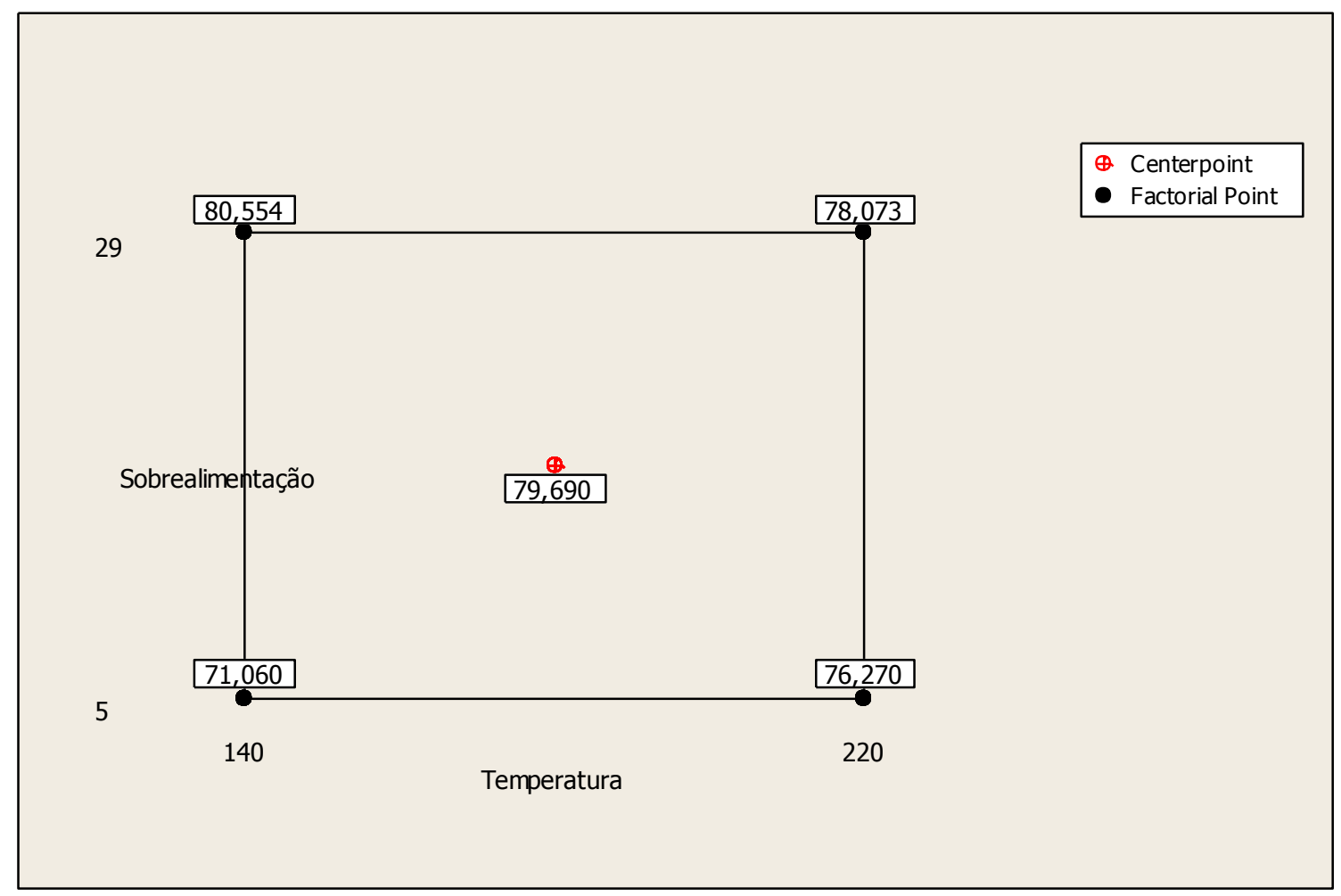

Figura 18 - Representação geométrica do planejamento fatorial $2^{2}$ da influência da etapa de fixação do processo de texturização por falsa torção na estabilidade do encrespamento. 
Tabela 10 - Análise de variância ANOVA (two way) da estabilidade do encrespamento.

\begin{tabular}{lccccc}
\hline $\begin{array}{c}\text { Fonte de } \\
\text { Variação }\end{array}$ & $\begin{array}{c}\text { Soma de } \\
\text { Quadrados }\end{array}$ & $\begin{array}{c}\text { Quadrado } \\
\text { Médio }\end{array}$ & $\begin{array}{c}\text { Grau de } \\
\text { Liberdade }\end{array}$ & F & P \\
\hline Temperatura & 18,619 & 18,619 & 1 & 28,78 & 0,000 \\
\hline Sobrealimentação & 319,056 & 319,056 & 1 & 493,21 & 0,000 \\
\hline Interação & 147,879 & 147,879 & 1 & 228,60 & 0,000 \\
\hline Curvatura & 81,958 & 81,958 & 1 & 117,46 & 0,000 \\
\hline Resíduo & 23,288 & 0,647 & 45 & & \\
\hline Total & 508,841 & & 49 & & \\
\hline
\end{tabular}

O Gráfico 18 ilustra a diferença entre as médias citadas pela análise ANOVA (two way), através de Boxplot dos dados obtidos no ensaio para a determinação da estabilidade do encrespamento.

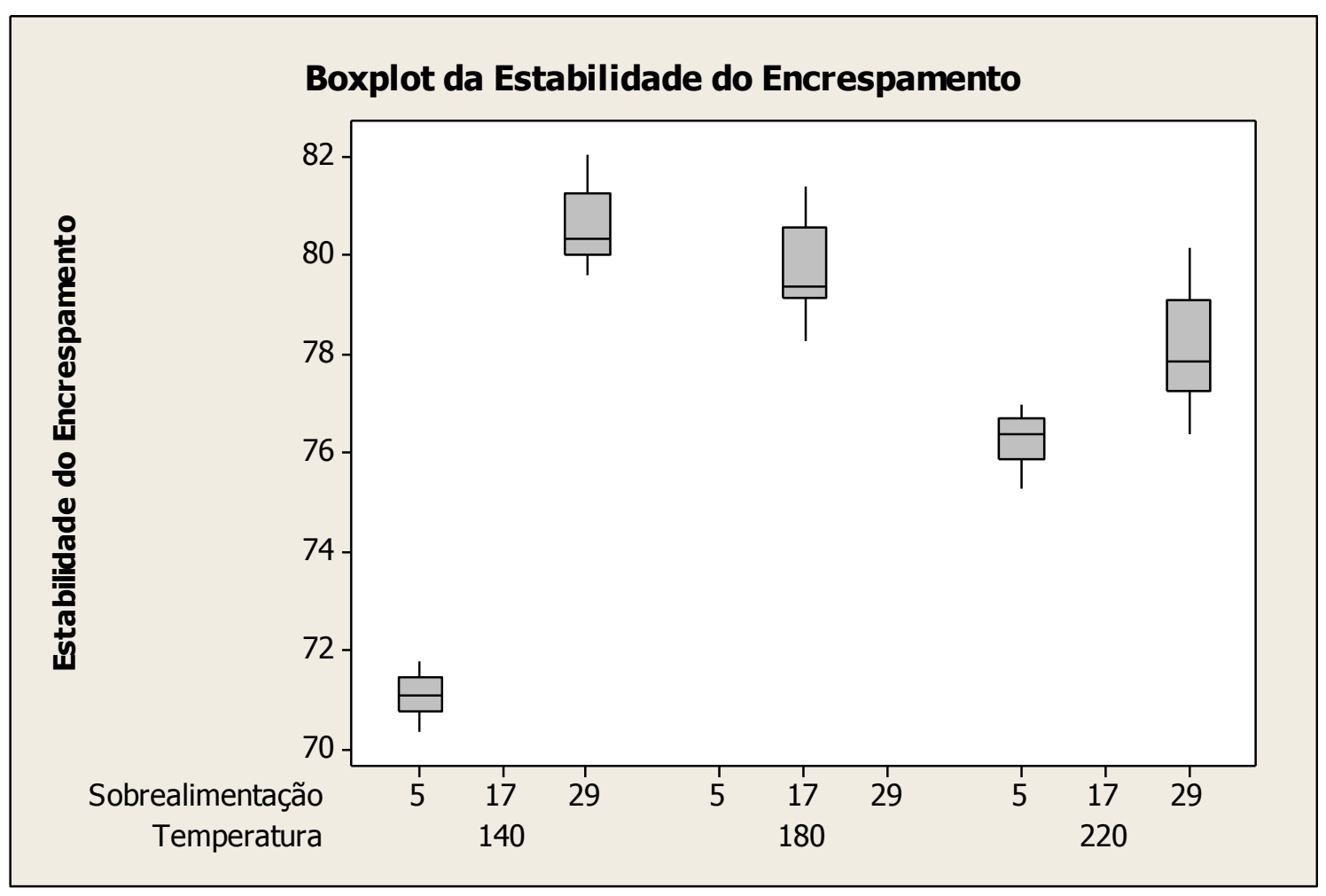

Gráfico 18 - Boxplot da estabilidade do encrespamento em função da temperatura e da sobrealimentação do forno de fixação 
Com a definição de que as mudanças de regulagens apresentaram alteração significativa na estabilidade do encrespamento, foi realizada a análise fatorial para iniciar a determinação da relação entre a variável dependente estabilidade do encrespamento com as variáveis independentes temperatura do forno de fixação e sobrealimentação do fio dentro do forno de fixação, bem como a relação com a interação das duas variáveis independentes. Com a análise fatorial, podemos avaliar o grau de influência das variáveis independentes temperatura do forno de fixação e sobrealimentação do fio dentro do forno de fixação, bem como a interação das duas variáveis sobre a estabilidade do encrespamento do fio texturizado. O relatório gerado pelo programa Minitab ${ }^{\circledR}$ está apresentado no Anexo $\mathrm{H}$.

Analisando os dados gerados podemos observar que a sobrealimentação do fio dentro do forno de fixação é o fator que mais influencia na estabilidade do encrespamento, assim como já foi observado na contração e no módulo do encrespamento do fio texturizado. A diferença aparece no fator que vem em seguida, que deixa de ser a temperatura do forno de fixação e passa a ser a interação das duas variáveis, fazendo com que a temperatura do forno de fixação seja considerada a variável menos influente na estabilidade do encrespamento no estudo em questão.

Para ilustrar as observações feitas temos o Gráfico 19, onde o gráfico de Pareto apresenta o grau de influência das variáveis independentes e da interação das variáveis na estabilidade do encrespamento e também nos apresenta que todos os três itens são estatisticamente relevantes. 


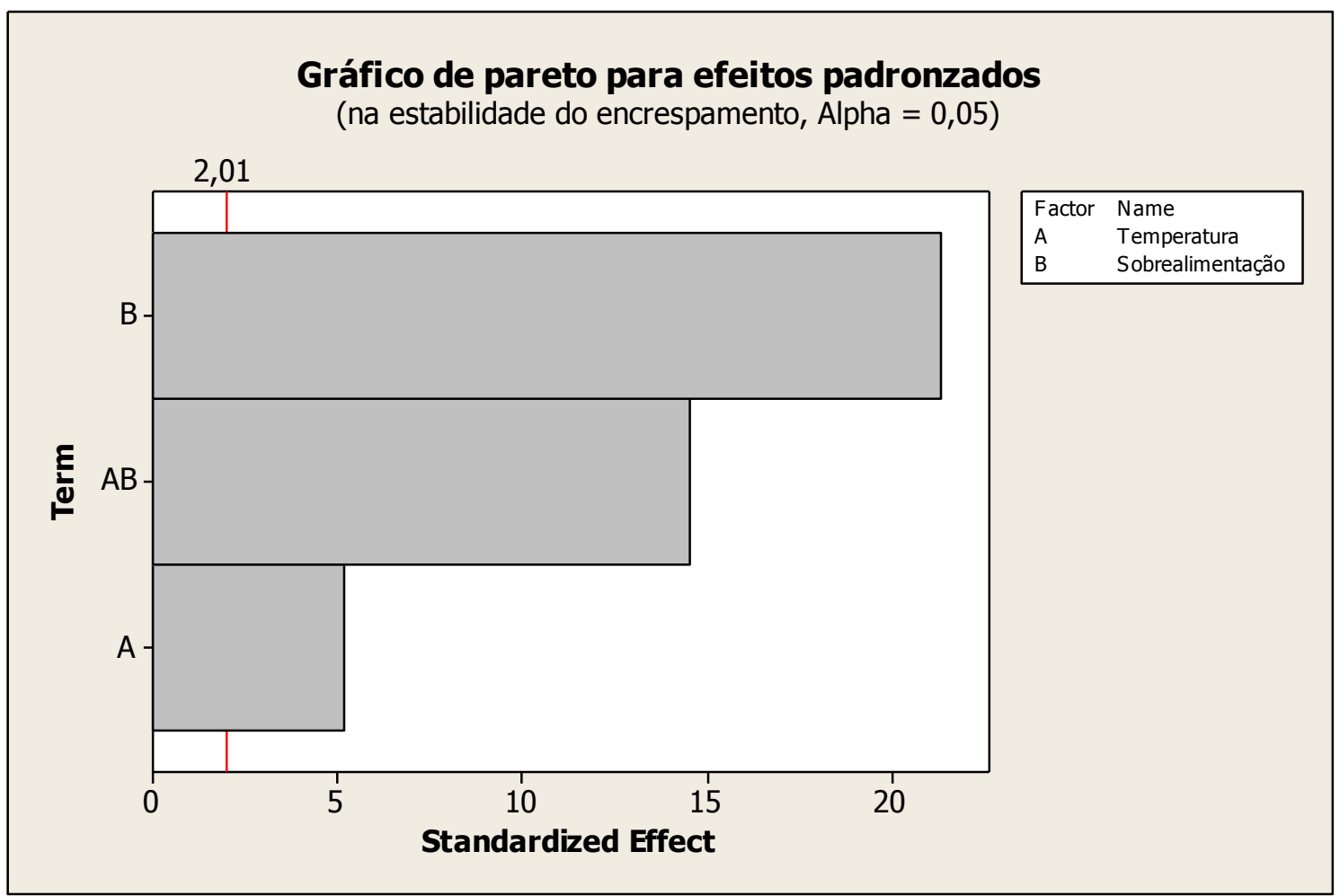

Gráfico 19 - Apresentação do grau de influência das variáveis temperatura do forno de fixação e sobrealimentação do fio dentro do forno de fixação e a interação das variáveis na estabilidade do encrespamento.

O Gráfico 20 apresenta as influências das variáveis independentes temperatura do forno de fixação e sobrealimentação do fio dentro do forno de fixação na estabilidade do encrespamento do fio texturizado. Mostra a grande importância que a sobrealimentação do fio no forno de fixação possui para a definição da estabilidade do encrespamento. 


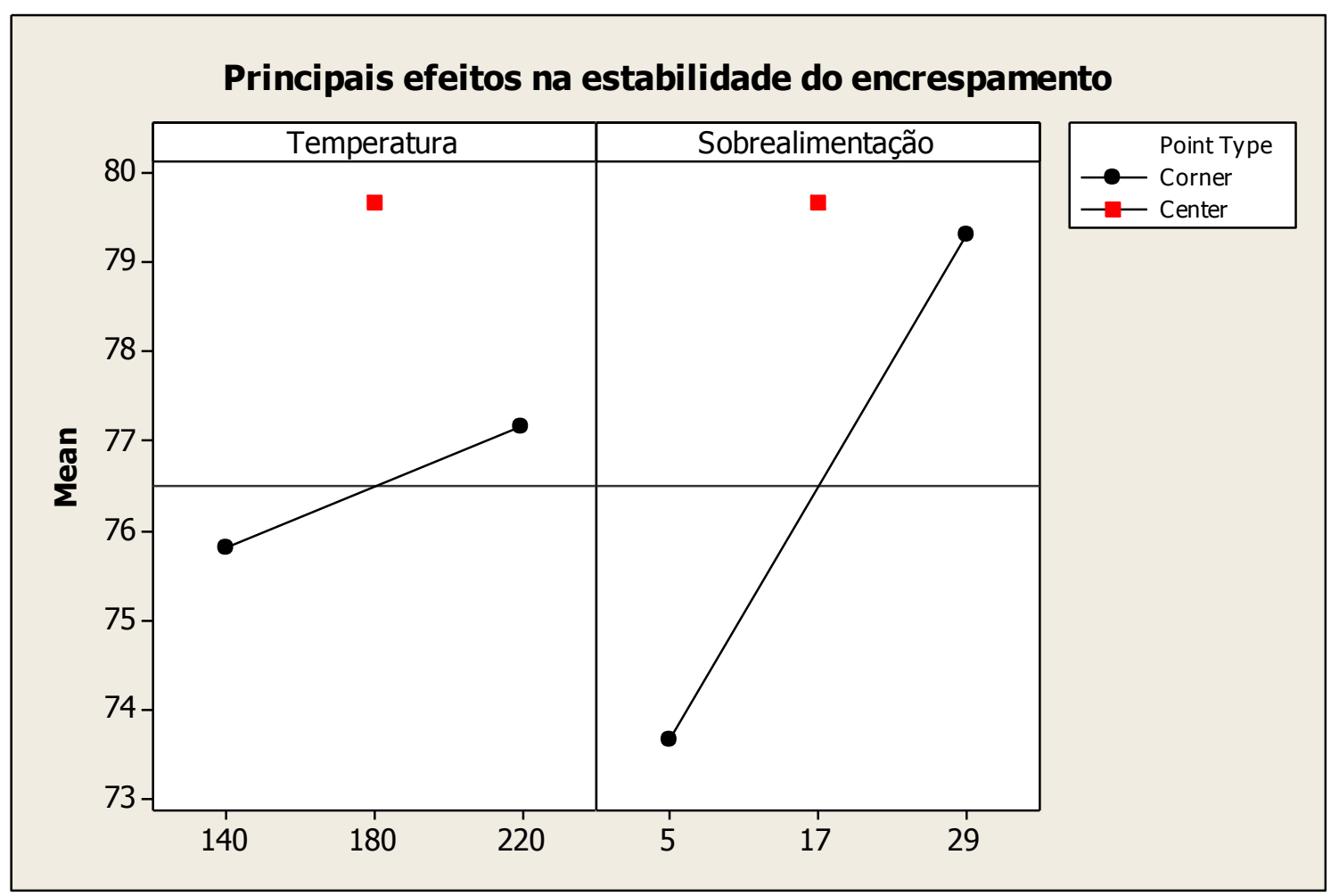

Gráfico 20 - Efeito da temperatura do forno de fixação e da sobrealimentação do fio no forno de fixação na estabilidade do encrespamento.

O Gráfico 21 ilustra a influência da interação das variáveis independentes na estabilidade do encrespamento do fio texturizado. A análise do gráfico nos permite observar que para atingir a máxima estabilidade do encrespamento, no experimento, é necessário termos a mínima temperatura com a máxima sobrealimentação do fio dentro do forno de fixação. Para obtenção da menor estabilidade do encrespamento a temperatura do forno de fixação mantém-se mínima $\left(140^{\circ} \mathrm{C}\right)$, enquanto a sobrealimentação do fio no forno de fixação também deve ser baixa $(5 \%)$. 


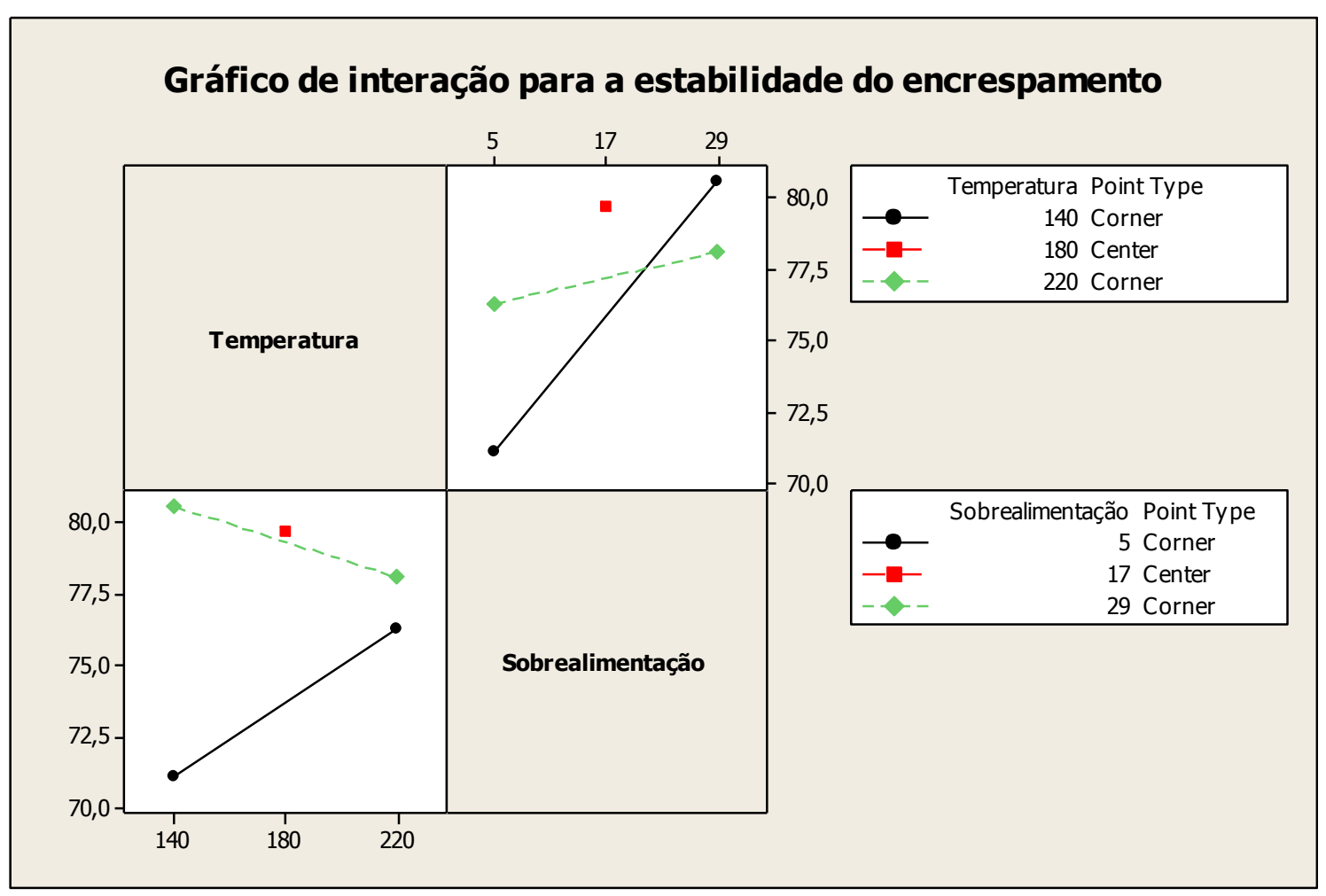

Gráfico 21 - Efeito da interação das variáveis temperatura do forno de fixação e sobrealimentação do fio dentro do forno de fixação na estabilidade do encrespamento.

A regressão linear foi utilizada para determinarmos um modelo matemático que represente a relação das variáveis independentes, em estudo, temperatura do forno de fixação e sobrealimentação do fio dentro do forno de fixação na estabilidade do encrespamento do fio texturizado. O relatório gerado pelo programa Minitab ${ }^{\circledR}$ é apresentado no Anexo I. A fórmula gerada pela análise segue apresentada abaixo na Equação 9:

$$
\mathrm{EE}=70,1+0,235 \mathrm{SA}+0,0171 \mathrm{TF}
$$

Onde:

EE - Estabilidade do encrespamento do fio texturizado;

SA - Sobrealimentação do fio dentro do forno de fixação;

TF - Temperatura do forno de fixação.

Para visualização do comportamento da estabilidade do encrespamento em função da sobrealimentação do fio dentro do forno de fixação e em função da temperatura do forno de fixação apresenta-se o Gráfico 22. 


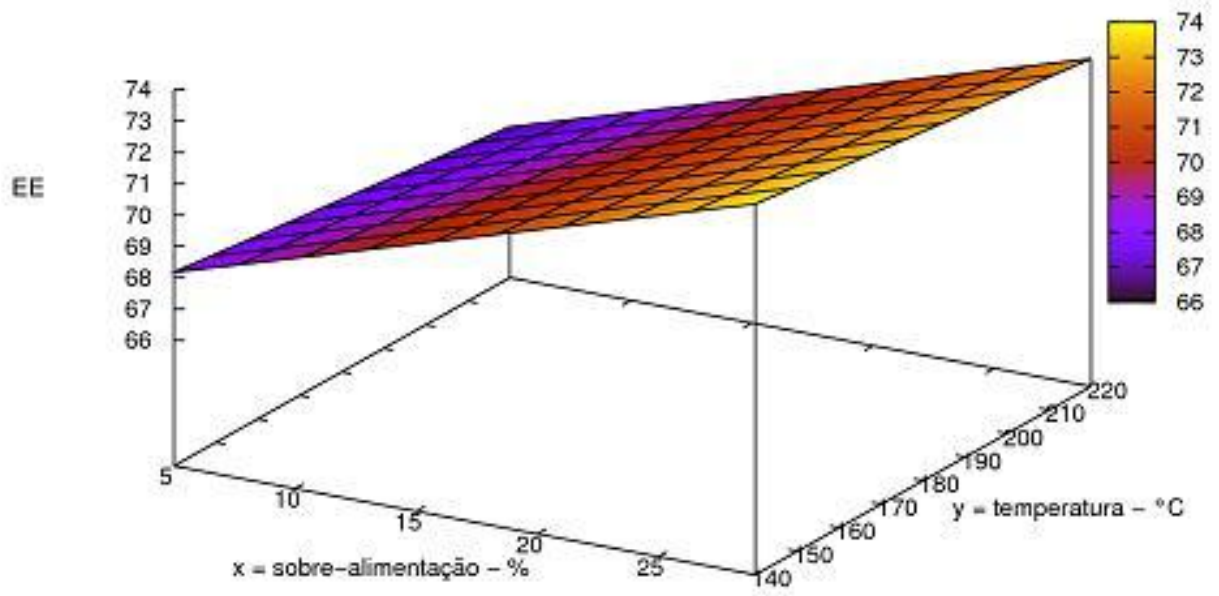

Gráfico 22 - Comportamento da Estabilidade do Encrespamento em função das regulagens de sobrealimentação do fio e da temperatura do forno de fixação. 


\section{CONCLUSÃO}

Após a realização de uma profunda pesquisa sobre o processo industrial de texturização de filamentos por falsa torção fixado (FTF), e após ensaios com geração e análise de dados, algumas conclusões puderam ser elaboradas.

Conforme estudos apresentados, as três propriedades analisadas são componentes importantes do volume do fio texturizado.

As análises dos resultados apontaram que as variáveis estudadas, temperatura do forno de fixação e a sobrealimentação do fio dentro do forno de fixação, são duas importantes variáveis que interferem diretamente nas características do volume do fio texturizado.

Na contração do encrespamento, foi possível observar, por meio da análise fatorial que a variável sobrealimentação dentro do forno de fixação possui maior influência em comparação à influência da temperatura do forno de fixação e à influência da interação entre as duas variáveis. Analisando o coeficiente de determinação ajustado da análise ( $\left.\mathrm{R}^{2} \operatorname{adj} .=98,53 \%\right)$, podemos concluir que a análise fatorial realizada representa bem o fenômeno apresentado no teste.

A regressão linear também apresentou um alto valor para o coeficiente de determinação ajustado ( $\mathrm{R}^{2}$ adj. $=88,0 \%$ ), o que nos permite concluir que a Equação 7 encontrada na análise representa, com boa margem de segurança, a relação da variável dependente contração do encrespamento em função das variáveis independentes temperatura do forno de fixação e a sobrealimentação do fio dentro do forno de fixação.

Analisando o módulo do encrespamento, pela análise fatorial, observamos que novamente a variável sobrealimentação do fio dentro do forno de fixação se destaca como a variável que mais influencia na propriedade estudada, sendo seguida pela variável temperatura do forno de fixação e por último a interação das duas variáveis. Para essa análise, o coeficiente de determinação ajustado apresentou o valor de $98,28 \%$, o que mais uma vez nos permite afirmar que os resultados apresentados possuem boa margem de confiança como um modelo representativo do fenômeno.

A regressão linear, com um coeficiente de determinação ajustado de 86,5\%, gerou a Equação 8 como uma equação confiável para a representação da relação do módulo do encrespamento em função da temperatura do forno de fixação e da sobrealimentação do fio dentro do forno de fixação. 
A análise fatorial realizada, com os dados obtidos para a estabilidade do encrespamento, gerou uma informação um pouco diferente das duas análises feitas previamente. A sobrealimentação do fio dentro do forno de fixação outra vez apresentou-se como a variável mais influente na propriedade em questão, porém a interação entre a temperatura do forno de fixação e a sobrealimentação do fio dentro do forno de fixação apresentou-se mais influente do que a própria temperatura do forno de fixação isoladamente. Para essa análise, o coeficiente de determinação ajustado foi de 94,29\%, indicando que novamente a análise é bastante representativa.

Contudo, o fato da interação ser mais influente do que a variável independente temperatura do forno de fixação, ao fazer a regressão linear é obtido a Equação 9, que devido o seu coeficiente de determinação ajustado ter valor de 54,5\% já não nos permite afirmar que a equação seja tão representativa para o sistema apresentado.

Todavia, o estudo nos permite concluir que para a produção de um fio mais volumoso, mais importante do que fornecer pouco calor para o fio na etapa de fixação do processo de texturização por falsa torção fixado, é necessário dar espaço para que o fio possa acomodar sua textura.

Uma vez que aumentamos a sobrealimentação do fio dentro do forno de fixação a tensão do fio dentro do forno fica muito reduzida (possivelmente até ausente), fazendo com que o fio tenha "espaço" para receber o calor fornecido pelo forno, encolher e então gerar um fio mais volumoso.

Esse estudo apresenta que o volume do fio sofre influencia oposta ao encolhimento residual. É possível observar claramente que no estudo feito por Hearle (2001, p. 171 e 172), apresentado na Tabela 2 e no Gráfico 5 do presente trabalho o encolhimento residual do fio texturizado possui maior influência da temperatura do forno de fixação do que da sobrealimentação do fio dentro do forno de fixação.

Outras variáveis do processo de texturização podem interferir no volume final do fio texturizado, como, por exemplo, taxa de estiragem, D/Y, temperatura do forno de fixação $\left(1^{\circ}\right.$ forno), entrelaçamento entre outros. Para um estudo mais elaborado sobre o volume do fio se faz necessário que todas as variáveis independentes sejam estudadas juntas, o que com o auxílio do planejamento de experimentos (ou em inglês design of experiments- DOE) se torne um trabalho menos complexo de se realizar. 


\section{REFERÊNCIAS BIBLIOGRÁFICAS}

\section{ASSOCIAÇÃO BRASILEIRA DA INDÚSTRIA TÊXTIL DE CONFECÇÃO (ABIT).} Consumo industrial de fibras e filamentos de 1970 a 2011. Disponível em:

<http://www.abit.org.br/site/navegacao.asp?id_menu=9\&id_sub=32\&idioma=PT>. Acesso em: 08/06/2012.

ANDREOLI, Cesare; FRETI, Fabrizio. Man Made Fibers. Reference Book of Textile Technologies. Itália. Fodazione Acimit. 2004.

ATKINSON, C. False twist textured yarns. Principles, process and applications. Cambridge: Woodhead Publishing Textiles. 2012.

BAUER-KURZ, Ina. Fiber crimp and crimp stability in nonwoven fabric process. Faculty of North Carolina State University, 2000.

BHATTACHARYA, S. S., SHAIKH, T. N., PRATAP, A. An investigation of thermal characteristic of mechanical crimp textured polyester yarn by differential scanning calorimeter (DSC). 5a Conferência Nacional das Propriedades Termoplasticas. American Institute of Physics. EUA, p. 67 - 74, 2010.

BROADBENT, Arthur D. Basic Principles of Textile Coloration. Bradford: Society of Dyers and Colourists. 2001.

CANOGLU, Suat. Effect of First Heater Temperature Variation on the Polyester Yarn Properties of False-Twist Texturin Techniques. Fibres \& Textiles in Eastern Europe. Vol $17, \mathrm{~N}^{\mathrm{o}} 5,2009$.

DAYIOGLU, H., KARAKAS, H. Influence of major false-twist texturing parameters on the structural properties of polyamide 6.6 yarn. Fibres \& Textiles in Eastern Europe. Vol 12, $\mathrm{N}^{\mathrm{o}} 2,2004$. 
DEMIR, Ali; BEHERY, Hassan Mohamed. Synthetic Filament Yarn. Nova Jersey PrenticeHall, Inc. 1997.

DIN 53840. Testing of textiles; determination of parameters fo curling of texture filaments yarns up to a linear density of 500 dtex. Alemanha. 1983.

DEOPURA, B. L. et al. Polyester and Polyamides. In: KRISHNAN, P. Santhana;

KULKARNI, S. T. Polyester Resins. Cambridge: Woodhead Publishing Textiles. 2008

Publishing Textiles. 2008

In: LIN, C. A. Manufacture of polyester fibers. Cambridge: Woodhead In: KAMATH, M. G., BHAT, G. S. Specialty fibers from polyester and polyamides. Cambridge: Woodhead Publishing Textiles. 2008

ESKIN, N. Analysis of a high temperature heater in a false twist texturing process. Energy Conversion and Management. v. 44, p. 2531 - 2547, 2003.

FOURNÉ, Franz. Synthetic Fibers: Machines and Equipment, Manufacture, Properties. Munich: Hanser, 1998.

FREITAS, I. AUIL, F. Effect of fixing stage from texturing synthetic filaments yarn process by false twist technology on the polyester yarn skein shrinkage. International Journal of Textile and Fashion Technology. v. 3, n 2, p. 39 - 46. 2013.

GLOBAL man-made fiber production increased to 56 millions tons. Man-Made Fiber. Year Book 2013. Chemical Fibers International. Alemanha, v. 64, p. 4, 2013.

GREER, R. E. J. Bulked Yarn Production. PhD Thesis, Universidade de Manchester, 1969. 
HEARLE, J. W. S.; HOLLICK, L.; WILSON, D. K. Yarn Texturing Technology. CRC Press. Inglaterra, 2001.

HAWTHRNE, B. L., Woven Stretch and Textured Fabrics. JohnWiley and Sons, Nova York, 1964.

KARAKAS, H. C. A comparison between the thermomechanical and structural changes in textured PET yarns after superheated steam and dry heat treatment. Fibers and Polymers. V. $5, \mathrm{~N}^{\mathrm{o}} 1,2004$.

LORD, Peter R. Handbook of Yarn Production: Technology, science and economics. Cambridge: Woodhead Publishing Textiles. 2003

McINTYRE, J. E. Synthetic Fibers: nylon, polyester, acrylic, polyolefin. In: EAST, A. J. Polyester Fibres. Cambridge: Woodhead Publishing Textiles. 2005

MILER, R. W. Carpet Fundamentals: Heat Setting Processes Impact Carpet Performance. Clemson University's Conference, Carpet Yarn Heat \& Twist Setting, February 24-25, 1999, Dalton, GA

MONTGOMERY, Douglas C.; RUNGER, George C.;HUBELE, Norma F. Estatística Aplicada à Engenharia. 2a Ed. Rio de Janeiro. LTC, 2011.

ÖZÇELIK, G., ÇAY, A., KIRTAY, E. A study of the thermal properties of textured knitted fabrics. Fibres \& Textiles in Eastern Europe. Vol 15, № 1, 2007.

RAO, B. R. Ionomeric Polyester Fiber. Textile Chemist and Colorist. American Association of Textile Chemist and Colorists. Carolina do Norte, Estados Unidos, v. 28, n. 10, p. 17-24, 1996.

RODGERS, J. E., GHOSH, Subhas. Dynamic bulk measuring system for textured nylon and polyester filaments. 
SHAIKH, Tasnim N.; BHATTACHARYA, Someswar S. Deriving an empirical formula to determine the optimum level of false-twist in mechanically-crimped textured polyester yarn. Textile Research Journal. 2011.

SILVA, Edmir A. Modelagem e otimização do processo de texturização por falsa torção. Universidade Federal de Itajubá. Disponível em <http://adm-neta.unifei.edu.br/phl/pdf/0036250.pdf>. Acesso em: 08/06/2012.

STEIN, Wolfgang. Comparative study of testing methods for textured continuous filaments yarn. Textechno.

TEXTECHNO - textile testing technology. Texturmat ME. Disponível em $<$ http://www.textechno.com/cms/index.php/en/yarn-testing-products-76/texturmat-meproducts-69>. Acessado em 22/01/2012.

YILDIRIM, Kenan; ALTUN, Sule; ULCAY, Yusuf. Relationship between yarn properties and process parameters in false-twist textured yarn. Journal of Engineered Fibers and Fabrics. V. 4. 2009. 
$\underline{\text { ANEXOS }}$

Anexo A: Relatório de análise da matéria-prima

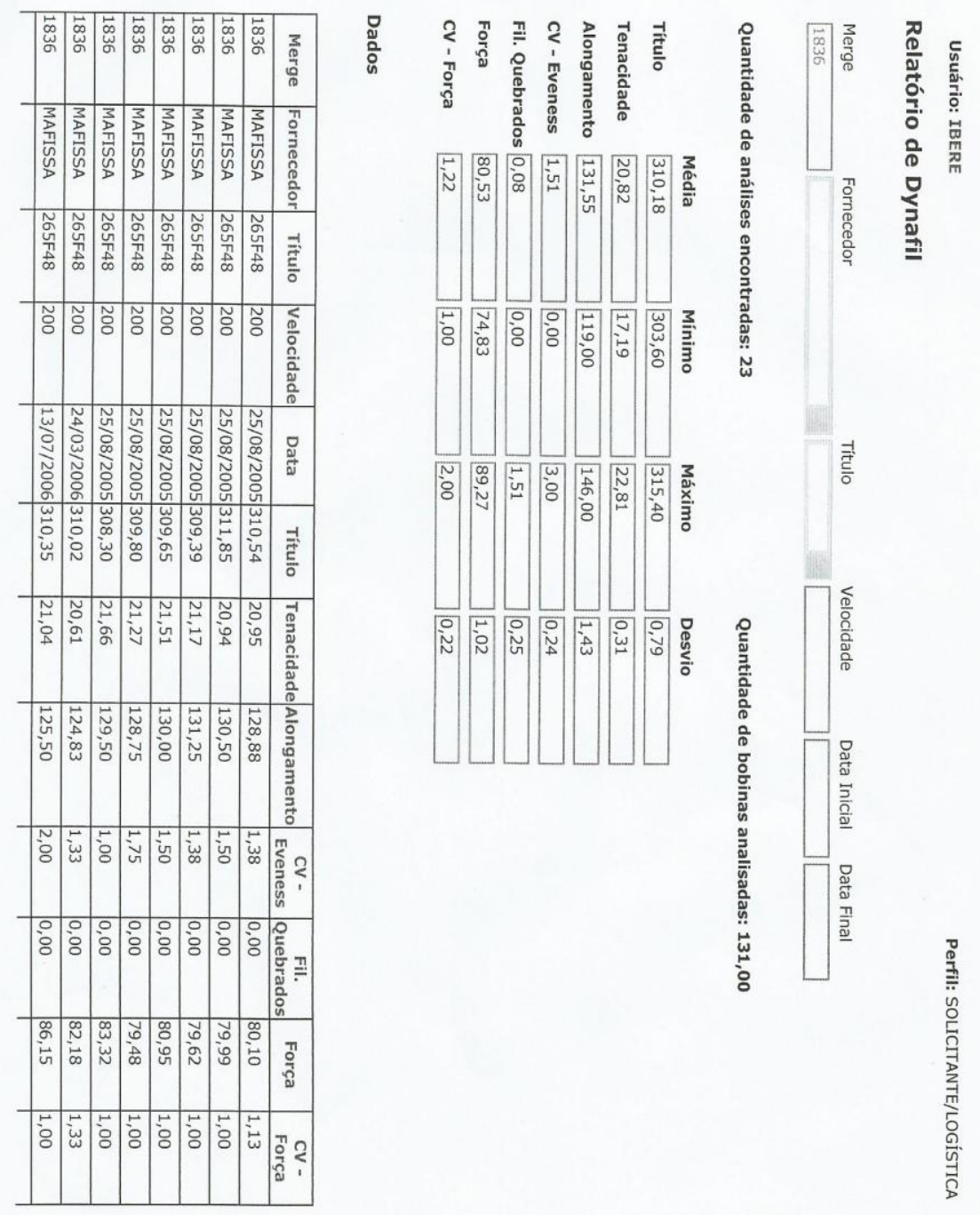




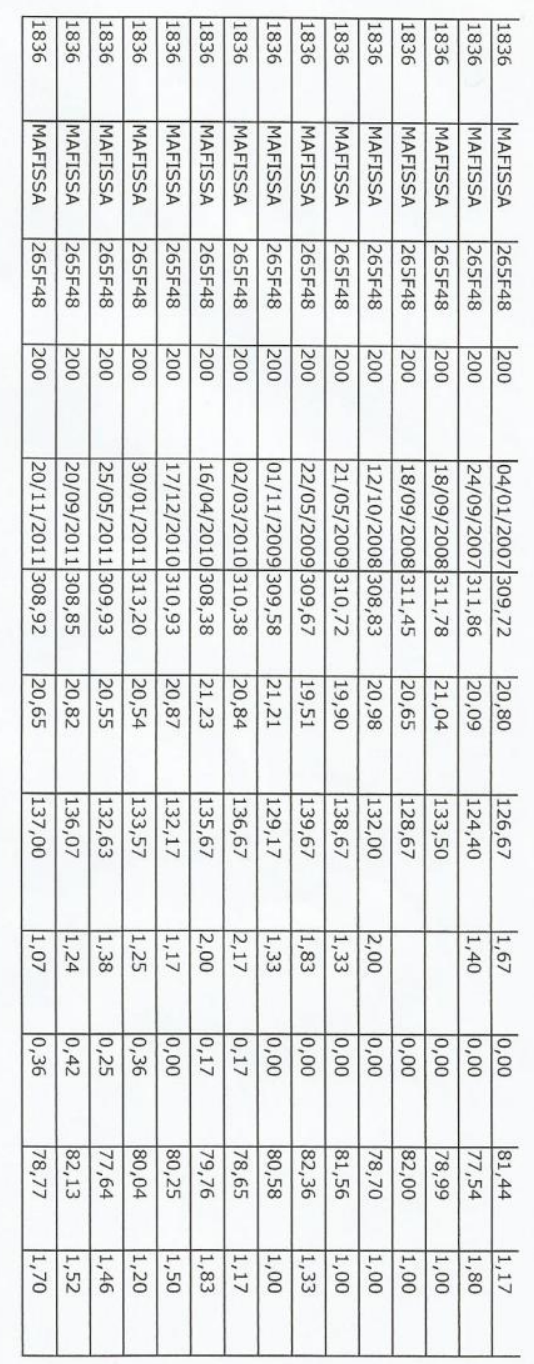


Anexo B: Relatório de análise do fio texturizado

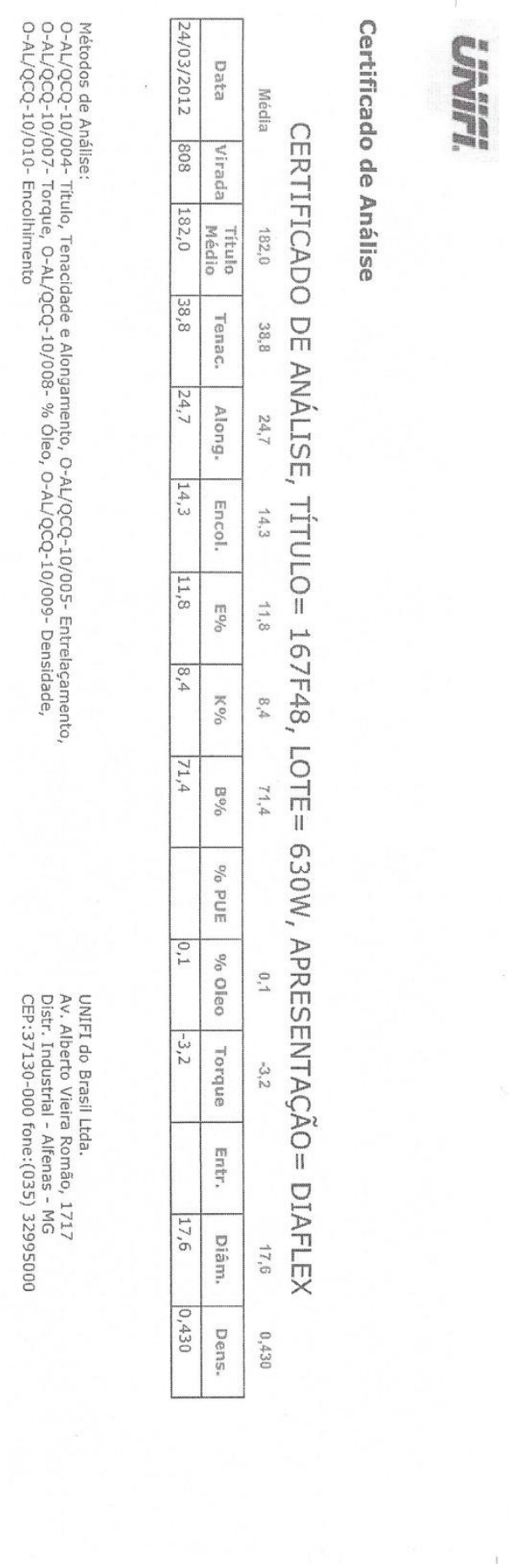


Anexo C: Resultados dos ensaios das propriedades de encrespamento

- Temperatura do segundo forno: 140ㄷ; Sobrealimentação dentro do forno: 5\%

Relatório de Análise

18/08/2014 14:21:01

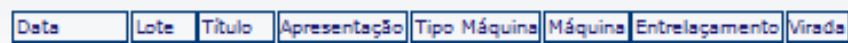

\begin{tabular}{|l|l|l|l||l|l|l|}
\hline $25 / 03 / 2012$ & TESTE 167548 & TBD & AFK1 & D10B & OT & 1 \\
\hline
\end{tabular}

\begin{tabular}{|c|c|c|c|c|c|c|c|c|c|c|c|}
\hline Posiģso & 1 & 2 & 3 & 4 & 5 & 6 & Médis & Desvis & Espec. & Minimo & Máximo \\
\hline \multirow{2}{*}{ Titulo (Dtex) } & 183,20 & 183,70 & 182,20 & 181,90 & 185,60 & 185,50 & 183,68 & 1,59 & & & \\
\hline & & & & & & & & & & & \\
\hline \multirow{2}{*}{ Tenscidsde (cN/tex) } & 38,65 & 39,70 & 40,45 & 39,28 & 39,92 & 40,28 & 39,71 & 0,67 & & & \\
\hline & & & & & & & & & & & \\
\hline \multirow{2}{*}{ Alongamento $(\%)$} & 23,39 & 24,06 & 25,49 & 24,08 & 25,59 & 27,35 & 24,99 & 1,44 & & & \\
\hline & & & & & & & & & & & \\
\hline \multirow{2}{*}{ Oleo (\%) } & 2,60 & 2,50 & 2,50 & 2,40 & 2,60 & 2,70 & 2,55 & 0,10 & & & \\
\hline & & & & & & & & & & & \\
\hline \multirow{2}{*}{ Encolhimento (\%) } & 17,84 & 17,79 & 17,53 & 18,60 & 18,78 & 16,28 & 17,80 & 0,59 & & & \\
\hline & & & & & & & & & & & \\
\hline \multirow{2}{*}{$E(\%)$} & 12,3600 & 12,7300 & 11,9300 & 12,1900 & 12,3600 & 12,3400 & 12,3200 & 0,2600 & & & \\
\hline & & & & & & & & & & & \\
\hline \multirow{2}{*}{$K(\%)$} & 8,6900 & 8,9600 & 8,4100 & 8,5700 & 8,7700 & 8,6400 & 18,6700 & 0,1900 & & & \\
\hline & & & & & & & & & & & \\
\hline \multirow{2}{*}{$B(\%)$} & 71,4600 & 71,2500 & 70,3400 & 70,6000 & 71,4400 & 70,9600 & 71,0100 & 0,4600 & & & \\
\hline & & & & & & & & & & & \\
\hline \multirow{2}{*}{ PUE $(\%)$} & & & & & & & & & & & \\
\hline & & & & & & & & & & & \\
\hline \multirow{2}{*}{ Torque $(T / m / s)$} & $-4,01$ & $-3,86$ & $-3,90$ & $-4,27$ & $-3,88$ & $-3,95$ & $-3,98$ & 0,15 & & & \\
\hline & & & & & & & & & & & \\
\hline \multicolumn{12}{|l|}{ Entrelscgamento $(\mathrm{NO} \mathbf{s} / \mathrm{m})$} \\
\hline & & & & & & & & & & & \\
\hline \multicolumn{12}{|l|}{ Retenģaso 1} \\
\hline Retenģă॰ 2 & & & & & & & & & & & \\
\hline & & & & & & & & & & & \\
\hline
\end{tabular}

* Retenģaso a 396 $=6 \%$

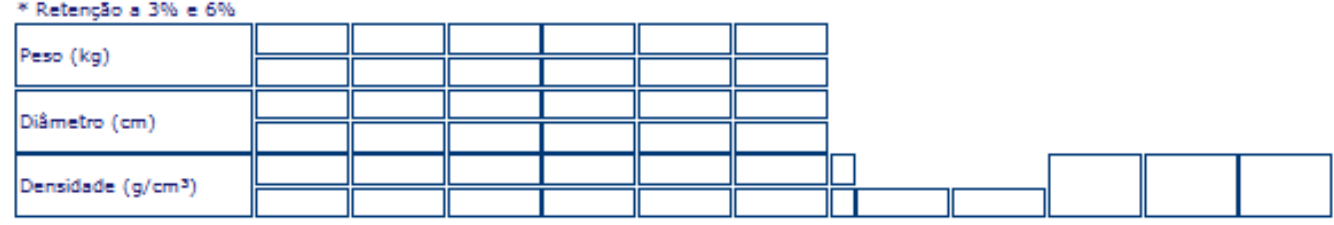


Relatório de Análise

18/08/2014 14:23:06

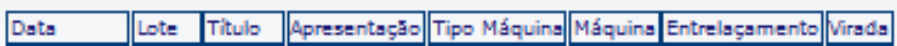

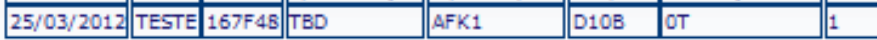

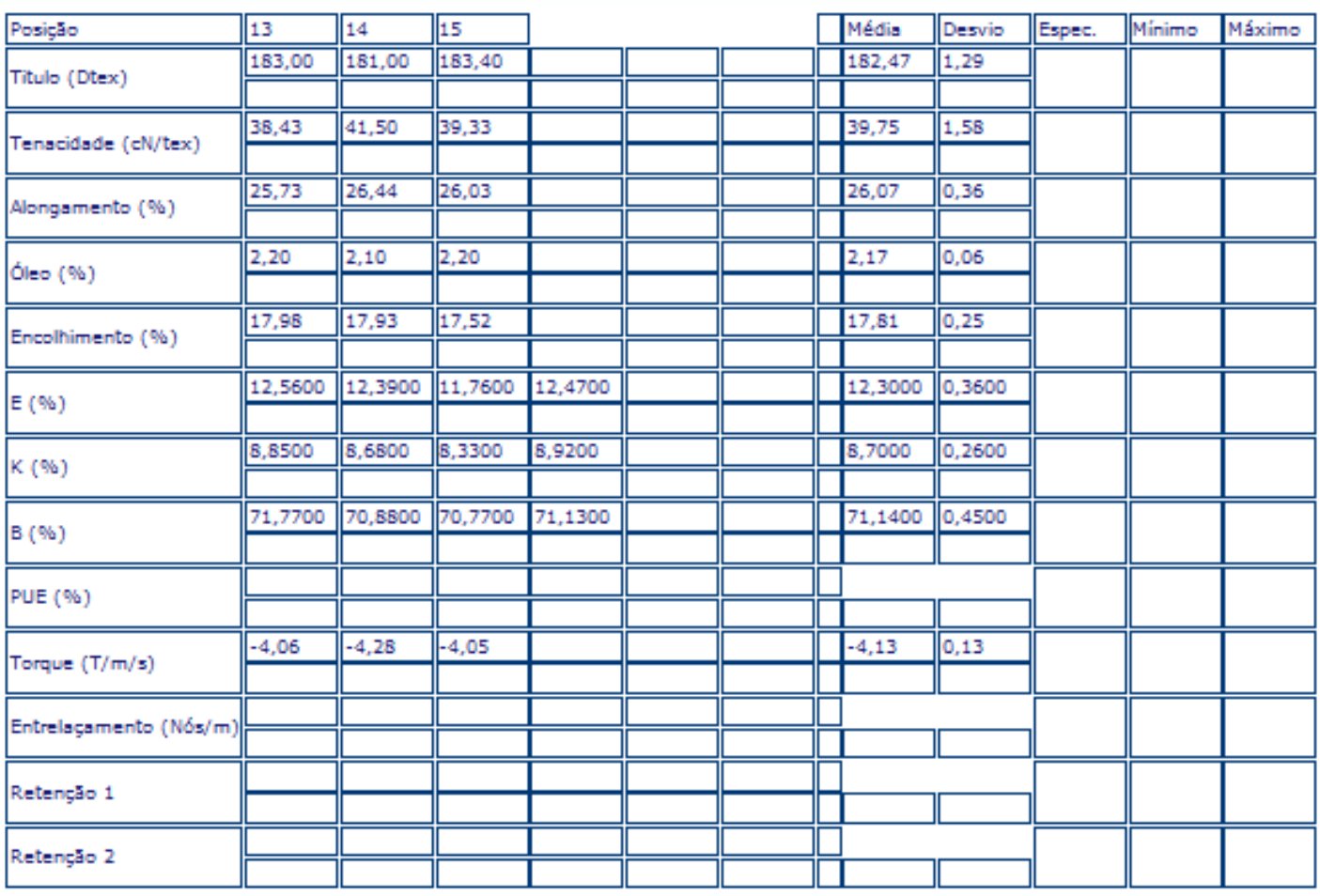

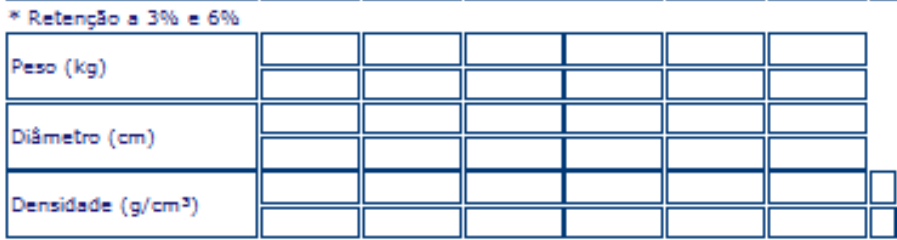

Observaça: MONA PED.A.T 
- Temperatura do segundo forno: 140 C; Sobrealimentação dentro do forno: $29 \%$

\section{Relatório de Análise}

$18 / 08 / 2014$ 14:29:25

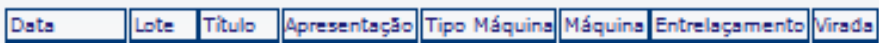

\begin{tabular}{|l|l|l||l||l|l||l|}
\hline $25 / 03 / 2012$ & TESTE & $167 F 48$ & TBD & AFK1 & D10B & OT \\
\hline
\end{tabular}

\begin{tabular}{|c|c|c|c|c|c|c|c|c|c|c|c|}
\hline Posiğaso & 1 & 2 & 3 & 4 & 5 & 6 & Média & Desvio & Espec. & Minimo & Máximo \\
\hline \multirow{2}{*}{ Titulo (Dtex) } & 188,50 & 188,50 & 189,50 & 191,30 & 191,40 & 189,60 & 169,80 & 1,29 & & & \\
\hline & & & & & & & & & & & \\
\hline \multirow{2}{*}{ Tenacidade (eN/tex) } & 39,49 & 40,34 & 40,36 & 37,54 & 39,94 & 39,78 & 39,58 & 1,05 & & & \\
\hline & & & & & & & & & & & \\
\hline \multirow{2}{*}{ Alongamento $(\%)$} & 27,02 & 25,41 & 26,80 & 24,21 & 24,82 & 25,35 & 25,60 & 1,10 & & & \\
\hline & & & & & & & & & & & \\
\hline \multirow{2}{*}{ Oleo (\%) } & 4,40 & 4,20 & 4,50 & 4,50 & 4,40 & 4,20 & 4,37 & 0,14 & & & \\
\hline & & & & & & & & & & & \\
\hline \multirow{2}{*}{ Encolhimento $(\%)$} & 29,17 & 30,63 & 28,87 & 30,45 & 29,92 & 30,45 & 29,92 & 0,74 & & & \\
\hline & & & & & & & & & & & \\
\hline \multirow{2}{*}{$E(\%)$} & 30,6400 & 30,1300 & 29,6400 & 30,5000 & 29,6400 & 28,5700 & 29,8500 & 0,7600 & & & \\
\hline & & & & & & & & & & & \\
\hline \multirow{2}{*}{$K(\%)$} & 20,1200 & 19,8300 & 19,5500 & 20,4600 & 19,6300 & 19,0700 & 19,7800 & 0,4800 & & & \\
\hline & & & & & & & & & & & \\
\hline \multirow{2}{*}{$B(\%)$} & 82,0200 & 81,3400 & $80,8 \mathrm{~B} 00$ & 81,2300 & 80,4900 & 80,1500 & 81,0200 & 0,6600 & & & \\
\hline & & & & & & & & & & & \\
\hline \multirow{2}{*}{ PUE (\%) } & & & & & & & & & & & \\
\hline & & & & & & & & & & & \\
\hline \multirow{2}{*}{ Torque $(\mathrm{T} / \mathrm{m} / \mathrm{s})$} & $-4,20$ & $-4,28$ & $-4,24$ & $-4,11$ & $-4,04$ & $-4,21$ & $-4,18$ & 0,09 & & & \\
\hline & & & & & & & & & & & \\
\hline \multirow{2}{*}{\multicolumn{12}{|c|}{ Entrelagsamento $(\mathrm{N} \delta \mathbf{s} / \mathrm{m})$}} \\
\hline & & & & & & & & & & & \\
\hline \multirow{2}{*}{\multicolumn{12}{|c|}{ Retençaso 1}} \\
\hline & & & & & & & & & & & \\
\hline \multirow{2}{*}{ Retenģ̃a 2} & & & & & & & & & & & \\
\hline & & & & & & & & & & & \\
\hline \multicolumn{7}{|c|}{ Retenģăo a 3\% $=6 \%$} & & & & & \\
\hline \multirow{2}{*}{\multicolumn{7}{|c|}{$P=50(\mathrm{~kg})$}} & & & & & \\
\hline & & & & & & & & & & & \\
\hline \multirow{2}{*}{\multicolumn{12}{|c|}{ Diâmetro $(\mathrm{cm})$}} \\
\hline & & & & & & & & & & & \\
\hline \multirow{2}{*}{ Densidade $\left(\mathrm{g} / \mathrm{cm}^{3}\right)$} & & & & & & & & & & & \\
\hline & & & & & & & & & & & \\
\hline
\end{tabular}

Observaçăo: ROSANA*E**PED**A/T 


\section{Relatório de Análise}

18/08/2014 14:31:14

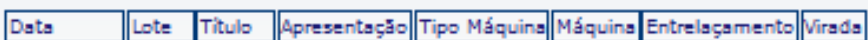

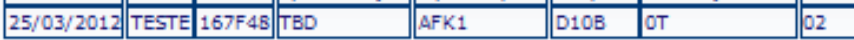

\begin{tabular}{|c|c|c|c|c|c|c|c|c|c|c|c|}
\hline 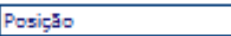 & 7 & 8 & 9 & 10 & 11 & 12 & Médis & Desvis & Espec. & Mínimo & Máximo \\
\hline \multirow{2}{*}{ Titulo (Dtex) } & 187,90 & 186,50 & 186,20 & 187,10 & 187,60 & 186,70 & 187,67 & 0,79 & & & \\
\hline & & & & & & & & & & & \\
\hline \multirow{2}{*}{ Tenscidade (eN/tex) } & 40,52 & 36,83 & 40,20 & 41,12 & 39,06 & 40,52 & 40,04 & 0,90 & & & \\
\hline & & & & & & & & & & & \\
\hline \multirow{2}{*}{ Alongsmento $(\%)$} & 24,90 & 25,02 & 26,41 & 26,33 & 23,01 & 26,24 & 25,32 & 1,32 & & & \\
\hline & & & & & & & & & & & \\
\hline \multirow{2}{*}{ Oleo (\%) } & 4,70 & 4,50 & 4,40 & 4,70 & 4,50 & 4,40 & 4,53 & 0,14 & & & \\
\hline & & & & & & & & & & & \\
\hline \multirow{2}{*}{ Encolhimento $(\%)$} & 28,40 & 28,25 & 27,58 & 29,58 & 28,00 & 28,84 & 28,44 & 0,70 & & & \\
\hline & & & & & & & & 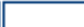 & & & \\
\hline \multirow{2}{*}{$E(\%)$} & 29,6200 & 27,8900 & 27,5200 & 28,2400 & & & 28,3200 & 0,9200 & & & \\
\hline & & & & & & & & & & & \\
\hline \multirow{2}{*}{$K(\%)$} & 20,4600 & 18,4200 & 18,0500 & 18,6500 & & & 18,9000 & 1,0700 & & & \\
\hline & & & & & & & & & & & \\
\hline \multirow{2}{*}{$B(\%)$} & 80,1400 & 80,1200 & 79,5900 & 79,5800 & & & 79,8600 & 0,3100 & & & \\
\hline & & & & & & & & & & & \\
\hline \multirow{2}{*}{\multicolumn{12}{|c|}{ PUE (\%) }} \\
\hline & & & & & & & & & & & \\
\hline \multirow{2}{*}{ Torque $(T / m / s)$} & $-4,07$ & $-4,21$ & $-4,24$ & $-4,18$ & $-4,19$ & $-4,27$ & $-4,19$ & 0,07 & & & \\
\hline & & & & & & & & & & & \\
\hline \multicolumn{12}{|l|}{ Entrelaģamento (Nos/m) } \\
\hline \multirow{2}{*}{\multicolumn{12}{|c|}{ Retenģa 1}} \\
\hline & & & & & & & & & & & \\
\hline \multirow[t]{2}{*}{ Retenģso 2} & & & & & & & & & & & \\
\hline & & & & & & & & & & & \\
\hline
\end{tabular}

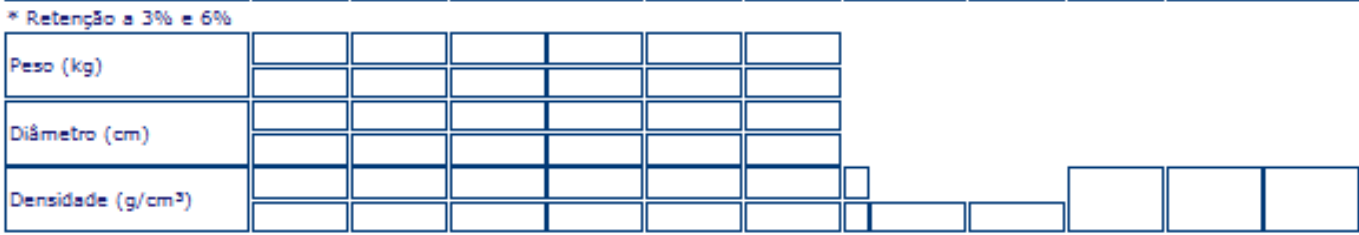

Observaças: ROSANA*A*PED**A/T 
- Temperatura do segundo forno: 180 ㄷ; Sobrealimentação dentro do forno: $17 \%$

\section{Relatório de Análise}

18/08/2014 14:33:02

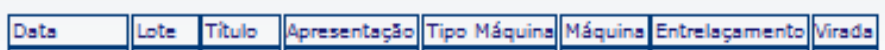

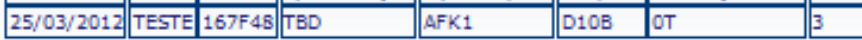

\begin{tabular}{|c|c|c|c|c|c|c|c|c|c|c|c|}
\hline Posiģăı & 1 & 2 & 3 & 4 & 5 & 6 & Médis & Desvis & Espec. & Mínimo & Máximo \\
\hline \multirow{2}{*}{ Titulo (Dtex) } & 189,30 & 189,00 & 187,60 & 187,80 & 189,90 & 190,90 & 189,08 & 1,25 & & & \\
\hline & & & & & & & & & & & \\
\hline \multirow{2}{*}{ Tenscidsde (cN/tex) } & 40,39 & 37,93 & 36,48 & 40,34 & 39,74 & 38,45 & 39,22 & 1,07 & & & \\
\hline & & & & & & & & & & & \\
\hline \multirow{2}{*}{ Alongsmento (96) } & 26,64 & 24,52 & 24,11 & 26,70 & 27,80 & 26,44 & 26,04 & 1,42 & & & \\
\hline & & & & & & & & & & & \\
\hline \multirow{2}{*}{ Oleo (\%) } & 3,30 & 3,50 & 3,30 & 3,50 & 3,20 & 3,60 & 3,40 & 0,15 & & & \\
\hline & & & & & & & & & & & \\
\hline \multirow{2}{*}{ Encolhimento (\%) } & 19,55 & 19,68 & 18,06 & 19,74 & 18,69 & 17,81 & 18,92 & 0,86 & & & \\
\hline & & & & & & & & & & & \\
\hline \multirow{2}{*}{$E(\%)$} & 24,6900 & 25,0000 & 22,5200 & 23,8100 & 22,7400 & 22,7400 & 23,5800 & 1,0800 & & & \\
\hline & & & & & & & & & & & \\
\hline \multirow{2}{*}{ K (\%) } & 16,7200 & 16,9100 & 15,2700 & 16,1400 & 15,5700 & 15,6600 & 16,0500 & 0,6600 & & & \\
\hline & & & & & & & & & & & \\
\hline \multirow{2}{*}{$B(96)$} & 81,0100 & 80,3600 & 79,1300 & 79,3300 & 79,0900 & 78,2600 & 79,5300 & 0,9900 & & & \\
\hline & & & & & & & & & & & \\
\hline \multirow{2}{*}{\multicolumn{12}{|c|}{ PUE (\%) }} \\
\hline & & & & & & & & & & & \\
\hline \multirow{2}{*}{ Torque $(T / m / s)$} & $-3,63$ & $-3,65$ & $-3,66$ & $-3,57$ & $-3,65$ & $-3,56$ & $-3,62$ & 0,04 & & & \\
\hline & & & & & & & & & & & \\
\hline \multicolumn{12}{|l|}{ Entrelsgsmento $(\mathrm{N} \delta \mathbf{s} / \mathrm{m})$} \\
\hline \multirow{2}{*}{\multicolumn{12}{|c|}{ Retenģăo 1}} \\
\hline & & & & & & & & & & & \\
\hline Retenģăo 2 & & & & & & & & & & & \\
\hline
\end{tabular}

* Retenģă o 39\% $=6 \%$

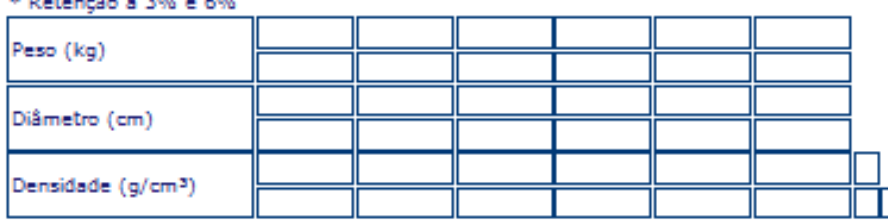

Observaçăo: ROSANA****PED**A/T 
Relatório de Análise

18/08/2014 14:34:13

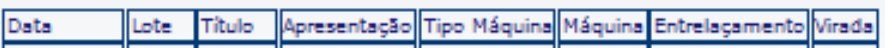

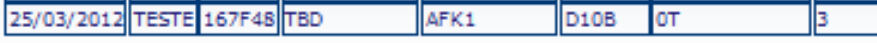

\begin{tabular}{|c|c|c|c|c|c|c|c|c|c|c|c|}
\hline Posiģas & 7 & 8 & 9 & 10 & 11 & 12 & Médis & Desvis & Espec. & Mínimo & Máximo \\
\hline \multirow{2}{*}{ Titulo (Dtex) } & 187,60 & 186,30 & 186,60 & 188,00 & 186,90 & 188,10 & 187,25 & 0,76 & & & \\
\hline & & & & & & & & & & & \\
\hline \multirow{2}{*}{ Tenscidsde (eN/tex) } & 39,43 & 40,65 & 40,68 & 40,03 & 36,17 & 36,25 & 39,54 & 1,12 & & & \\
\hline & & & & & & & & & & & \\
\hline \multirow{2}{*}{ Alongamento ( $(\%)$} & 24,60 & 26,83 & 25,08 & 25,72 & 23,67 & 25,26 & 25,19 & 1,06 & & & \\
\hline & & & & & & & & & & & \\
\hline \multirow{2}{*}{ Oleo ( $(\%)$} & 3,10 & 3,20 & 2,90 & 3,00 & 2,90 & 3,00 & 3,02 & 0,12 & & & \\
\hline & & & & & & & & & & & \\
\hline \multirow{2}{*}{ Encolhimento (\%) } & 19,24 & 20,11 & 20,29 & 18,56 & 18,41 & 19,42 & 19,34 & 0,77 & & & \\
\hline & & & & & & & & & & & \\
\hline \multirow{2}{*}{$E(\%)$} & 24,0300 & 24,0600 & 25,0700 & 23,2900 & & & 24,1100 & 0,7300 & & & \\
\hline & & & & & & & & & & & \\
\hline \multirow{2}{*}{$K(\%)$} & 16,7300 & 16,0000 & 16,9600 & 15,7400 & & & 16,3600 & 0,5900 & & & \\
\hline & & & & & & & & & & & \\
\hline \multirow{2}{*}{$B(\%)$} & 79,3100 & 79,4300 & 81,3700 & 79,5900 & & & 79,9300 & 0,9700 & & & \\
\hline & & & & & & & & & & & \\
\hline \multirow{2}{*}{\multicolumn{12}{|c|}{ PUE (\%) }} \\
\hline & & & & & & & & & & & \\
\hline Torque $(T / \mathrm{m} / \mathrm{s})$ & & & $-3,94$ & $-3,70$ & $-3,67$ & $\mid-3,72$ & $-3,77$ & 0,11 & & & \\
\hline \multicolumn{12}{|l|}{ Entrelaģamento $(\mathrm{N} \delta \mathbf{s} / \mathbf{m})$} \\
\hline \multirow{2}{*}{\multicolumn{12}{|c|}{ Retengaso 1}} \\
\hline & & & & & & & & & & & \\
\hline \multicolumn{12}{|l|}{ Retengaso 2} \\
\hline Nevengato & & & & & & & & & & & \\
\hline
\end{tabular}

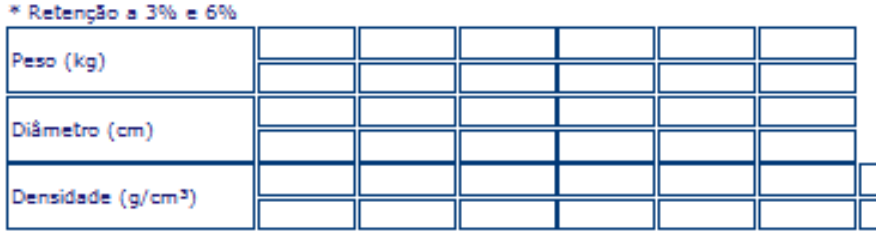

Observaģa: ROSANA****\%PD**A/T 
- Temperatura do segundo forno: 220 C; Sobrealimentação dentro do forno: $5 \%$

Relatório de Análise

$18 / 08 / 2014$ 14:43:15

\begin{tabular}{|l||l|l|l||l||l|l|l|}
\hline Dats & Lote & Títuls & Apresentaģå & Tipo Máquina & Máquing & Entrelagsamento & Virads \\
\hline $24 / 03 / 2012$ & TESTE 4 & $167 \mathrm{~F} 48$ & TBD & AFK1 & D10B & OT \\
\hline
\end{tabular}

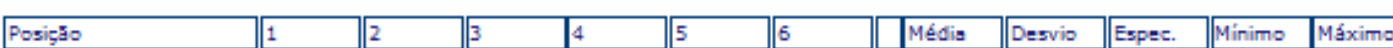

\begin{tabular}{|c|c|c|c|c|c|c|c|c|c|c|c|}
\hline Posiģ̧o & - & $L^{-2}$ & 㱐 & $14^{4}$ & $\|^{5}$ & 6 & Média & Desvio & Espec. & Minimo & Máximo \\
\hline \multirow{2}{*}{ Titulo (Dtex) } & 188,40 & 188,70 & 187,80 & 187,40 & 188,90 & 186,80 & 188,00 & 0,81 & & & \\
\hline & & & & & & & & & & & \\
\hline \multirow{2}{*}{ Tenacidade (eN/tex) } & 38,45 & 36,29 & 40,05 & 39,35 & 39,00 & 36,11 & 36,88 & 0,74 & & & \\
\hline & & & & & & & & & & & \\
\hline \multirow{2}{*}{ Alongamento (\%) } & 24,28 & 24,61 & 26,24 & 26,53 & 25,09 & 24,91 & 25,28 & 0,91 & & & \\
\hline & & & & & & & & & & & \\
\hline \multirow{2}{*}{ Oleo (\%) } & 2,90 & 2,90 & 2,90 & 2,90 & 2,80 & 2,80 & 2,87 & 0,05 & & & \\
\hline & & & & & & & & & & & \\
\hline \multirow{2}{*}{ Encolhimento (\%) } & 3,16 & 3,68 & 3,81 & 3,00 & 3,00 & 2,93 & 3,26 & 0,36 & & & \\
\hline & & & & & & & & & & & \\
\hline \multirow{2}{*}{$E(\%)$} & 10,9000 & 10,9700 & 10,2500 & 9,4300 & 10,2500 & 8,5400 & 10,0600 & 0,9300 & & & \\
\hline & & & & & & & & & & & \\
\hline \multirow{2}{*}{$K(\%)$} & 7,2200 & 7,3600 & 6,8000 & 6,2700 & 6,7600 & 5,5500 & 16,6600 & 0,6700 & & & \\
\hline & & & & & & & & & & & \\
\hline \multirow{2}{*}{$B(\%)$} & 76,3500 & 76,5900 & 76,6600 & 75,2600 & 76,9500 & 75,8000 & 76,2700 & 0,6300 & & & \\
\hline & & & & & & & & & & & \\
\hline \multirow{2}{*}{\multicolumn{12}{|c|}{ PUE (\%) }} \\
\hline & & & & & & & & & & & \\
\hline \multirow{2}{*}{ Torque $(\mathrm{T} / \mathrm{m} / \mathrm{s})$} & $-2,50$ & $-2,23$ & $-2,28$ & $-1,75$ & $-1,94$ & $-1,96$ & $-2,11$ & 0,27 & & & \\
\hline & & & & & & & & & & & \\
\hline \multirow{2}{*}{\multicolumn{12}{|c|}{ Entrelsgsamento $(\mathrm{N} \delta \mathrm{s} / \mathrm{m})$}} \\
\hline & & & & & & & & & & & \\
\hline \multicolumn{12}{|l|}{ Retenģaso 1} \\
\hline & & & & & & & & & & & \\
\hline Retenģ̆ăo 2 & & & & & & & & & & & \\
\hline
\end{tabular}

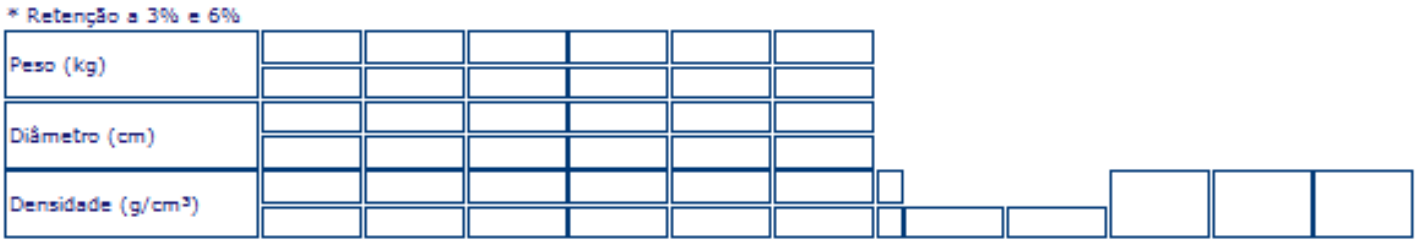

Observağăo: ZILMA**TESTE A-T DIG ZILMAA 
Relatório de Análise

18/08/2014 14:46:49

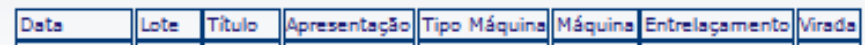

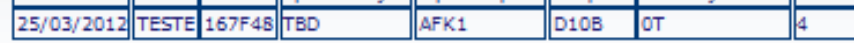

\begin{tabular}{|c|c|c|c|c|c|c|c|c|c|c|c|}
\hline Posiğăo & 7 & 8 & 9 & 10 & 11 & 12 & Médias & Desvis & Espec. & Mínimo & Máximo \\
\hline \multirow{2}{*}{ Tituls (Dtex) } & 184,70 & 186,70 & 186,10 & 185,10 & 186,30 & 187,10 & 186,00 & 0,93 & & & \\
\hline & & & & & & & & & & & \\
\hline \multirow{2}{*}{ Tenacidade (eN/tex) } & 40,74 & 39,47 & 39,57 & 41,27 & 39,31 & 39,72 & 40,01 & 0,80 & & & \\
\hline & & & & & & & & & & & \\
\hline \multirow{2}{*}{ Alongsmento (\%) } & 28,07 & 26,36 & 26,85 & 27,79 & 25,52 & 25,95 & 26,76 & 1,01 & & & \\
\hline & & & & & & & & & & & \\
\hline \multirow{2}{*}{ Oleo (9) } & 2,90 & 3,00 & 2,80 & 3,20 & 3,20 & 3,00 & 3,02 & 0,16 & & & \\
\hline & & & & & & & & & & & \\
\hline \multirow{2}{*}{ Encolhimento (\%) } & 3,03 & 3,15 & 2,81 & 3,00 & 3,34 & 3,08 & 3,07 & 0,18 & & & \\
\hline & & & & & & & & & & & \\
\hline \multirow{2}{*}{$E(\%)$} & 9,6600 & 10,3700 & 10,7200 & 10,5000 & & & 10,3200 & 0,4500 & & & \\
\hline & & & & & & & & & & & \\
\hline \multirow{2}{*}{$\mathrm{K}(\%)$} & 6,3600 & 6,9100 & 7,1100 & 6,9600 & & & 6,8500 & 0,3200 & & & \\
\hline & & & & & & & & & & & \\
\hline \multirow{2}{*}{$B(\%)$} & 75,8900 & 75,9600 & 76,8400 & 76,4000 & & & 76,2700 & 0,4400 & & & \\
\hline & & & & & & & & & & & \\
\hline \multirow{2}{*}{\multicolumn{12}{|c|}{ PUE $(\%)$}} \\
\hline & & & & & & & & & & & \\
\hline \multirow{2}{*}{ Torque $(T / m / s)$} & $-2,09$ & $-2,06$ & $-2,31$ & $-2,30$ & $-2,01$ & $-1,85$ & $-2,10$ & 0,18 & & & \\
\hline & & & & & & & & & & & \\
\hline \multicolumn{12}{|c|}{ Entrelsgsamento $(\mathrm{N} \delta \mathrm{s} / \mathrm{m})$} \\
\hline \multirow{2}{*}{\multicolumn{12}{|c|}{ Retengăo 1}} \\
\hline & & & & & & & & & & & \\
\hline \multirow{2}{*}{\multicolumn{12}{|c|}{ Retengya 2}} \\
\hline \multirow{2}{*}{\multicolumn{12}{|c|}{${ }^{*}$ Retengaso a $396=6 \%$}} \\
\hline & & & & & & & & & & & \\
\hline \multirow{2}{*}{\multicolumn{12}{|c|}{ Peso (kg) }} \\
\hline & & & & & & & & & & & \\
\hline \multicolumn{12}{|l|}{ Diâmetro $(\mathrm{cm})$} \\
\hline Densidgde $\left(\mathrm{g} / \mathrm{cm}^{3}\right)$ & & & & & & & & & & & \\
\hline Densidade $\left(9 / \mathrm{cm}^{2}\right)$ & & & & & & & & & & & \\
\hline
\end{tabular}

Observaģa: MONA PED. A/C A.T 
- Temperatura do segundo forno: 220C; Sobrealimentação dentro do forno: $29 \%$

Relatório de Análise

18/08/2014 14:47:45

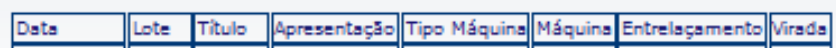

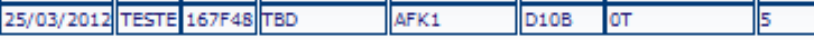

\begin{tabular}{|c|c|c|c|c|c|c|c|c|c|c|c|}
\hline Posiģ̆ăo & 1 & 2 & 3 & 4 & 5 & 6 & Médis & Desvis & Espec. & Minimo & Máximo \\
\hline \multirow{2}{*}{ Titulo (Dtex) } & 186,90 & 185,80 & 187,50 & 185,20 & 185,00 & 186,50 & 186,48 & 1,50 & & & \\
\hline & & & & & & & & & & & \\
\hline \multirow{2}{*}{ Tenacidsde (eN/tex) } & 37,83 & 40,76 & 40,86 & 36,72 & 40,67 & 36,55 & 39,57 & 1,35 & & & \\
\hline & & & & & & & & & & & \\
\hline \multirow{2}{*}{ Alongamento (96) } & 26,04 & 27,18 & 26,29 & 23,87 & 27,42 & 25,20 & 26,00 & 1,32 & & & \\
\hline & & & & & & & & & & & \\
\hline \multirow{2}{*}{ óleo (\%) } & 3,00 & 3,00 & 3,00 & 3,10 & 3,10 & 3,20 & 3,07 & 0,08 & & & \\
\hline & & & & & & & & & & & \\
\hline \multirow{2}{*}{ Ensolhimento $(\%)$} & 17,09 & $15,8 \mathrm{~B}$ & 17,36 & 115,63 & 17,03 & 17,03 & 116,67 & 0,73 & & & \\
\hline & & & & & & & & 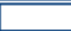 & & & \\
\hline \multirow{2}{*}{$E(\%)$} & 23,3100 & 21,0400 & 23,5900 & 20,6900 & 23,4000 & 23,3700 & 22,5700 & 1,3300 & & & \\
\hline & & & & & & & & & & & \\
\hline \multirow{2}{*}{$K(\%)$} & 15,3100 & 13,7500 & 15,5400 & 13,5500 & 15,3300 & 15,4700 & 14,8300 & 0,9200 & & & \\
\hline & & & & & & & & & & & \\
\hline \multirow{2}{*}{$B(\%)$} & 79,6500 & 76,8400 & 78,9200 & 76,3700 & 78,2500 & 78,2900 & 78,0500 & 1,2400 & & & \\
\hline & & & & & & & & & & & \\
\hline \multicolumn{12}{|l|}{ PUE (\%) } \\
\hline \multirow[b]{2}{*}{ Torque $(T / m / s)$} & -3.68 & -3.80 & -3.75 & -3.71 & -3.77 & -3.75 & -3.73 & 0,04 & & & \\
\hline & & & & & & & & & & & \\
\hline \multirow{2}{*}{\multicolumn{12}{|c|}{$\mid$ Entrelsgamento $(\mathrm{N} \delta \mathrm{s} / \mathrm{m}) \mid$}} \\
\hline & & & & & & & & & & & \\
\hline \multicolumn{12}{|l|}{ Retenģ̃o 1} \\
\hline \multirow{2}{*}{ Retenģă 2} & & & & & & & & & & & \\
\hline & & & & & & & & & & & \\
\hline
\end{tabular}

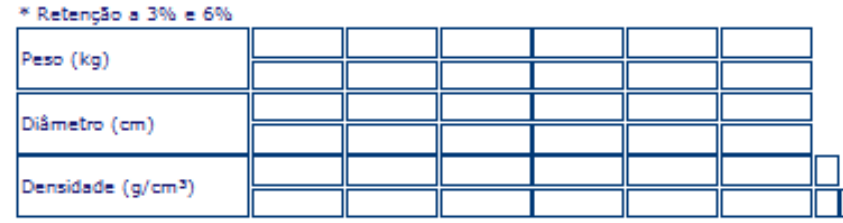

Observaģa: MONA AVC A.T 


\section{Relatório de Análise}

18/08/2014 14:49:05

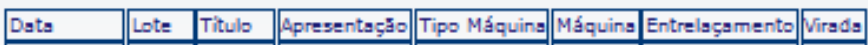

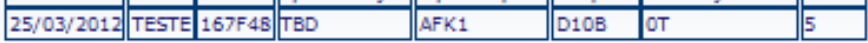

\begin{tabular}{|c|c|c|c|c|c|c|c|c|c|c|c|}
\hline 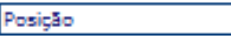 & 7 & 8 & 9 & 10 & 11 & 12 & Médis & Desvis & Espec. & Mínimo & Máximo \\
\hline \multirow{2}{*}{ Titulo (Dtex) } & 186,60 & 186,00 & 184,80 & 185,80 & 185,50 & 186,20 & 185,82 & 0,62 & & & \\
\hline & & & & & & & & & & & \\
\hline \multirow{2}{*}{ Tenacidade (eN/tex) } & 38,90 & 40,76 & 41,08 & 39,69 & 39,17 & 38,82 & 39,74 & 0,97 & & & \\
\hline & & & & & & & & & & & \\
\hline \multirow{2}{*}{ Alongsmento $(\%)$} & 23,80 & 25,84 & 27,28 & 26,34 & 24,36 & 24,77 & 25,40 & 1,32 & & & \\
\hline & & & & & & & & & & & \\
\hline \multirow{2}{*}{ Oleo $(\%)$} & 3,00 & 3,00 & 3,30 & 3,10 & 2,90 & 2,90 & 3,03 & 0,15 & & & \\
\hline & & & & & & & & & & & \\
\hline \multirow{2}{*}{ Encolhimento ( } & 16,56 & 15,14 & 17,40 & 17,24 & 15,79 & 16,96 & 16,52 & 0,89 & & & \\
\hline & & & & & & & & & & & \\
\hline \multirow{2}{*}{$E(\%)$} & 23,0500 & 21,4500 & 22,6500 & 23,2700 & & & 22,6100 & 0,8100 & & & \\
\hline & & & & & & & & & & & \\
\hline \multirow{2}{*}{$K(\%)$} & 15,1900 & 14,1400 & 14,8800 & 15,3600 & & & 14,6900 & 0,5400 & & & \\
\hline & & & & & & & & & & & \\
\hline \multirow{2}{*}{$B(\%)$} & 80,1500 & 77,3700 & 77,4300 & 77,4600 & & & 78,1000 & 1,3700 & & & \\
\hline & & & & & & & & & & & \\
\hline \multirow{2}{*}{ PUE (\%) } & & & & & & & & & & & \\
\hline & & & & & & & & & & & \\
\hline \multirow{2}{*}{ Torque $(T / m / s)$} & $-3,64$ & $-1,18$ & $-3,62$ & $-3,72$ & $-3,79$ & $-3,74$ & $-3,28$ & 1,03 & & & \\
\hline & & & & & & & & & & & \\
\hline \multicolumn{12}{|l|}{ Entrelsçamento (NOs/m) } \\
\hline \multirow{2}{*}{\multicolumn{12}{|c|}{ Retenģaso 1}} \\
\hline & & & & & & & & & & & \\
\hline Retengaso 2 & & & & & & & & & & & \\
\hline
\end{tabular}

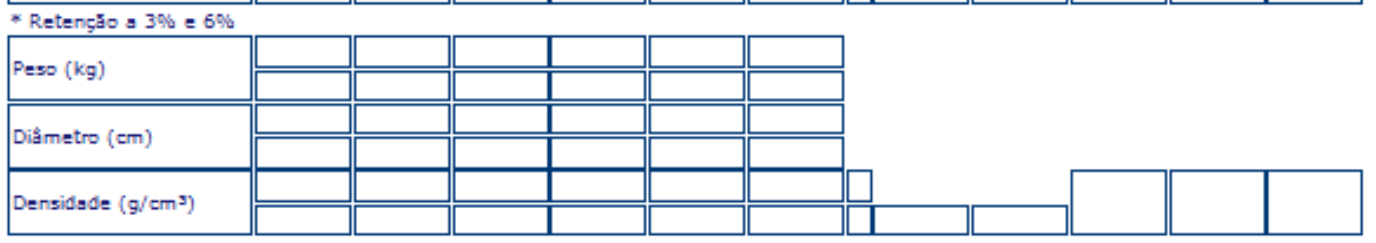

Observaçaso: MONA PED, AVC A.T 


\section{Anexo D: Relatório do Minitab ${ }^{\circledR}$ da análise fatorial completa da contração do encrespamento}

\section{Factorial Fit: CC versus Temperatura; Sobrealimentação}

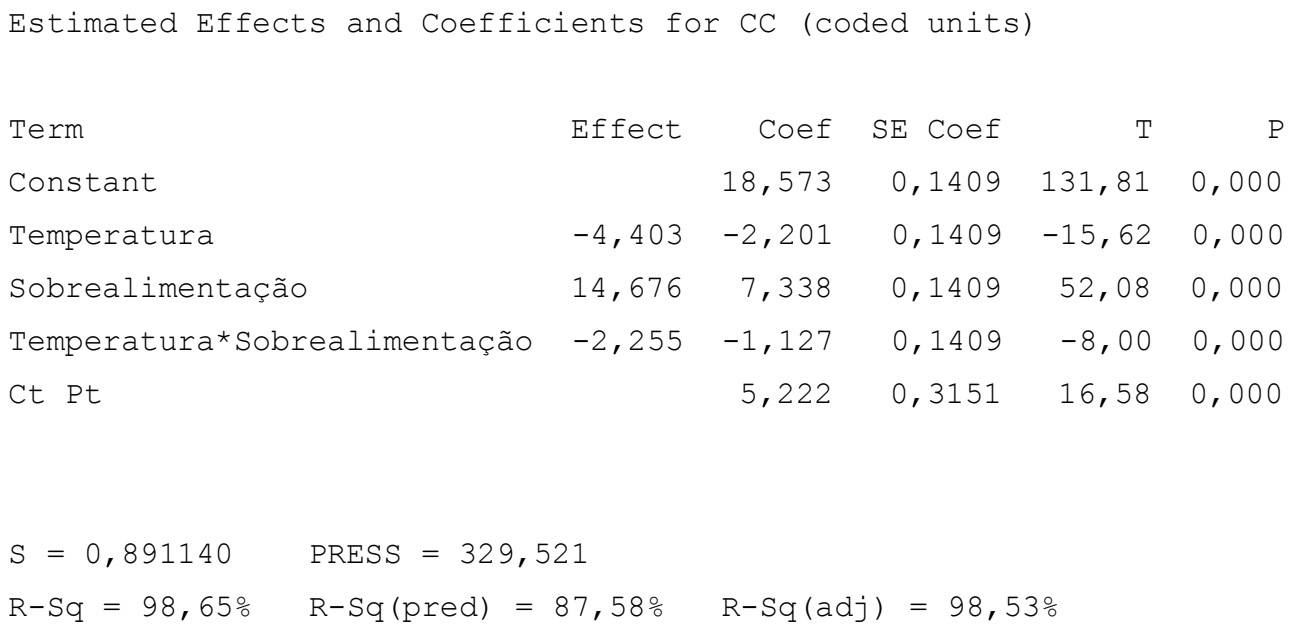


Least Squares Means for CC

Mean SE Mean

Temperatura

$20,77 \quad 0,1993$

220

$16,37 \quad 0,1993$

Sobrealimentação

\begin{tabular}{|c|c|}
\hline 5 & 11,23 \\
\hline & 25,91 \\
\hline
\end{tabular}

Temperatura* Sobrealimentação

$\begin{array}{rrrr}140 & 5 & 12,31 & 0,2818 \\ 220 & 5 & 10,16 & 0,2818 \\ 140 & 29 & 29,24 & 0,2818 \\ 220 & 29 & 22,58 & 0,2818\end{array}$

Mean for Center Point $=23,79$ 
Anexo E: Relatório do Minitab ${ }^{\circledR}$ da regressão linear da contração do encrespamento

\section{Regression Analysis: CC versus Temperatura; Sobrealimentação}

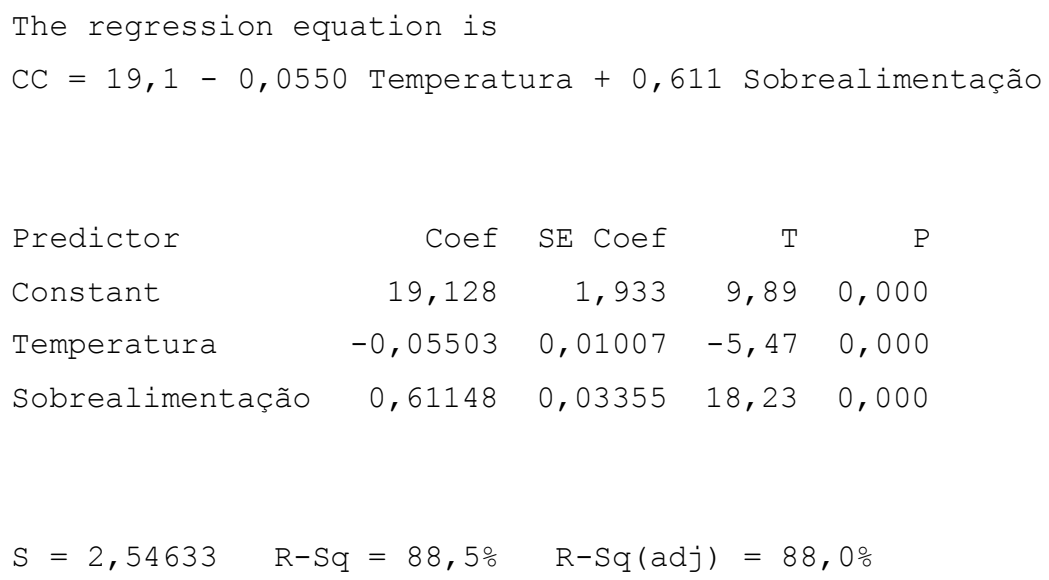




\section{Anexo F: Relatório do Minitab ${ }^{\circledR}$ da análise fatorial do módulo do encrespamento}

\section{Factorial Fit: CM versus Temperatura; Sobrealimentação}

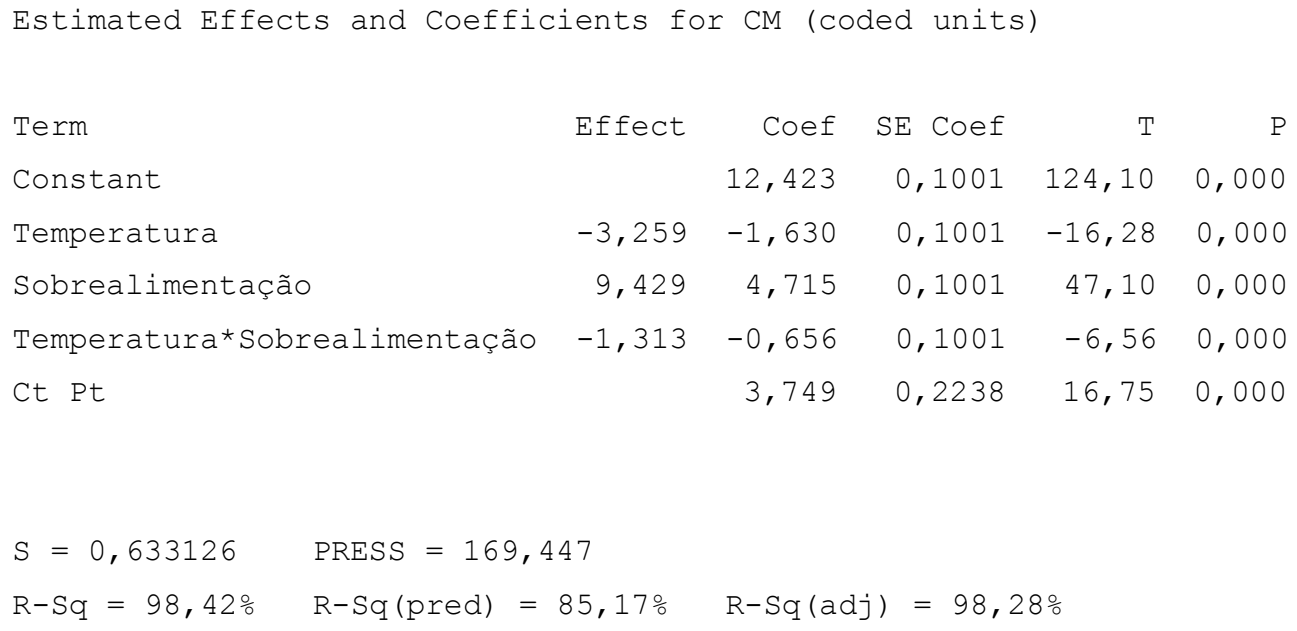

$\begin{array}{lrrrrrr}\text { Source } & \text { DF } & \text { Seq SS } & \text { Adj SS } & \text { Adj MS } & \text { F } & \text { P } \\ \text { Main Effects } & 2 & 995,27 & 995,27 & 497,636 & 1241,46 & 0,000 \\ \text { Temperatura } & 1 & 106,21 & 106,21 & 106,211 & 264,97 & 0,000 \\ \text { Sobrealimentação } & 1 & 889,06 & 889,06 & 889,060 & 2217,95 & 0,000 \\ \text { 2-Way Interactions } & 1 & 17,24 & 17,24 & 17,240 & 43,01 & 0,000 \\ \quad \text { Temperatura*Sobrealimentação } & 1 & 17,24 & 17,24 & 17,240 & 43,01 & 0,000 \\ \quad \text { Curvature } & 1 & 112,41 & 112,41 & 112,410 & 280,43 & 0,000 \\ \text { Residual Error } & 45 & 18,04 & 18,04 & 0,401 & & \\ \quad \text { Pure Error } & 45 & 18,04 & 18,04 & 0,401 & & \\ \text { Total } & 49 & 1142,96 & & & & \end{array}$

Estimated Coefficients for CM using data in uncoded units

$\begin{array}{lr}\text { Term } & \text { Coef } \\ \text { Constant } & 8,89219 \\ \text { Temperatura } & -0,0174865 \\ \text { Sobrealimentação } & 0,639063 \\ \text { Temperatura*Sobrealimentação } & -0,00136771 \\ \text { Ct Pt } & 3,74850\end{array}$


Mean SE Mean

Temperatura

$\begin{array}{lll}140 & 14,053 & 0,1416 \\ 220 & 10,794 & 0,1416\end{array}$

Sobrealimentação

$\begin{array}{rrr}5 & 7,709 & 0,1416 \\ 29 & 17,138 & 0,1416\end{array}$

Temperatura*Sobrealimentação

$\begin{array}{rrrr}140 & 5 & 8,682 & 0,2002 \\ 220 & 5 & 6,736 & 0,2002 \\ 140 & 29 & 19,424 & 0,2002 \\ 220 & 29 & 14,852 & 0,2002\end{array}$

Mean for Center Point $=16,172$ 
Anexo G: Relatório do Minitab ${ }^{\circledR}$ da regressão linear do módulo do encrespamento

\section{Regression Analysis: CM versus Temperatura; Sobrealimentação}

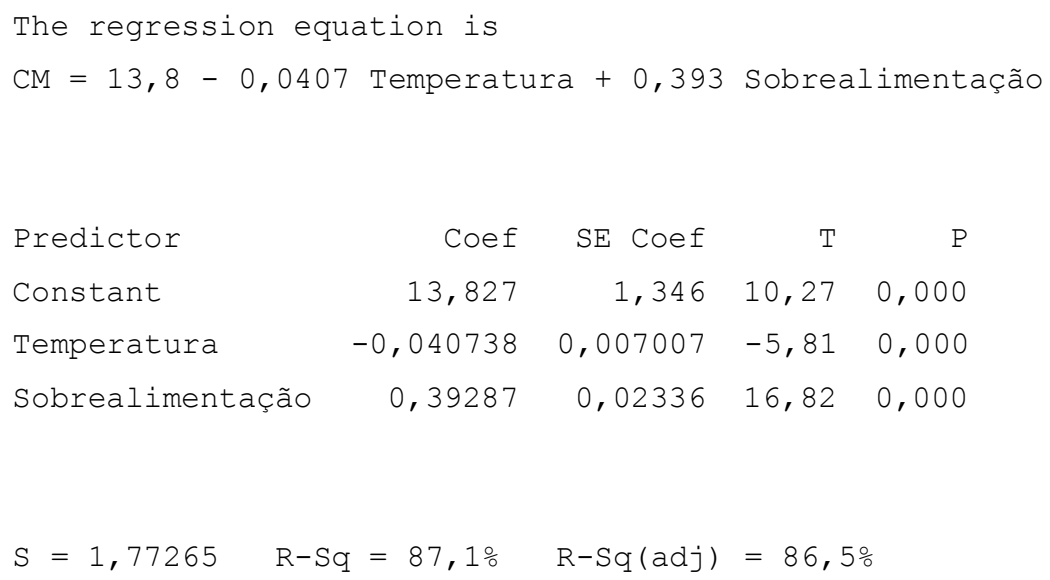




\section{Anexo H: Relatório do Minitab ${ }^{\circledR}$ da análise fatorial da estabilidade do encrespamento}

\section{Factorial Fit: CS versus Temperatura; Sobrealimentação}

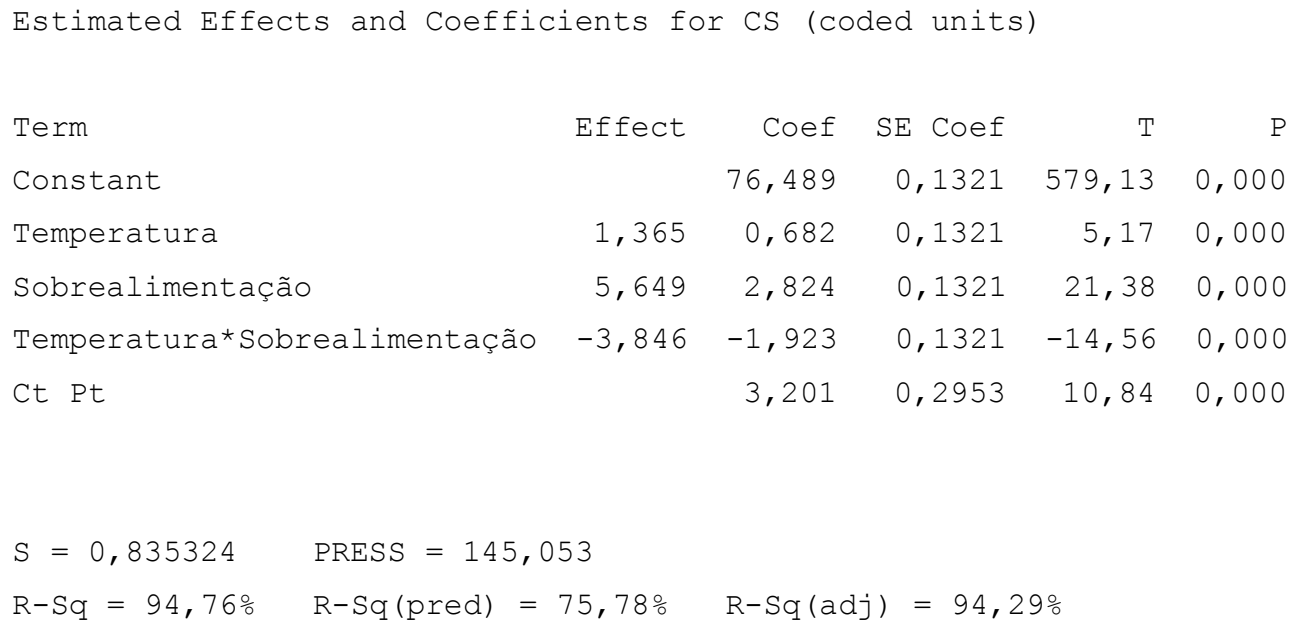


Mean SE Mean

Temperatura

140

$75,81 \quad 0,1868$

220

$77,17 \quad 0,1868$

Sobrealimentação

5

$73,66 \quad 0,1868$

29

$79,31 \quad 0,1868$

Temperatura*Sobrealimentação

$\begin{array}{rrrr}140 & 5 & 71,06 & 0,2642 \\ 220 & 5 & 76,27 & 0,2642 \\ 140 & 29 & 80,55 & 0,2642 \\ 220 & 29 & 78,07 & 0,2642\end{array}$

Mean for Center Point $=79,69$ 
Anexo I: Relatório do Minitab ${ }^{\circledR}$ da regressão linear da estabilidade do encrespamento Regression Analysis: CS versus Temperatura; Sobrealimentação

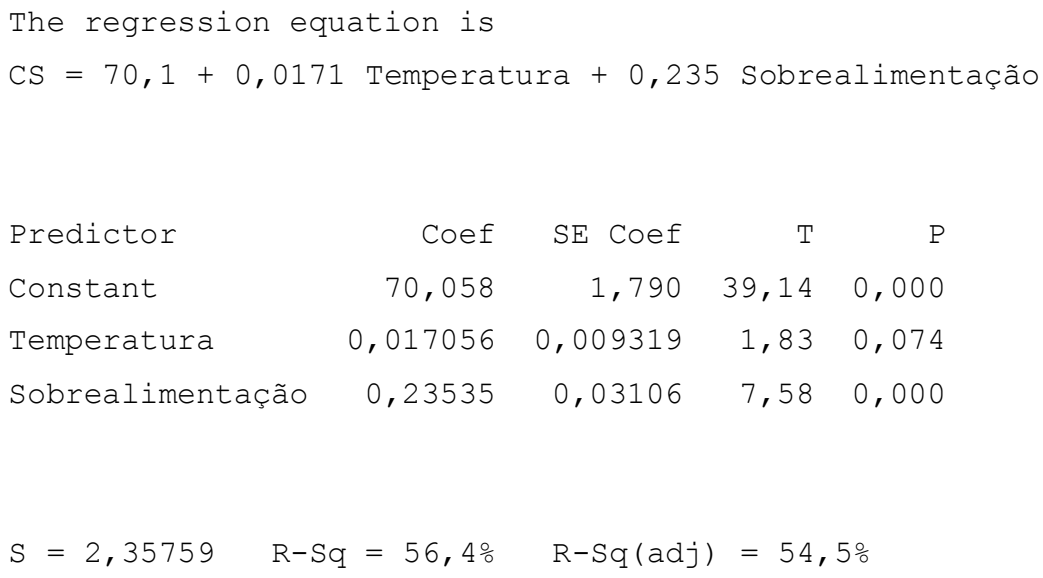

